\title{
Macrocyclization of Folded Diamines in Cavitands
}

Qixun Shi, ${ }^{\S}$ Daniele Masseroni ${ }^{\S}$ and Julius Rebek, Jr. ${ }^{\S} \dagger, *$

${ }^{\S}$ Department of Chemistry, Fudan University, 220 Handan Road, Shanghai 200433, China

${ }^{\dagger}$ The Skaggs Institute for Chemical Biology and Department of Chemistry, The Scripps

Research Institute, 10550 North Torrey Pines Road, La Jolla, CA 92037, USA

To whom correspondence should be addressed: jrebek@scripps.edu; Fax: 858-784-2876;

Tel: 858-784-2250.

\section{Supporting Information}

\section{Table of Contents}

1. Experimental Procedures

2. Upfield portions COSY NMR spectra of $\mathrm{C}_{12}$ diamine, $\mathrm{C}_{12}$ amino acid and $\mathrm{C}_{12}$ dilactam with cavitand 2 complex

S10

3. Partial stacked ${ }^{1} \mathrm{H}$ NMR spectra of amino acid synthesis reaction from diamines and succinic anhydrides with/without cavitand 2

4. Partial stacked ${ }^{1} \mathrm{H}$ NMR spectra of macrocyclic dilactam synthesis from amino acids, sulfo$\mathrm{NHS}$ and $\mathrm{EDC} \cdot \mathrm{HCl}$ with/without cavitand 2

5. Extraction of compound $\mathbf{3 b}$ from amino acids, sulfo-NHS and $\mathrm{EDC} \cdot \mathrm{HCl}$ reaction mixture and confirmed by HRMS

6. Partial stacked ${ }^{1} \mathrm{H}$ NMR spectra of macrocyclic dilactam synthesis from diamines and disuccinimidyl succinate with/without cavitand 2

7. Partial stacked ${ }^{1} \mathrm{H}$ NMR spectra of macrocyclic dilactam synthesis from diamines and disuccinimidyl glutarate with/without cavitand 2

8. Extraction of compound 3b, 3c, $\mathbf{4 b}$ and $4 \mathbf{c}$ from diamines and disuccinimidyl succinate/glutarate reaction mixture and confirmed by HRMS

9. Recycling and reuse of cavitand $\mathbf{2}$ from the diamines and disuccinimidyl succinate/glutarate reaction

10. References 


\section{Experimental Procedures}

General. Chemicals were obtained from TCI, Acros, J\&K, Energy Chemical, InnoChem or Adamas-beta ${ }^{\circledR}$ and used as received. ${ }^{1} \mathrm{H}$ and COSY spectra were recorded using either a Bruker ARX400 or Bruker DMX500 spectrometer at the temperatures indicated. NMR solvents were purchased from Cambridge Isotope Laboratories, Inc. NMR chemical shifts are reported in ppm using the residual solvent peaks: $\delta=4.79 \mathrm{ppm}$ for $\mathrm{D}_{2} \mathrm{O}\left({ }^{1} \mathrm{H} \mathrm{NMR}\right), \delta$ $=3.31 \mathrm{ppm}\left({ }^{1} \mathrm{H} \mathrm{NMR}\right)$ and $49.00 \mathrm{ppm}\left({ }^{13} \mathrm{C} \mathrm{NMR}\right)$ for $\mathrm{CD}_{3} \mathrm{OD}, \delta=2.50 \mathrm{ppm}$ for DMSO$\mathrm{d}_{6}\left({ }^{1} \mathrm{H} \mathrm{NMR}\right), \delta=7.26 \mathrm{ppm}\left({ }^{1} \mathrm{H} \mathrm{NMR}\right)$ and $77.16 \mathrm{ppm}\left({ }^{13} \mathrm{C} \mathrm{NMR}\right)$ for $\mathrm{CDCl}_{3}$. Data are presented as follows: 1 ) chemical shifts, 2) multiplicity ( $\mathrm{s}=$ singlet, $\mathrm{d}=$ doublet, $\mathrm{t}=$ triplet, $\mathrm{q}=$ quartet, quint $=$ quintet, $\mathrm{m}=$ multiplet and/or multiple resonances, $\mathrm{br}=$ broadened signal, app = apparent splitting pattern), 3) coupling constant (Hz), 4) integration. Reactions were performed under nitrogen with anhydrous solvent, unless otherwise noted.

Synthesis. The cavitand 2, ${ }^{1}$ 4-[(12-aminododecyl)amino]-4-oxo-butanoic acid, ${ }^{2}$ 1,14tetradecanediamine ( $\mathrm{C}_{14}$ diamine $),{ }^{3}$ 1,16-hexadecanediamine $\left(\mathrm{C}_{16} \text { diamine }\right)^{4}$ and 1,18octadecanediamine $\left(\mathrm{C}_{18}\right.$ diamine $){ }^{5}$ 1,6-diazacyclooctadecane-2,5-dione ${ }^{6}$ were prepared according to the procedures reported in the literature.

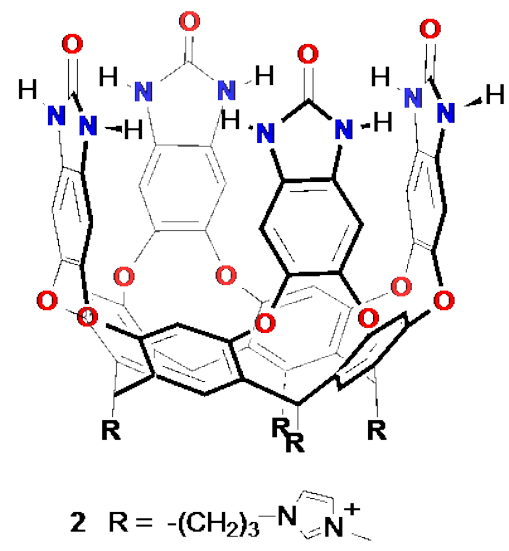

Scheme 1. The structure of cavitand 2

\section{Amino acid syntheses from diamines and succinic anhydrides in the presence of} cavitand 2. General procedures: $0.61 \times 10^{-3} \mathrm{mmol}$ diamines and 1.5 equiv. cavitand 2 in 
$0.6 \mathrm{~mL} \mathrm{D}_{2} \mathrm{O}$ were sonicated overnight in an NMR tube at $45{ }^{\circ} \mathrm{C}$. Then $\mathrm{NaOH}$ aqueous solution (70 $\mathrm{mM}$ in $\mathrm{D}_{2} \mathrm{O}$ ) and succinic anhydride solution (87 $\mathrm{mM}$ in $\mathrm{CD}_{3} \mathrm{OD}$ ) were added alternately. After each addition, the sample was shaken for few minutes by hand. The reactions were monitored by ${ }^{1} \mathrm{H}$ NMR and the yields were calculated by integration of the ${ }^{1} \mathrm{H}$ NMR spectra by using added dimethyl sulfone as an internal standard.

\section{Amino acid syntheses from diamines and succinic anhydride without cavitand 2.}

General procedures: To a solution of $0.61 \times 10^{-3} \mathrm{mmol}$ diamines in $0.6 \mathrm{~mL} \mathrm{CD}_{3} \mathrm{OD}$ in NMR tube was added 1.0 equiv. $\mathrm{NaOH}$ aqueous solution (70 $\mathrm{mM}$ in $\mathrm{D}_{2} \mathrm{O}$ ) and 1.0 equiv. succinic anhydride solution (87 $\mathrm{mM}$ in $\mathrm{CD}_{3} \mathrm{OD}$ ). After each addition, the sample was shaken for few minutes by hand. The reactions were monitored by ${ }^{1} \mathrm{H}$ NMR and the yields were calculated by integration of the ${ }^{1} \mathrm{H}$ NMR spectra by using TMS as internal standard.

Macrocyclic dilactam syntheses from amino acids, sulfo-NHS and EDC $\cdot \mathbf{H C l}$ in the presence of cavitand 2. General procedures: $0.61 \times 10^{-3} \mathrm{mmol}$ amino acid and 1.5 equiv. cavitand 2 in $0.6 \mathrm{~mL} \mathrm{D}_{2} \mathrm{O}$ in NMR tube were sonicated overnight at $45{ }^{\circ} \mathrm{C}$. Then $\mathrm{N}$-Hydroxysulfosuccinimide sodium salt (sulfo-NHS) (104 mM in $\mathrm{D}_{2} \mathrm{O}$ ) and EDC. $\mathrm{HCl}$ (110 $\mathrm{mM}$ in $\mathrm{D}_{2} \mathrm{O}$ ) was added by portions and the reaction mixture was stirred at rt in NMR tube. The reactions were stopped when all the amino acids were consumed. The reactions were monitored by ${ }^{1} \mathrm{H}$ NMR and the yields were calculated by integration of the ${ }^{1} \mathrm{H}$ NMR spectra by using added $\mathrm{MeOH}$ as internal standard.

Macrocyclic dilactam syntheses from amino acids, sulfo-NHS and EDC $\cdot$ HCl without cavitand 2. General procedures: $0.61 \times 10^{-3} \mathrm{mmol}$ amino acid was dissolved in $0.6 \mathrm{~mL}$ $\mathrm{CD}_{3} \mathrm{OD} / \mathrm{D}_{2} \mathrm{O}(4 / 1, \mathrm{v} / \mathrm{v})$ in an NMR tube. Then sulfo-NHS (104 $\mathrm{mM}$ in $\mathrm{D}_{2} \mathrm{O}$ ) and $\mathrm{EDC} \cdot \mathrm{HCl}\left(110 \mathrm{mM}\right.$ in $\left.\mathrm{D}_{2} \mathrm{O}\right)$ was added by portions and the reaction mixture was stirred at rt in NMR tube. The reactions were monitored by ${ }^{1} \mathrm{H}$ NMR and the yields were calculated by integration of the ${ }^{1} \mathrm{H}$ NMR spectra by using added $\mathrm{CH}_{3} \mathrm{CN}$ as internal standard. 
Macrocyclic dilactam syntheses from diamines and disuccinimidyl succinate/glutarate in the presence of cavitand 2. General procedures: $0.61 \times 10^{-3}$ mmol diamines and 1.5 equiv. cavitand 2 in $0.6 \mathrm{~mL} \mathrm{D}_{2} \mathrm{O}$ in NMR tube were sonicated overnight at $45{ }^{\circ} \mathrm{C}$. Then 3.0 equiv. $\mathrm{NaOH}$ aqueous solution $\left(70.0 \mathrm{mM}\right.$ in $\left.\mathrm{D}_{2} \mathrm{O}\right)$ was added. Excess solid disuccinimidyl succinate/glutarate was added to the mixture and the suspension was shaken by hand. The reactions were monitored by ${ }^{1} \mathrm{H}$ NMR and the yields were calculated by integration of the ${ }^{1} \mathrm{H}$ NMR spectra by using added $\mathrm{MeOH}$ as internal standard.

\section{Macrocyclic dilactam syntheses from diamines and disuccinimidyl} succinate/glutarate without cavitand 2. General procedures: To a solution of $0.61 \mathrm{x}$ $10^{-3}$ mmol diamines in $0.6 \mathrm{~mL}$ DMSO- $\mathrm{d}_{6}$ in an NMR tube was added 3 equiv. $\mathrm{NaOH}$ aqueous solution (70 $\mathrm{mM}$ in $\mathrm{D}_{2} \mathrm{O}$ ). Then excess solid disuccinimidyl succinate/glutarate was added and the resulting solution was shaken by hand. The reactions were monitored by ${ }^{1} \mathrm{H}$ NMR and the yields were calculated by integration of the ${ }^{1} \mathrm{H}$ NMR spectra by using TMS as internal standard.

Synthesis of authentic amino acids: The syntheses of $C_{11}, C_{14}$ and $C_{16}$ amino acids were performed as inspired by a published procedure. ${ }^{2}$ A solution of succinic anhydride (0.134 g, $1.34 \mathrm{mmol}$, 0.5 equiv.) in $\mathrm{DCM} / \mathrm{Et}_{2} \mathrm{O}(16 \mathrm{~mL} / 16 \mathrm{~mL})$ mixed solvent was added dropwise to the diamine (1 equiv.) suspension in DCM $(10 \mathrm{~mL})$ in an ice bath. Then the suspension was allowed to reach rt and stirred for a few days. After that, the mixture was filtered and washed completely with DCM. The white solid was recrystallized several times from EtOH.

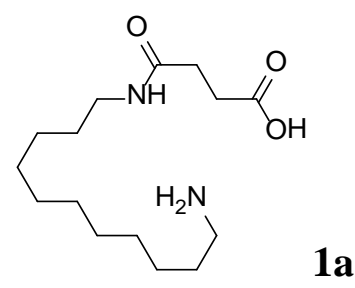

$\mathrm{C}_{11}$ amino acid 1a: Yield: 33\%; ${ }^{1} \mathrm{H}$ NMR (400 MHz, $\left.\mathrm{D}_{2} \mathrm{O}\right) \delta 3.15(\mathrm{t}, J=8.0 \mathrm{~Hz}, 2 \mathrm{H})$, $2.97(\mathrm{t}, J=8.0 \mathrm{~Hz}, 2 \mathrm{H}), 2.43(\mathrm{~s}, 4 \mathrm{H}), 1.60-1.66(\mathrm{~m}, 2 \mathrm{H}), 1.46-1.48(\mathrm{~m}, 2 \mathrm{H}), 1.28$ (m, 
14H); ${ }^{13} \mathrm{C}$ NMR (125 MHz, $\left.\mathrm{D}_{2} \mathrm{O}\right) \delta 180.9,175.6,39.5,39.3,33.3,32.5,28.37,28.34$, 28.29, 28.1, 28.05, 28.05, 26.6, 25.8, 25.4; HRMS (ESI) calcd. for $\left([\mathrm{M}+\mathrm{H}]^{+}\right)$: $\mathrm{C}_{15} \mathrm{H}_{31} \mathrm{~N}_{2} \mathrm{O}_{3}$ 287.2329; Found: 287.2332;

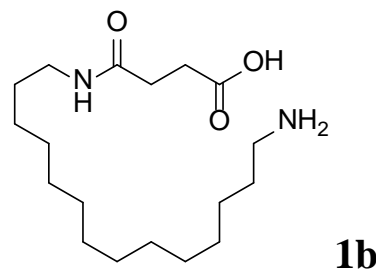

$\mathrm{C}_{14}$ amino acid 1b: Yield: 15\%; ${ }^{1} \mathrm{H}$ NMR (400 MHz, $\left.\mathrm{D}_{2} \mathrm{O}\right) \delta 3.15(\mathrm{t}, J=8.0 \mathrm{~Hz}, 2 \mathrm{H})$, 2.97 (t, $J=8.0 \mathrm{~Hz}, 2 \mathrm{H}), 2.43$ (s, 4H), 1.60-1.65 (m, 2H), 1.46-1.49 (m, 2H), 1.27 (m, $20 \mathrm{H}) ;{ }^{13} \mathrm{C}$ NMR (125 MHz, CD $\left.{ }_{3} \mathrm{OD}\right) \delta 180.7,175.8,40.8,40.3,34.8,34.1,30.43,30.40$, 30.35, 30.35, 30.35, 30.35, 30.31, 30.16, 30.10, 28.7, 27.8, 27.4; HRMS (ESI) calcd. for $\left([\mathrm{M}+\mathrm{H}]^{+}\right): \mathrm{C}_{18} \mathrm{H}_{37} \mathrm{~N}_{2} \mathrm{O}_{3}$ 329.2799; Found: 329.2798;

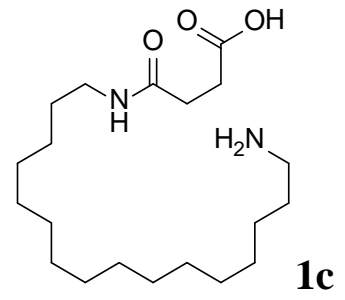

$\mathrm{C}_{16}$ amino acid 1c: Yield: trace; ${ }^{1} \mathrm{H}$ NMR (400 MHz, $\left.\mathrm{CD}_{3} \mathrm{OD}\right) \delta 3.14(\mathrm{t}, J=8.0 \mathrm{~Hz}, 2 \mathrm{H})$, 2.85 (t, $J=8.0 \mathrm{~Hz}, 2 \mathrm{H}), 2.43$ (s, 4H), 1.60-1.63 (m, 2H), 1.46-1.52 (m, 2H), 1.30 (m, 24H); HRMS (ESI) calcd. for ([M+H] $\left.]^{+}\right): \mathrm{C}_{20} \mathrm{H}_{41} \mathrm{~N}_{2} \mathrm{O}_{3}$ 355.2955; Found: 355.2956;

Syntheses of authentic macrocyclic dilactams: The appropriate diamino compound (2 equiv.) was dissolved in toluene/DMF 1/1 (0.001 M) and a solution of glutaryl/succinyl chloride (1 equiv.) in toluene $(0.001 \mathrm{M})$ was added dropwise over 5 hours. After the addition was completed, the resulting suspension was stirred at room temperature under nitrogen for 24 hours. The organic solvent was concentrated under reduced pressure and the crude products were purified by silica gel flash column chromatography (ethyl acetate and ethyl acetate/methanol 95/5) to give the macrocyclic compounds. 


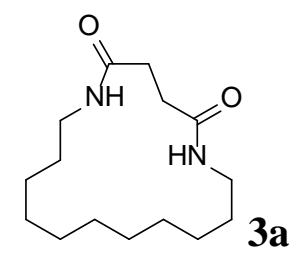

1,6-diazacycloheptadecane-2,5-dione 3a: Yield: $15 \%$; ${ }^{1} \mathrm{H}$ NMR (400 MHz, $\left.\mathrm{CDCl}_{3}\right) \delta$ 6.42 (bs, 2H), 3.28 (q, $J=4$ Hz, $J=8$ Hz, 4H), 2.56 (s, 4H), 1.55-1.4 (m, 4H), 1.39-1.15 (m, 14H); ${ }^{13} \mathrm{C}$ NMR (125 MHz, $\left.\mathrm{CDCl}_{3}\right) \delta 172.8,39.2,32,31.1,29.9,29.2,27.2,26.3$, 25.2; HRMS (ESI) calcd. for ([M+H] $\left.{ }^{+}\right): \mathrm{C}_{15} \mathrm{H}_{29} \mathrm{~N}_{2} \mathrm{O}_{2}$ 269.2224; Found: 269.2227;

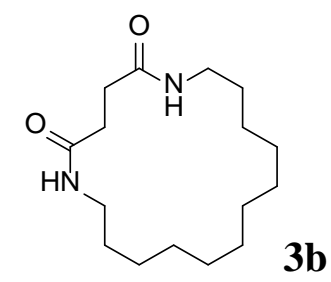

1,6-diazacyclooctadecane-2,5-dione 3b: Yield: 25\%; ${ }^{1} \mathrm{H}$ NMR (400 MHz, $\left.\mathrm{CDCl}_{3}\right) \delta 6.2$ (bs, 2H), 3.22 (q, $J=4 \mathrm{~Hz}, J=8 \mathrm{~Hz}, 4 \mathrm{H}$ ), 2.51 (s, 4H), 1.56-1.42 (m, 4H), 1.4-1.18 (m, $16 \mathrm{H}) ;{ }^{13} \mathrm{C}$ NMR $\left(125 \mathrm{MHz}, \mathrm{CDCl}_{3}\right) \delta 172.5,39.5,32.5,28.9,27.3,26.8,26.5,25.7$; HRMS (ESI) calcd. for $\left([\mathrm{M}+\mathrm{H}]^{+}\right): \mathrm{C}_{16} \mathrm{H}_{31} \mathrm{~N}_{2} \mathrm{O}_{2}$ 283.2380; Found: 283.2390;

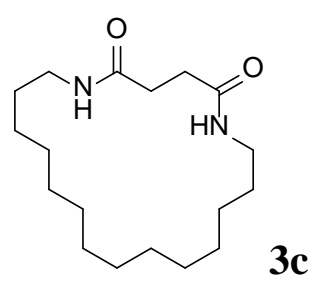

1,6-diazacycloicosane-2,5-dione 3c: Yield: $18 \% ;{ }^{1} \mathrm{H}$ NMR $\left(400 \mathrm{MHz}, \mathrm{CDCl}_{3}\right) \delta 6.2$ (bs, $2 \mathrm{H})$, 3.3-3.16 (m, 4H), 2.57 (s, 4H), 1.56-1.41 (m, 4H), 1.39-1.17 (m, 20H); ${ }^{13} \mathrm{C}$ NMR (125 MHz, $\left.\mathrm{CDCl}_{3}\right) \delta$ 172.6, 39.7, 32.3, 29.9, 29.1, 28, 27.8, 27.4, 27.3, 26; HRMS (ESI) calcd. for ([M+H] $\left.]^{+}\right): \mathrm{C}_{18} \mathrm{H}_{35} \mathrm{~N}_{2} \mathrm{O}_{2}$ 311.2693; Found: 311.2695;

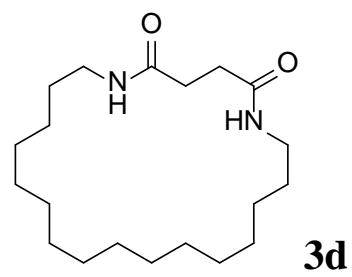


1,6-diazacyclodocosane-2,5-dione 3d: Yield: $17 \% ;{ }^{1} \mathrm{H}$ NMR (400 MHz, $\mathrm{CDCl}_{3}$ ) $\delta 6.3$ (bs, 2H), 3.22 (q, $J=4 \mathrm{~Hz}, J=8 \mathrm{~Hz}, 4 \mathrm{H}), 2.53$ (s, 4H), 1.55-1.4 (m, 4H), 1.39-1.07 (m, 24H); ${ }^{13} \mathrm{C}$ NMR (125 MHz, $\left.\mathrm{CDCl}_{3}\right) \delta 172.7,39.8,32.5,29.8,29.5,28.5,28.4,27.9,27.5,27.4$, 26.4; HRMS (ESI) calcd. for ([M+H] $\left.]^{+}\right): \mathrm{C}_{20} \mathrm{H}_{39} \mathrm{~N}_{2} \mathrm{O}_{2}$ 339.3006; Found: 339.2993;

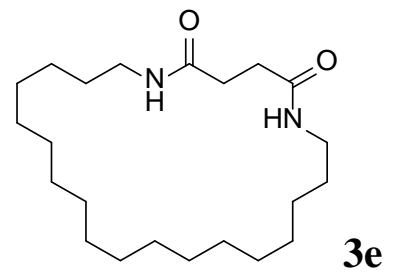

1,6-diazacyclotetracosane-2,5-dione 3e: Yield: $15 \%$; ${ }^{1} \mathrm{H}$ NMR (400 MHz, $\left.\mathrm{CDCl}_{3}\right) \delta 6.15$ (bs, 2H), 3.21 (q, $J=4 \mathrm{~Hz}, J=8 \mathrm{~Hz}, 4 \mathrm{H}$ ), 2.5 (s, 4H), 1.54-1.39 (m, 4H), 1.35-1.12 (m, 24H); ${ }^{13} \mathrm{C}$ NMR (125 MHz, $\left.\mathrm{CDCl}_{3}\right) \delta 172.7,39.6,32.6,29.7,29.4,28.5,28.2,27.9,27.5$, 27.1, 25.4, 22; HRMS (ESI) calcd. for $\left([\mathrm{M}+\mathrm{H}]^{+}\right)$: $\mathrm{C}_{22} \mathrm{H}_{43} \mathrm{~N}_{2} \mathrm{O}_{2}$ 367.3319; Found: 367.3304;

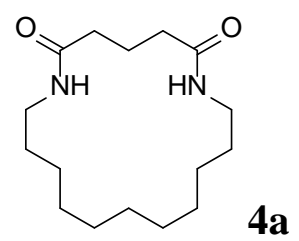

1,7-diazacyclooctadecane-2,6-dione 4a: Yield: $18 \% ;{ }^{1} \mathrm{H}$ NMR (400 MHz, $\left.\mathrm{CDCl}_{3}\right) \delta 6.2$ (bs, 2H), 3.32 (q, $J=4 \mathrm{~Hz}, J=8 \mathrm{~Hz}, 4 \mathrm{H}$ ), 2.35 (t, $J=8 \mathrm{~Hz}, 4 \mathrm{H}$ ), 2-1.89 (m, 2H), 1.58-1.4 (m, 4H), 1.4-1.18 (m, 14H); ${ }^{13} \mathrm{C}$ NMR (125 MHz, $\left.\mathrm{CDCl}_{3}\right) \delta 172.9,38.8,35.5,29,28$, 27.8, 27, 25.3, 22.8; HRMS (ESI) calcd. for $\left([\mathrm{M}+\mathrm{H}]^{+}\right)$: $\mathrm{C}_{16} \mathrm{H}_{31} \mathrm{~N}_{2} \mathrm{O}_{2}$ 283.2380; Found: 283.2386;

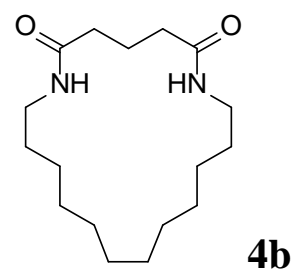

1,7-diazacyclononadecane-2,6-dione 4b: Yield: $20 \% ;{ }^{1} \mathrm{H}$ NMR (400 $\left.\mathrm{MHz}, \mathrm{CDCl}_{3}\right) \delta 6$ (bs, 2H), 3.29 (q, $J=4 \mathrm{~Hz}, J=8 \mathrm{~Hz}, 4 \mathrm{H}$ ), 2.28 (t, $J=8 \mathrm{~Hz}, 4 \mathrm{H}), 1.98-1.92$ (m, 2H), 1.561.46 (m, 4H), 1.4-1.2 (m, $16 \mathrm{H}) ;{ }^{13} \mathrm{C}$ NMR (125 MHz, $\mathrm{CDCl}_{3}$ ) $\delta 172.9,39,35.4$, 29, 28.2, 
27.8, 27.6, 26, 22.2; HRMS (ESI) calcd. for $\left([\mathrm{M}+\mathrm{H}]^{+}\right)$: $\mathrm{C}_{17} \mathrm{H}_{33} \mathrm{~N}_{2} \mathrm{O}_{2}$ 297.2537; Found: 297.2532;

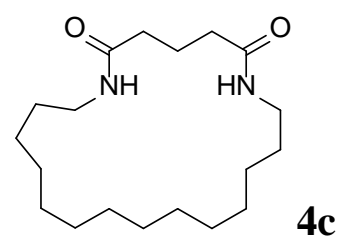

1,7-diazacyclohenicosane-2,6-dione 4c: Yield: 21\%; ${ }^{1} \mathrm{H}$ NMR (400 MHz, $\left.\mathrm{CDCl}_{3}\right) \delta 6.2$ (bs, 2H), 3.29 (q, $J=4 \mathrm{~Hz}, J=8 \mathrm{~Hz}, 4 \mathrm{H}$ ), 2.32 (t, $J=8 \mathrm{~Hz}, 4 \mathrm{H}$ ), 2-1.91 (m, 2H), 1.581.44 (m, 4H), 1.4-1.17 (m, 20H); ${ }^{13} \mathrm{C}$ NMR (125 MHz, $\left.\mathrm{CDCl}_{3}\right) \delta$ 172.8, 39.3, 35.5, 29.3, 28.4, 28.3, 28.1, 27.7, 26.1, 22.3; HRMS (ESI) calcd. for $\left([\mathrm{M}+\mathrm{H}]^{+}\right): \mathrm{C}_{19} \mathrm{H}_{37} \mathrm{~N}_{2} \mathrm{O}_{2}$ 325.2850; Found: 325.2854;

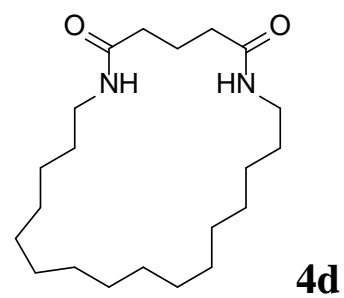

1,7-diazacyclotricosane-2,6-dione 4d: Yield: 20\%; ${ }^{1} \mathrm{H}$ NMR (400 MHz, $\left.\mathrm{CDCl}_{3}\right) \delta 5.9$ (bs, 2H), 3.26 (q, $J=4 \mathrm{~Hz}, J=8 \mathrm{~Hz}, 4 \mathrm{H}), 2.26$ (t, $J=8 \mathrm{~Hz}, 4 \mathrm{H}), 2-1.9$ (m, 2H), 1.54-1.42 (m, $4 \mathrm{H}), 1.36-1.2(\mathrm{~m}, 24 \mathrm{H}) ;{ }^{13} \mathrm{C}$ NMR $\left(125 \mathrm{MHz}, \mathrm{CDCl}_{3}\right) \delta 172.8,39.5,35.4,29.5,28.7$, 28.6, 28.4, 28.2, 28.1, 26.4, 22.1; HRMS (ESI) calcd. for $\left([\mathrm{M}+\mathrm{H}]^{+}\right): \mathrm{C}_{21} \mathrm{H}_{41} \mathrm{~N}_{2} \mathrm{O}_{2}$ 353.3163; Found: 353.3152;

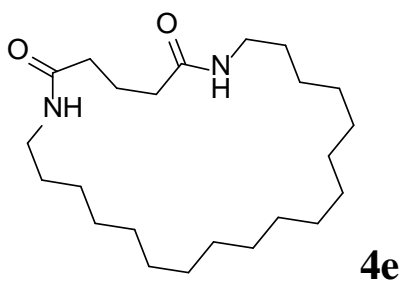

1,7-diazacyclopentacosane-2,6-dione 4e: Yield: 21\%; ${ }^{1} \mathrm{H}$ NMR (400 MHz, $\left.\mathrm{CDCl}_{3}\right) \delta 5.9$ (bs, 2H), 3.24 (q, $J=4 \mathrm{~Hz}, J=8 \mathrm{~Hz}, 4 \mathrm{H}$ ), 2.26 (t, $J=8 \mathrm{~Hz}, 4 \mathrm{H}), 2-1.9$ (m, 2H), 1.54-1.43 (m, 4H), 1.35-1.2 (m, 28H); ${ }^{13} \mathrm{C}$ NMR (125 MHz, $\left.\mathrm{CDCl}_{3}\right) \delta$ 171.9, 38.6, 34.4, 28.5, 28, 
27.8, 27.7, 27.5, 27.3, 25.7, 21; HRMS (ESI) calcd. for ([M+H] $\left.]^{+}\right): \mathrm{C}_{23} \mathrm{H}_{45} \mathrm{~N}_{2} \mathrm{O}_{2}$ 381.3476; Found: 381.3479; 


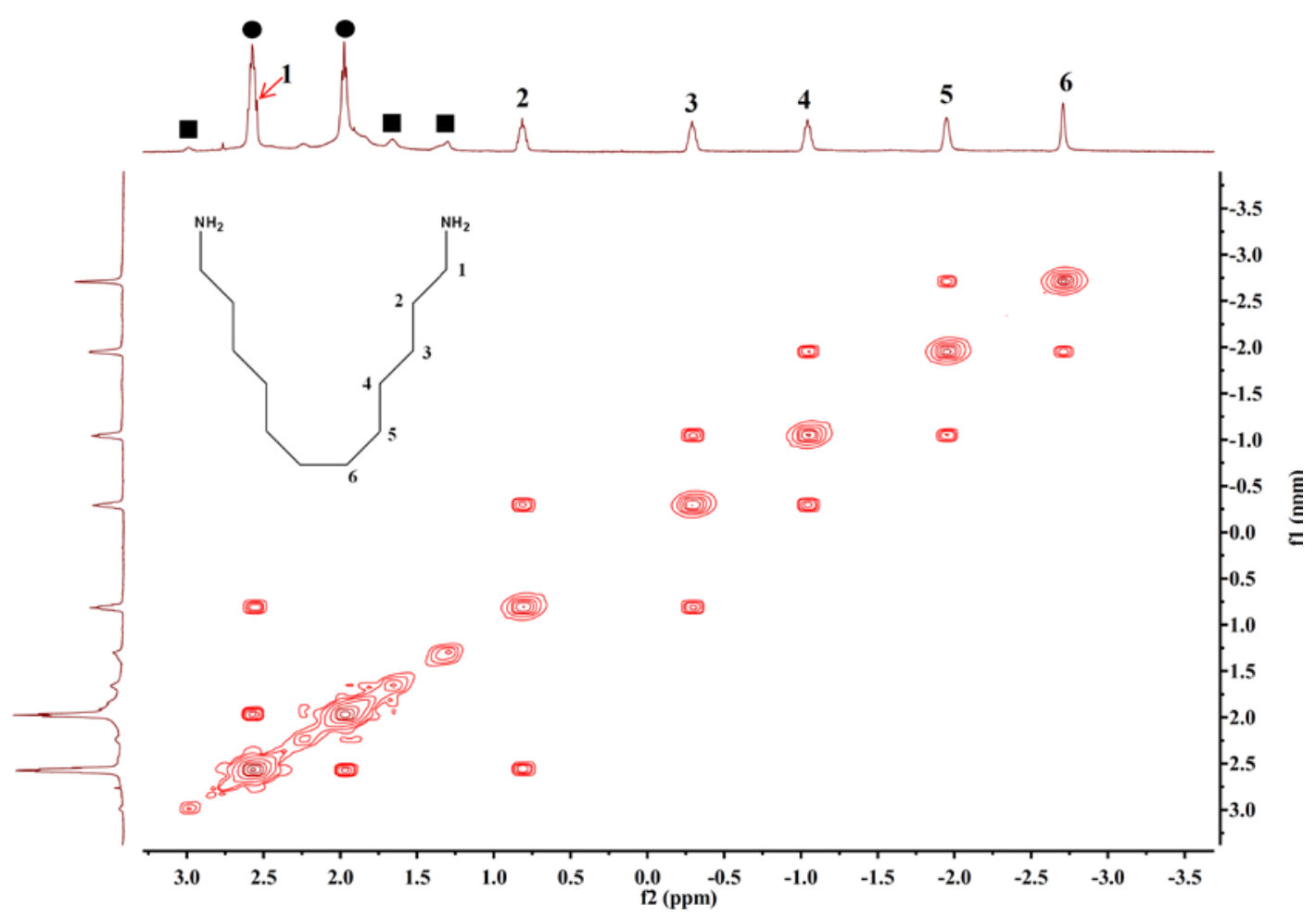

Figure S1. Upfield portions of the COSY NMR spectrum of $\mathrm{C}_{12}$ diamine/cavitand 2 (500 $\mathrm{MHz}, 299.5 \mathrm{~K}, \mathrm{D}_{2} \mathrm{O}$ ). The peaks labelled with circle are from the cavitand "feet" and the peaks labelled with square are from the free diamine. 


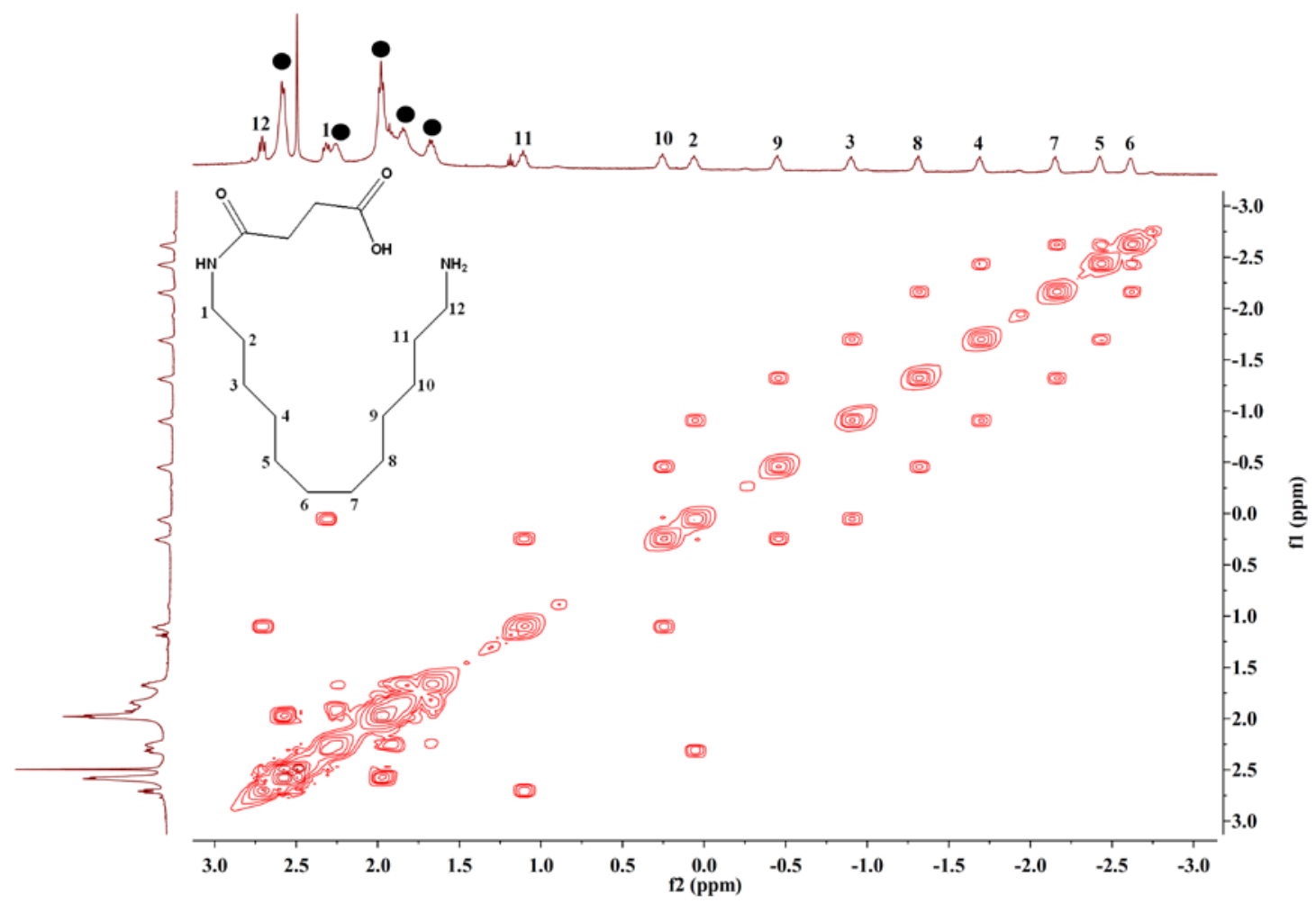

Figure S2. Upfield portions of the COSY NMR spectrum of $\mathrm{C}_{12}$ amino acid/cavitand 2 (500 MHz, $299.5 \mathrm{~K}, \mathrm{D}_{2} \mathrm{O}$ ). The peaks labelled with circle are from the cavitand "feet". 


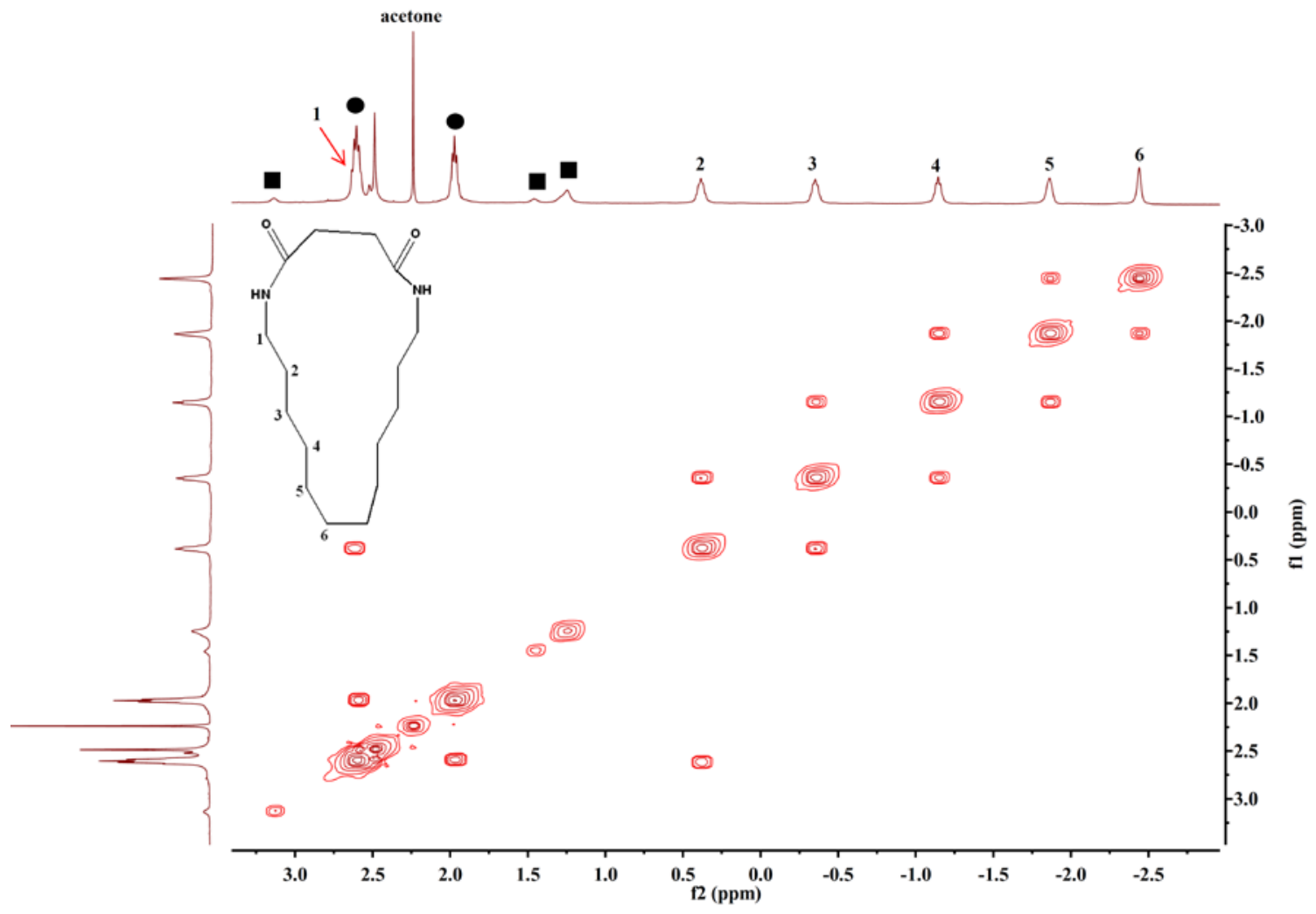

Figure S3. Upfield portions of the COSY NMR spectrum of $\mathrm{C}_{12}$ dilactam $3 \mathbf{b}$ /cavitand 2 (500 MHz, $299.5 \mathrm{~K}, \mathrm{D}_{2} \mathrm{O}$ ). The peaks labelled with circle are from the cavitand "feet" and the peaks labelled with square are from the free dilactam. 


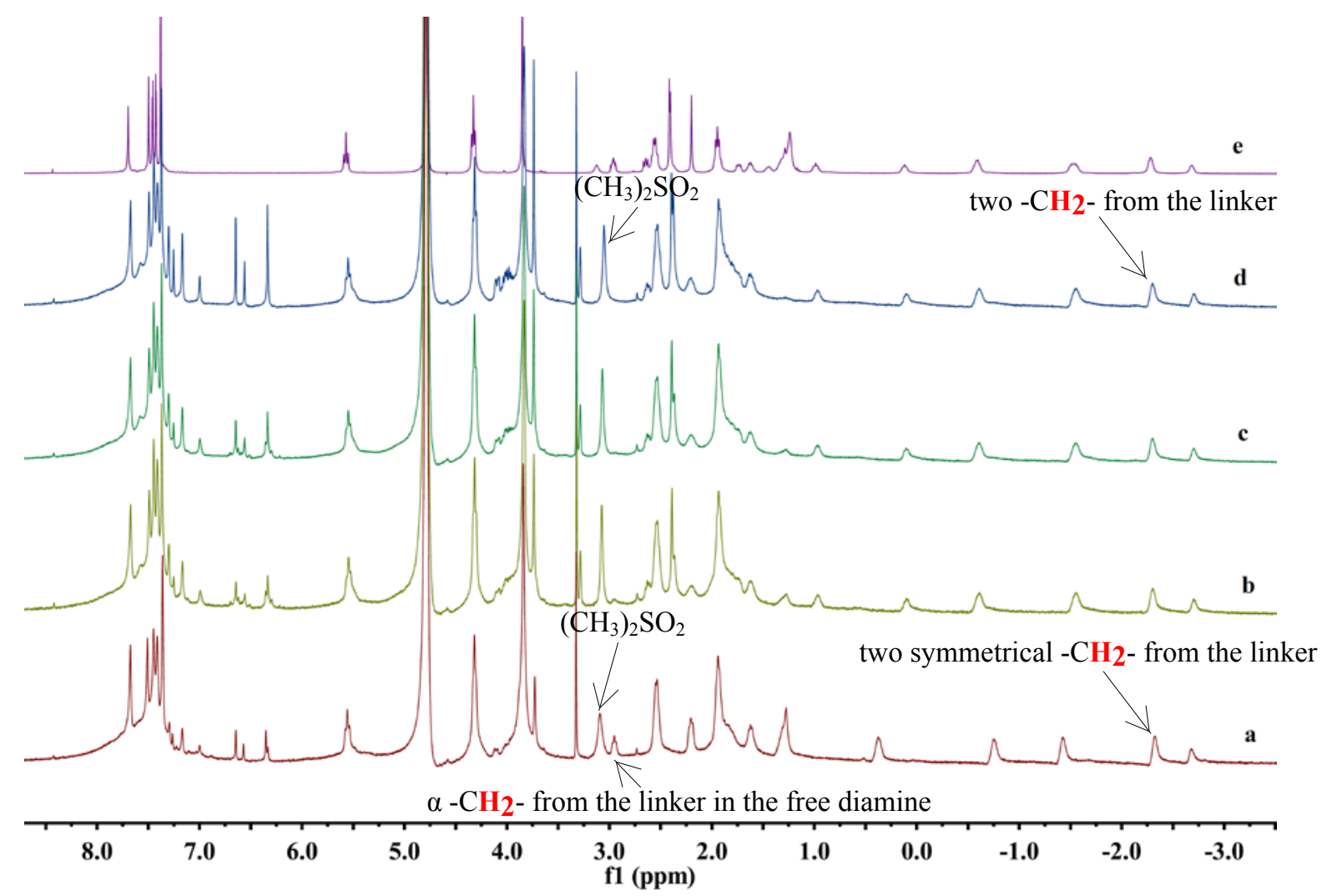

Figure S4. ${ }^{1} \mathrm{H}$ NMR spectra of cavitand 2 complexes (400 MHz, $299.5 \mathrm{~K}, \mathrm{D}_{2} \mathrm{O}$ ) (the peaks indicated with an arrow were used to determine yields): (a) $\mathrm{C}_{11}$ diamine/cavitand 2 in $\mathrm{D}_{2} \mathrm{O}$; Addition of dimethyl sulfone aqueous solution (as internal standard) and 1 equiv. $\mathrm{NaOH}$ aqueous solution (70 $\mathrm{mM}$ in $\mathrm{D}_{2} \mathrm{O}$ ); (b) Addition of 1 equiv. succinic anhydride solution ( $87 \mathrm{mM}$ in $\mathrm{CD}_{3} \mathrm{OD}$ ) and shaking for $4 \mathrm{~min}$. by hand, then addition of another 1.0 equiv. $\mathrm{NaOH}$ and 1.0 equiv. succinic anhydride and shaking for another 4 min.; (c) After 50 min. for (b); (d) After 25 hr for (b); (e) The authentic target product 1a/cavitand 2 in $\mathrm{D}_{2} \mathrm{O}$. 


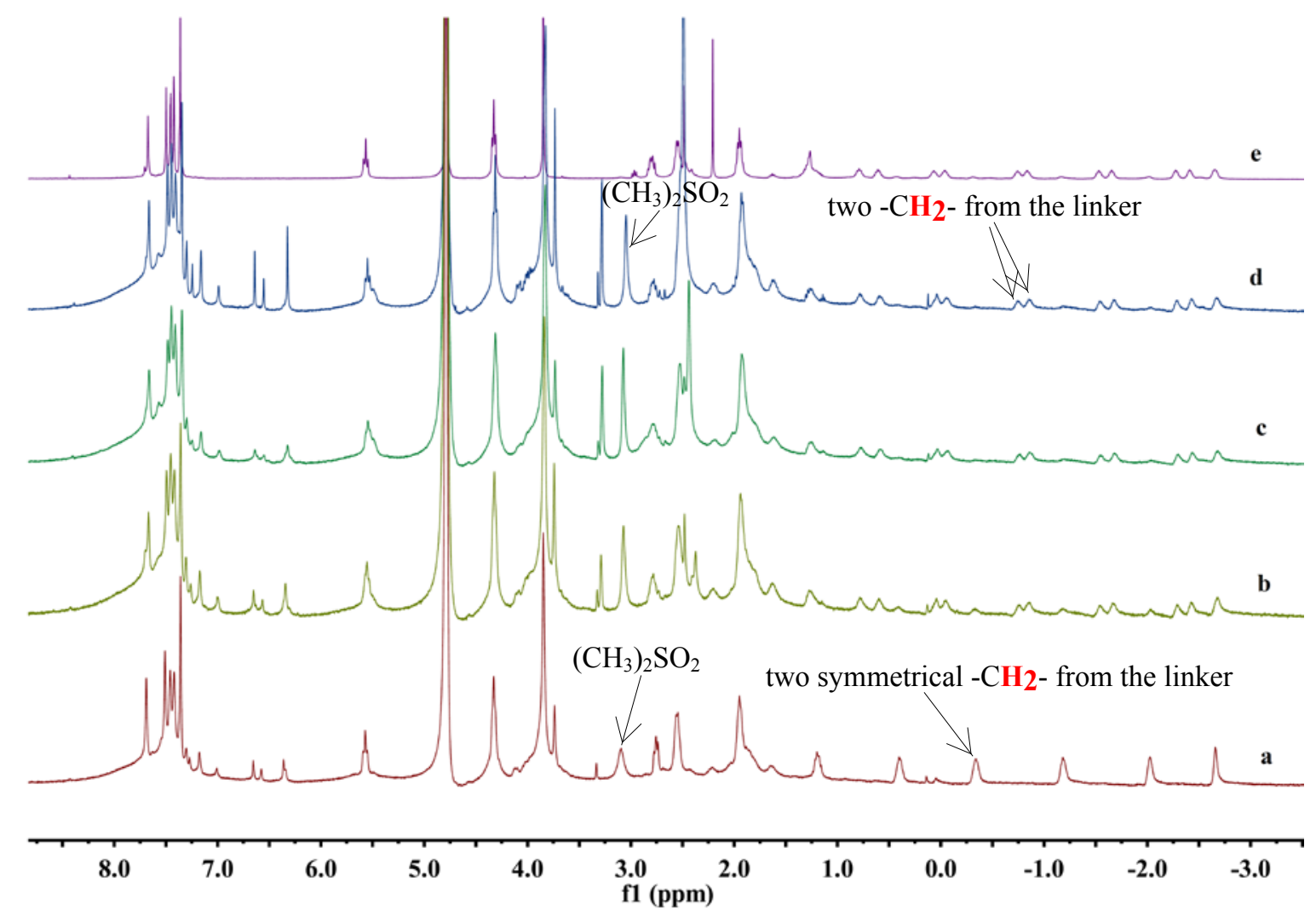

Figure S5. ${ }^{1} \mathrm{H}$ NMR spectra of cavitand 2 complexes (400 MHz, $299.5 \mathrm{~K}, \mathrm{D}_{2} \mathrm{O}$ ) (the peaks indicated with an arrow were used to determine yields): (a) $\mathrm{C}_{14}$ diamine/cavitand 2 in $\mathrm{D}_{2} \mathrm{O}$; Addition of dimethyl sulfone aqueous solution (as internal standard) and 1 equiv. $\mathrm{NaOH}$ aqueous solution (70 $\mathrm{mM}$ in $\mathrm{D}_{2} \mathrm{O}$ ); (b) Addition of 1 equiv. succinic anhydride solution ( $87 \mathrm{mM}$ in $\mathrm{CD}_{3} \mathrm{OD}$ ) and shaking for $4 \mathrm{~min}$. by hand, then addition of another 1 equiv. $\mathrm{NaOH}$ and 1 equiv. succinic anhydride and shaking for another 4 min.; (c) Addition of another 1 equiv. $\mathrm{NaOH}$ and 2 equiv. succinic anhydride and shaking for another 4 min.; (d) After 22 hr for (c); (e) The authentic target product 1b/ cavitand 2 in $\mathrm{D}_{2} \mathrm{O}$. 


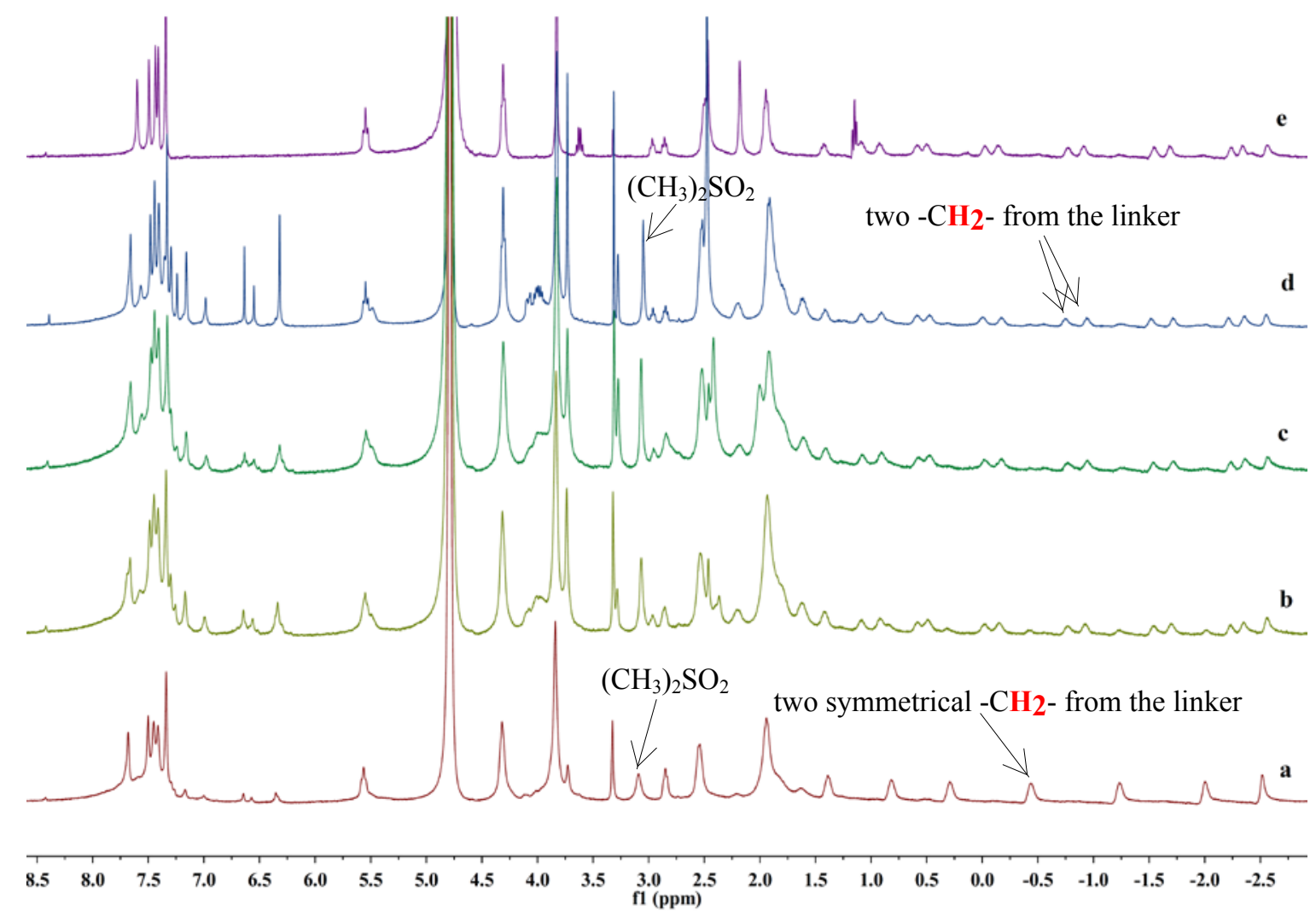

Figure S6. ${ }^{1} \mathrm{H}$ NMR spectra of cavitand 2 complexes $\left(400 \mathrm{MHz}, 299.5 \mathrm{~K}, \mathrm{D}_{2} \mathrm{O}\right.$ ) (the peaks indicated with an arrow were used to determine yields): (a) $\mathrm{C}_{16}$ diamine/cavitand 2 in $\mathrm{D}_{2} \mathrm{O}$; Addition of dimethyl sulfone aqueous solution (as internal standard) and 1 equiv. $\mathrm{NaOH}$ aqueous solution (70 $\mathrm{mM}$ in $\mathrm{D}_{2} \mathrm{O}$ ); (b) Addition of 1 equiv. succinic anhydride solution ( $87 \mathrm{mM}$ in $\mathrm{CD}_{3} \mathrm{OD}$ ) and shaking for $4 \mathrm{~min}$. by hand, then addition of another 1 equiv. $\mathrm{NaOH}$ and 1 equiv. succinic anhydride and shaking for another 4 min.; (c) Addition of another 1 equiv. $\mathrm{NaOH}$ and 2.0 equiv. succinic anhydride and shaking for another 4 min.; (d) After $25 \mathrm{hr}$ for (c); (e) The authentic target product 1c/ cavitand 2 in $\mathrm{D}_{2} \mathrm{O}$. 


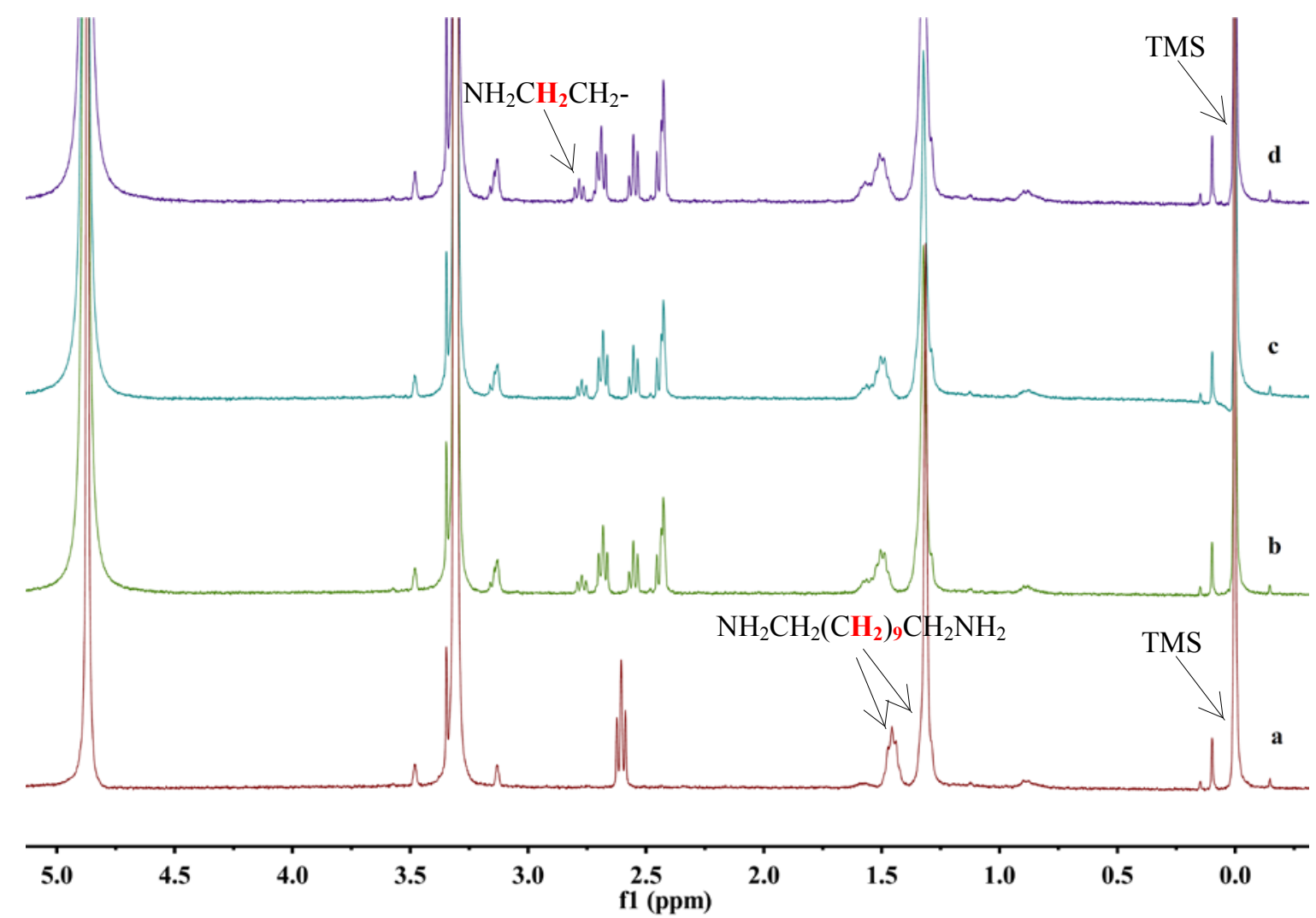

Figure S7. Partial ${ }^{1} \mathrm{H}$ NMR spectra (400 MHz, $299.5 \mathrm{~K}, \mathrm{CD}_{3} \mathrm{OD}$ ) (the peaks indicated with an arrow were used to determine yields): (a) $\mathrm{C}_{11}$ diamine solution (1 $\mathrm{mM}$ ) in $\mathrm{CD}_{3} \mathrm{OD}$ (TMS as the internal standard). Addition of 1 equiv. $\mathrm{NaOH}$ aqueous solution (70 mM in $\mathrm{D}_{2} \mathrm{O}$ ); (b) Addition of 1 equiv. succinic anhydride solution (87 $\mathrm{mM}$ in $\mathrm{CD}_{3} \mathrm{OD}$, No TMS) to (a); (c) After 25 min. for (b); (d) After $25 \mathrm{hr}$ for (b). 

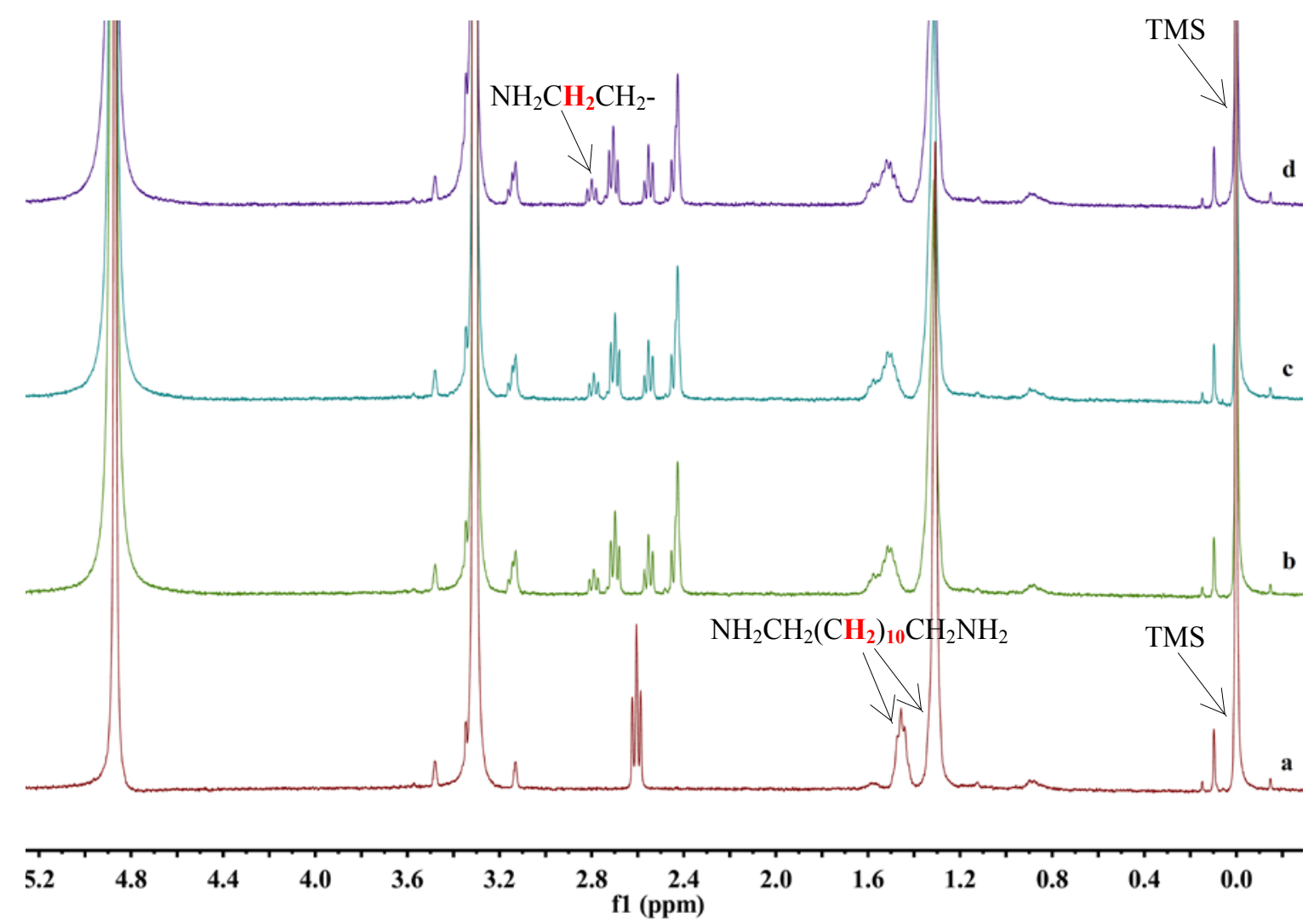

Figure S8. Partial ${ }^{1} \mathrm{H}$ NMR spectra (400 MHz, $299.5 \mathrm{~K}, \mathrm{CD}_{3} \mathrm{OD}$ ) (the peaks indicated with an arrow were used to determine yields): (a) $\mathrm{C}_{12}$ diamine solution (1 $\mathrm{mM}$ ) in $\mathrm{CD}_{3} \mathrm{OD}$ (TMS as the internal standard). Addition of 1 equiv. $\mathrm{NaOH}$ aqueous solution $(70 \mathrm{mM}$ in $\mathrm{D}_{2} \mathrm{O}$ ); (b) Addition of 1 equiv. succinic anhydride solution (87 $\mathrm{mM}$ in $\mathrm{CD}_{3} \mathrm{OD}$, No TMS) to (a); (c) After 20 min. for (b); (d) After $25 \mathrm{hr}$ for (b). 


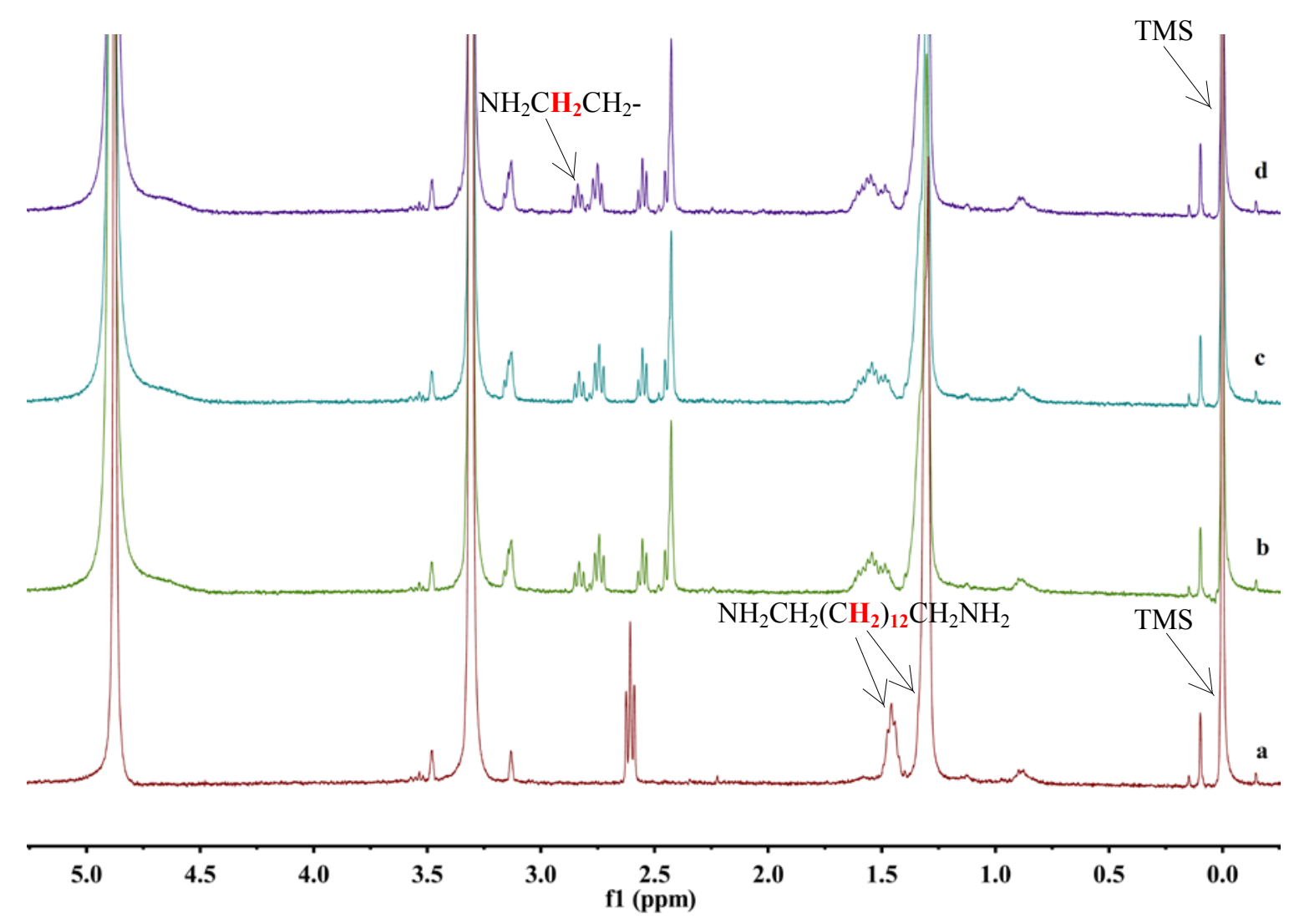

Figure S9. Partial ${ }^{1} \mathrm{H}$ NMR spectra (400 MHz, $299.5 \mathrm{~K}, \mathrm{CD}_{3} \mathrm{OD}$ ) (the peaks indicated with an arrow were used to determine yields): (a) $\mathrm{C}_{14}$ diamine solution (1 mM) in $\mathrm{CD}_{3} \mathrm{OD}$ (TMS as the internal standard). Addition of 1 equiv. $\mathrm{NaOH}$ aqueous solution $(70 \mathrm{mM}$ in $\mathrm{D}_{2} \mathrm{O}$ ); (b) Addition of 1 equiv. succinic anhydride solution (87 $\mathrm{mM}$ in $\mathrm{CD}_{3} \mathrm{OD}$, No TMS) to (a); (c) After 23 min. for (b); (d) After 25 hr for (b); 

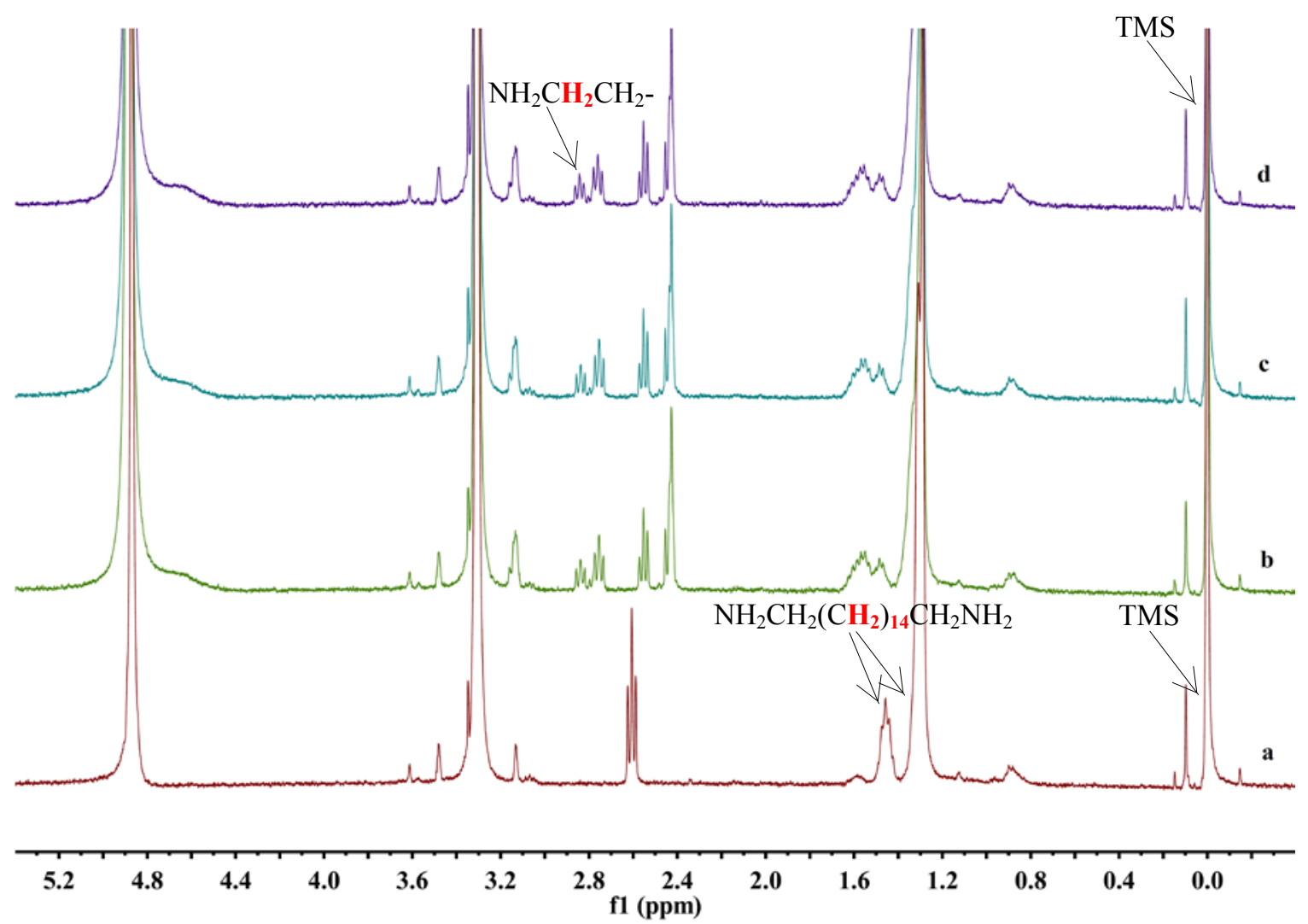

Figure S10. Partial ${ }^{1} \mathrm{H}$ NMR spectra (400 $\mathrm{MHz}, 299.5 \mathrm{~K}, \mathrm{CD}_{3} \mathrm{OD}$ ) (the peaks indicated with an arrow were used to determine yields): (a) $\mathrm{C}_{16}$ diamine solution (1 mM) in $\mathrm{CD}_{3} \mathrm{OD}$ (TMS as the internal standard). Addition of 1 equiv. $\mathrm{NaOH}$ aqueous solution (70 mM in $\mathrm{D}_{2} \mathrm{O}$ ); (b) Addition of 1 equiv. succinic anhydride solution (87 $\mathrm{mM}$ in $\mathrm{CD}_{3} \mathrm{OD}$, No TMS) to (a); (c) After 20 min. for (b); (d) After $25 \mathrm{hr}$ for (b). 


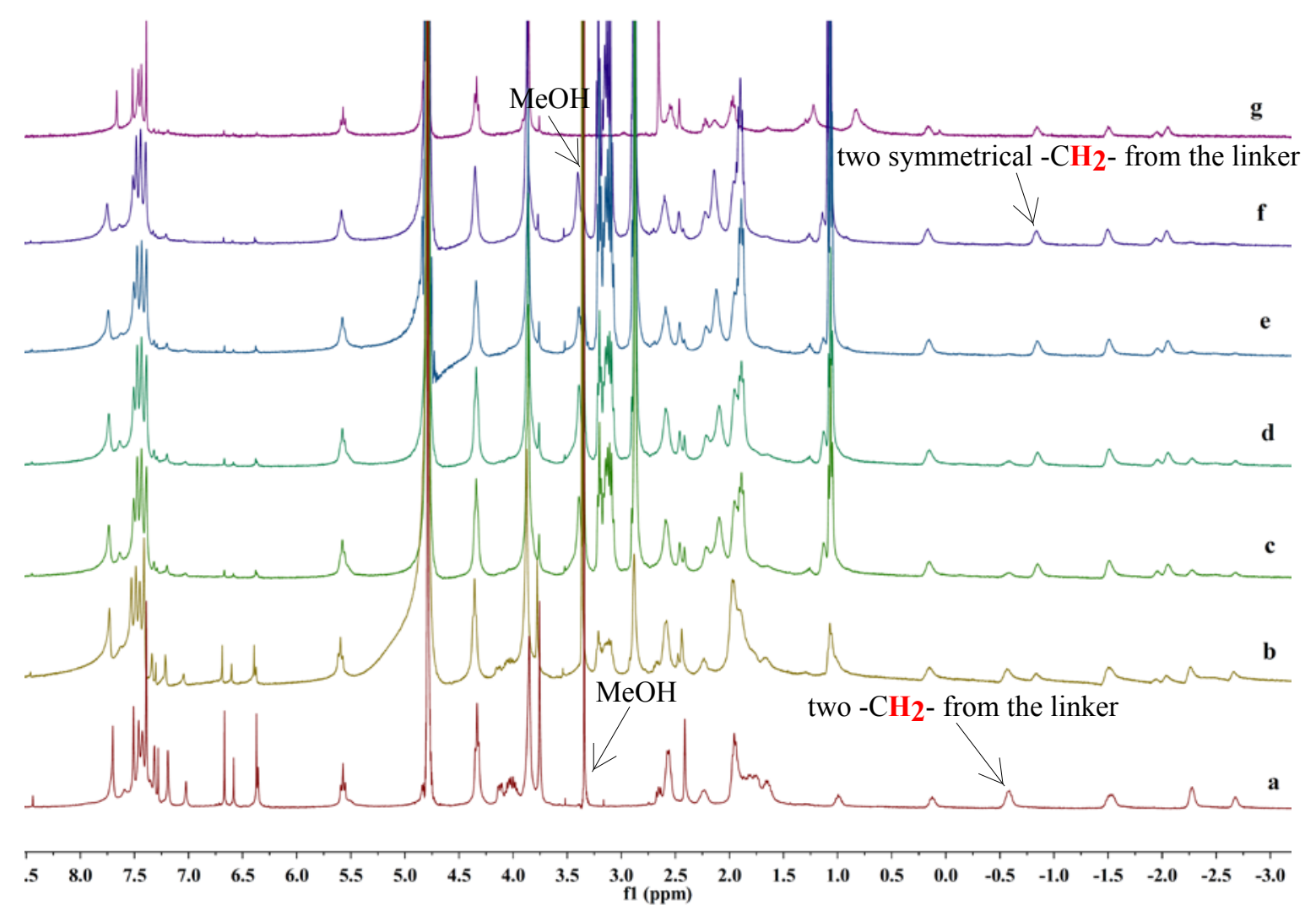

Figure S11. ${ }^{1} \mathrm{H}$ NMR spectra of cavitand 2 complexes $\left(400 \mathrm{MHz}, 299.5 \mathrm{~K}, \mathrm{D}_{2} \mathrm{O}\right.$ ) (the peaks indicated with an arrow were used to determine yields): (a) $\mathrm{C}_{11}$ amino acid (1 $\mathrm{mM}$ )/Cavitand 2 in $\mathrm{D}_{2} \mathrm{O}$. (b) Addition of 1 equiv. sulfo-NHS aqueous solution (104 $\mathrm{mM}$ in $\left.\mathrm{D}_{2} \mathrm{O}\right)$ and 2 equiv. EDC. $\mathrm{HCl}$ aqueous solution (110 $\mathrm{mM}$ in $\left.\mathrm{D}_{2} \mathrm{O}\right)$ to (a) and stirring at rt for 8h; (c) Addition of another 2 equiv. EDC $\cdot \mathrm{HCl}$ aqueous solution to (b) and stirring at rt for 20h; (d) Addition of another 2 equiv. EDC $\cdot \mathrm{HCl}$ aqueous solution to (c) and stirring at rt for 20h; (e) Addition of another 0.2 equiv. sulfo-NHS aqueous solution and 2 equiv. EDC. $\mathrm{HCl}$ aqueous solution to (d) and stirring at rt for 68h; (f) Addition of another 1 equiv. EDC. $\mathrm{HCl}$ aqueous solution to (e) and stirring at rt for 24h; (g) The authentic target product $3 \mathbf{a} /$ cavitand $\mathbf{2}$ in $\mathrm{D}_{2} \mathrm{O}$. 


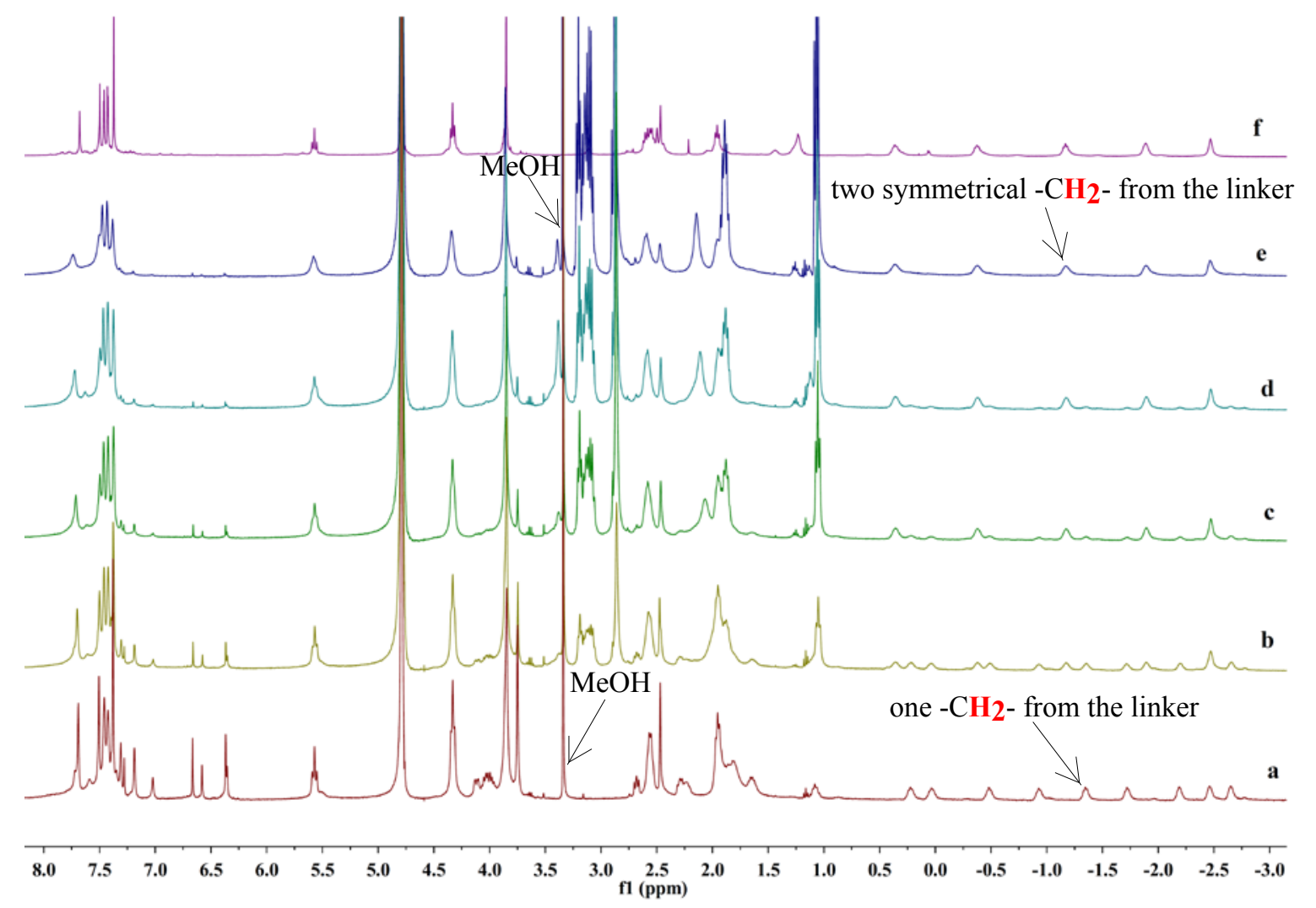

Figure S12. ${ }^{1} \mathrm{H}$ NMR spectra of cavitand 2 complexes (400 MHz, $299.5 \mathrm{~K}, \mathrm{D}_{2} \mathrm{O}$ ) (the peaks indicated with an arrow were used to determine yields): (a) $\mathrm{C}_{12}$ amino acid (1 $\mathrm{mM}$ )/Cavitand 2 in $\mathrm{D}_{2} \mathrm{O}$. (b) Addition of 1 equiv. sulfo-NHS aqueous solution (104 $\mathrm{mM}$ in $\left.\mathrm{D}_{2} \mathrm{O}\right)$ and 2 equiv. EDC. $\mathrm{HCl}$ aqueous solution $\left(110 \mathrm{mM}\right.$ in $\left.\mathrm{D}_{2} \mathrm{O}\right)$ to (a) and stirring at rt for 7h; (c) Addition of another 2 equiv. EDC $\cdot \mathrm{HCl}$ aqueous solution to (b) and stirring at rt for 20h; (d) Addition of another 2 equiv. EDC $\cdot \mathrm{HCl}$ aqueous solution to (c) and stirring at rt for 19h; (e) Addition of another 0.5 equiv. sulfo-NHS aqueous solution and 2 equiv. EDC $\cdot \mathrm{HCl}$ aqueous solution to (d) and stirring at rt for 43h; (f) The authentic target product $3 \mathbf{b}$ /cavitand 2 in $\mathrm{D}_{2} \mathrm{O}$. 


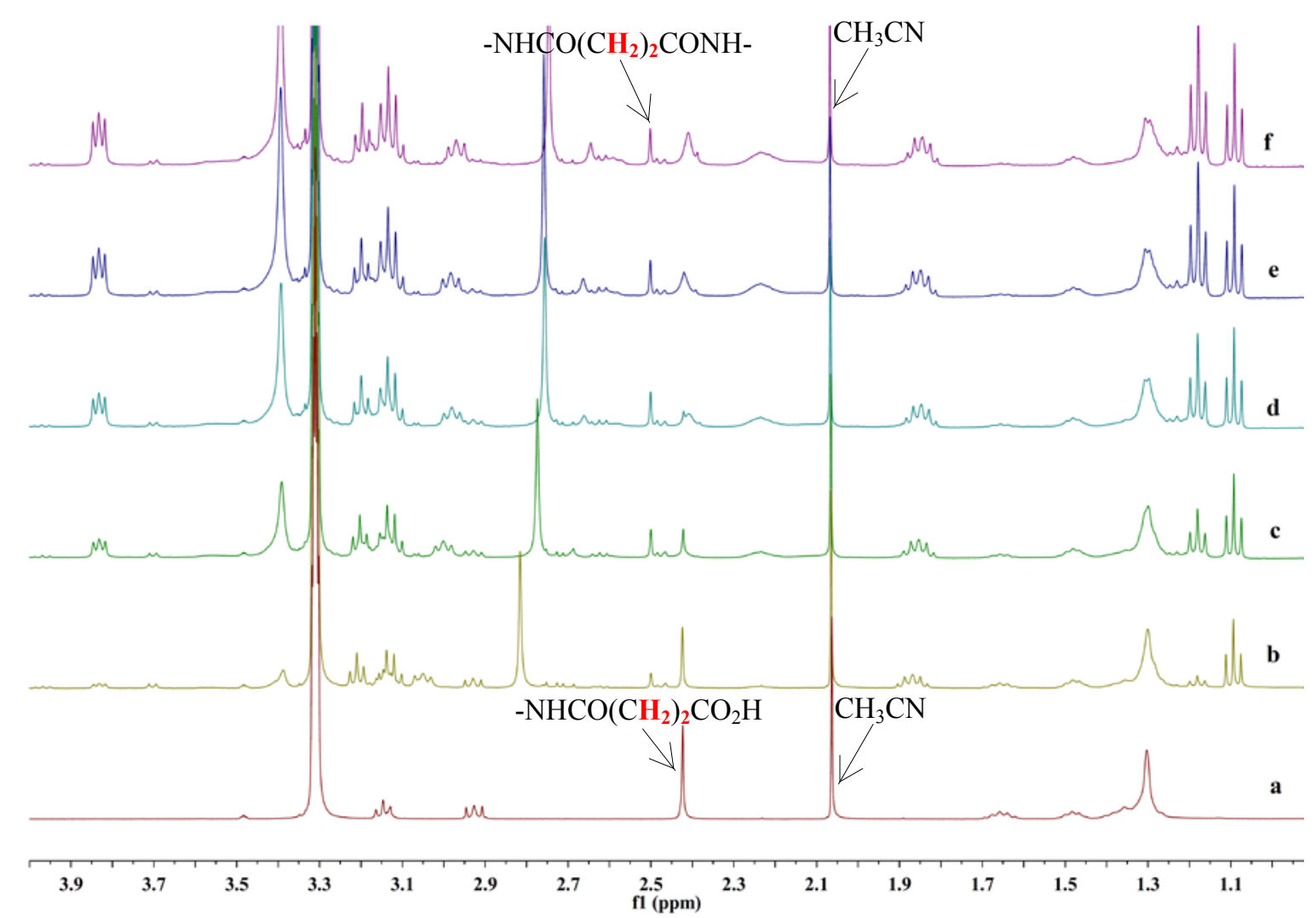

Figure S13. Partial ${ }^{1} \mathrm{H}$ NMR spectra $\left(400 \mathrm{MHz}, 299.5 \mathrm{~K}, \mathrm{CD}_{3} \mathrm{OD} / \mathrm{D}_{2} \mathrm{O} 4 / 1 \mathrm{v} / \mathrm{v}\right.$ ) (the peaks indicated with an arrow were used to determine yields): (a) $\mathrm{C}_{11}$ amino acid (1 $\mathrm{mM})$ in $\mathrm{CD}_{3} \mathrm{OD} / \mathrm{D}_{2} \mathrm{O}(4 / 1, \mathrm{v} / \mathrm{v})\left(\mathrm{CH}_{3} \mathrm{CN}\right.$ as internal standard); (b) Addition of 1 equiv. sulfo-NHS aqueous solution (104 $\mathrm{mM}$ in $\left.\mathrm{D}_{2} \mathrm{O}\right)$ and 2 equiv. $\mathrm{EDC} \cdot \mathrm{HCl}$ aqueous solution (110 mM in $\mathrm{D}_{2} \mathrm{O}$ ) to (a) and stirring at rt for 20h; (c) Addition of another 2 equiv. EDC $\cdot \mathrm{HCl}$ aqueous solution to (b) and stirring at rt for 20h; (d) Addition of another 2 equiv. EDC· $\mathrm{HCl}$ aqueous solution to (c) and stirring at rt for 20h; (e) Addition of another 0.2 equiv. sulfo-NHS aqueous solution and 2 equiv. EDC. $\mathrm{HCl}$ aqueous solution to (d) and stirring at $\mathrm{rt}$ for 24h; (f) Addition of another 1 equiv. EDC $\cdot \mathrm{HCl}$ aqueous solution to (e) and stirring at rt for 24h; 


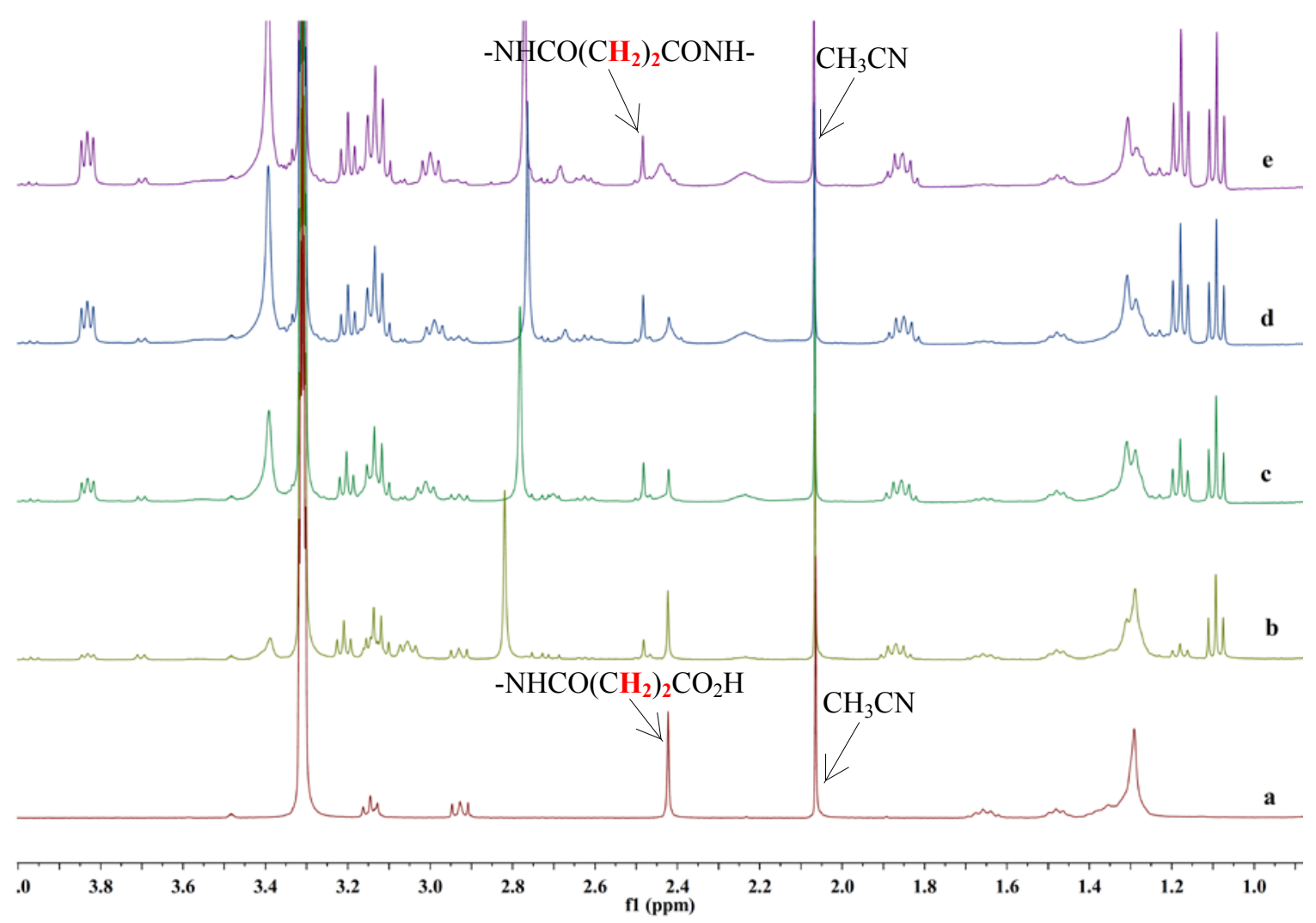

Figure S14. Partial ${ }^{1} \mathrm{H}$ NMR spectra $\left(400 \mathrm{MHz}, 299.5 \mathrm{~K}, \mathrm{CD}_{3} \mathrm{OD} / \mathrm{D}_{2} \mathrm{O} 4 / 1 \mathrm{v} / \mathrm{v}\right)$ (the peaks indicated with an arrow were used to determine yields): (a) $\mathrm{C}_{12}$ amino acid (1 $\mathrm{mM})$ in $\mathrm{CD}_{3} \mathrm{OD} / \mathrm{D}_{2} \mathrm{O}(4 / 1, \mathrm{v} / \mathrm{v})\left(\mathrm{CH}_{3} \mathrm{CN}\right.$ as internal standard); (b) Addition of 1 equiv. sulfo-NHS aqueous solution (104 $\mathrm{mM}$ in $\left.\mathrm{D}_{2} \mathrm{O}\right)$ and 2 equiv. $\mathrm{EDC} \cdot \mathrm{HCl}$ aqueous solution (110 $\mathrm{mM}$ in $\mathrm{D}_{2} \mathrm{O}$ ) to (a) and stirring at $\mathrm{rt}$ for 20h; (c) Addition of another 2 equiv. EDC $\cdot \mathrm{HCl}$ aqueous solution to (b) and stirring at $\mathrm{rt}$ for 20h; (d) Addition of another 2 equiv. EDC $\cdot \mathrm{HCl}$ aqueous solution to (c) and stirring at rt for 20h; (e) Addition of another 0.5 equiv. sulfo-NHS aqueous solution and 2 equiv. EDC $\mathrm{HCl}$ aqueous solution to (d) and stirring at rt for 24h; 


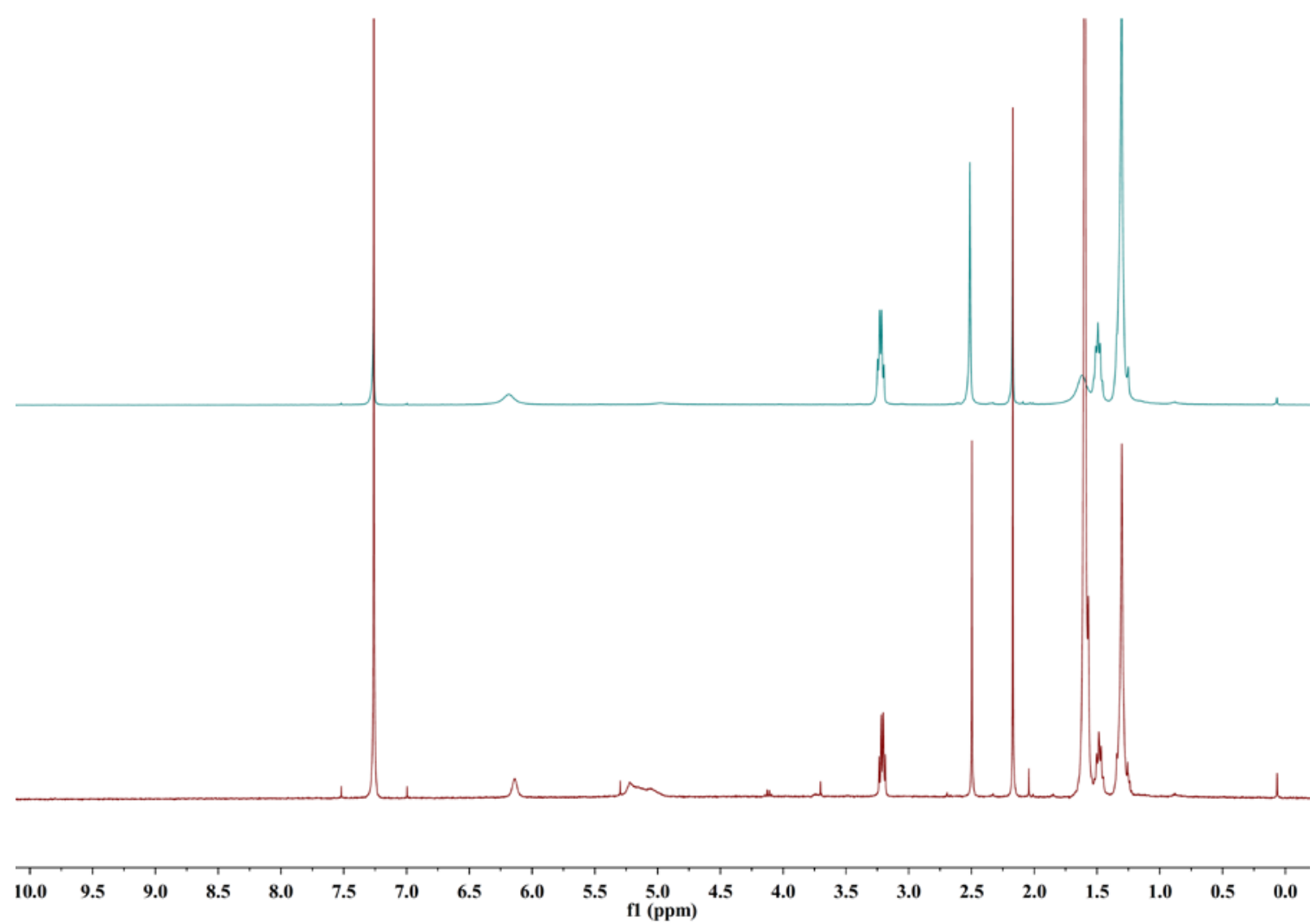

Figure S15. ${ }^{1} \mathrm{H}$ NMR spectra (400 MHz, $299.5 \mathrm{~K}, \mathrm{CDCl}_{3}$ ): (a) $\mathrm{CDCl}_{3}$ extraction solution for the reaction mixture from $\mathrm{C}_{12}$ amino acid, sulfo-NHS (1.5 equiv.) and EDC. $\mathrm{HCl}(8$ equiv.) in the presence of cavitand 2. Confirmed also by HRMS (see Fig. S16); (b) Authentic product $\mathbf{3 b}$. 


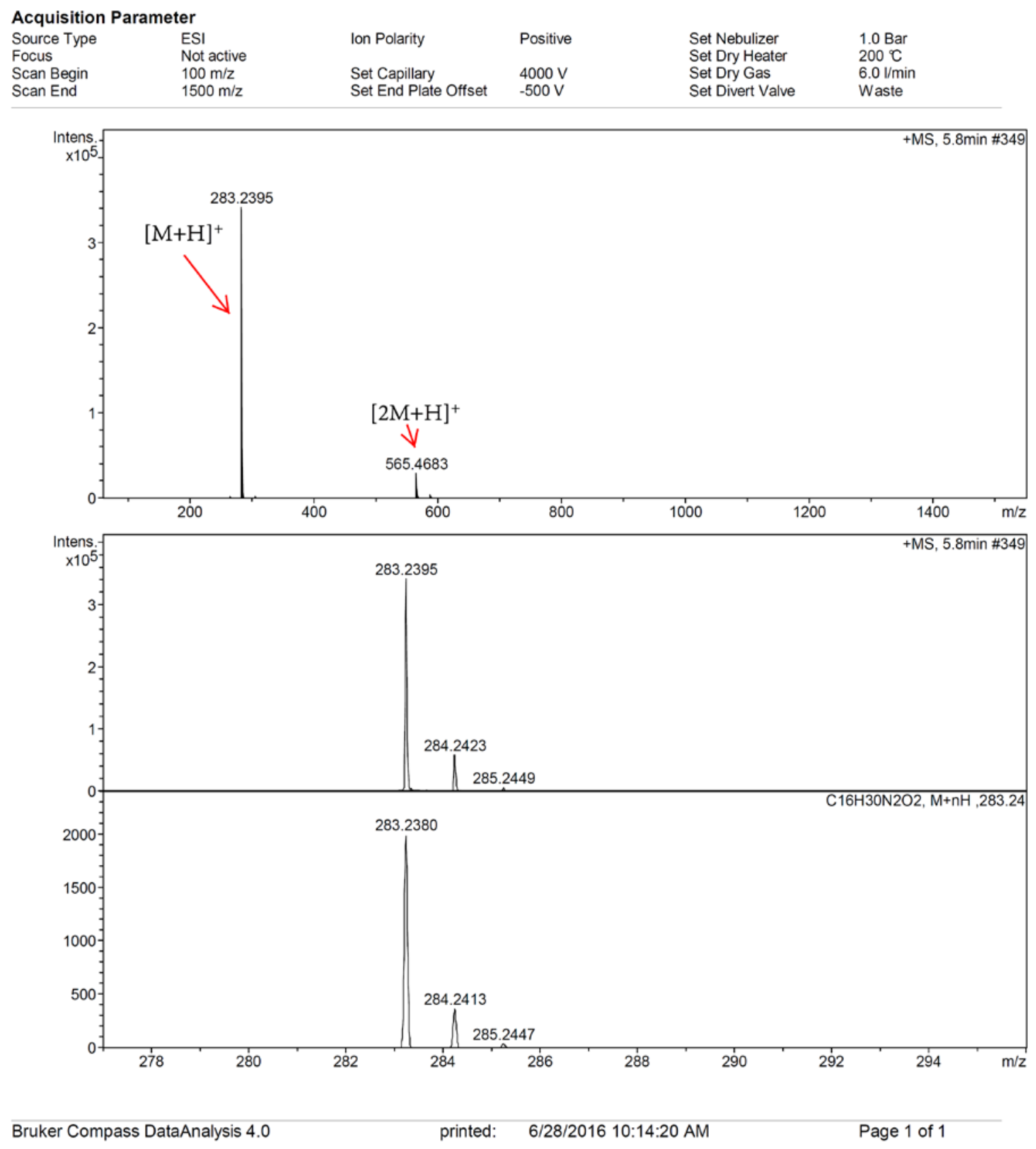

Figure S16. HRMS for Fig. S15 (a) 


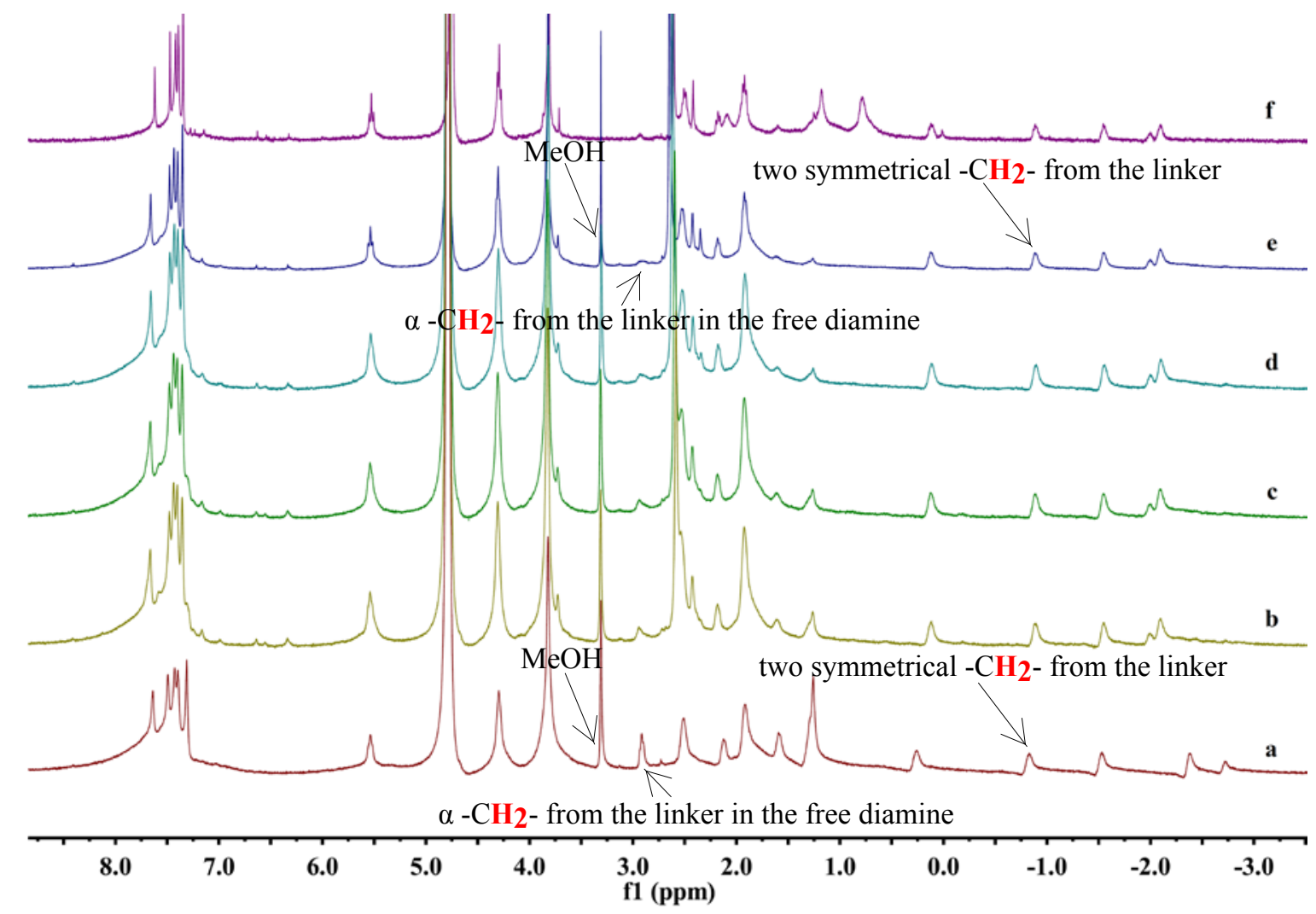

Figure S17. ${ }^{1} \mathrm{H}$ NMR spectra of cavitand 2 complexes (400 MHz, $299.5 \mathrm{~K}, \mathrm{D}_{2} \mathrm{O}$ ) (the peaks indicated with an arrow were used to determine yields): (a) $\mathrm{C}_{11}$ diamine $(1 \mathrm{mM}) /$ Cavitand 2 in $\mathrm{D}_{2} \mathrm{O}$, addition of 3 equiv. $\mathrm{NaOH}$ aqueous solution $\left(70 \mathrm{mM}\right.$ in $\mathrm{D}_{2} \mathrm{O}$ ); (b) Addition of excess of disuccinimidyl succinate and shaking for 2 min. by hand; (c) After 12 min. for (b); (d) After 45 min. for (b); (e) After 120 min. for (b); (f) The authentic target product $3 \mathbf{a} /$ cavitand $\mathbf{2}$ in $\mathrm{D}_{2} \mathrm{O}$. 


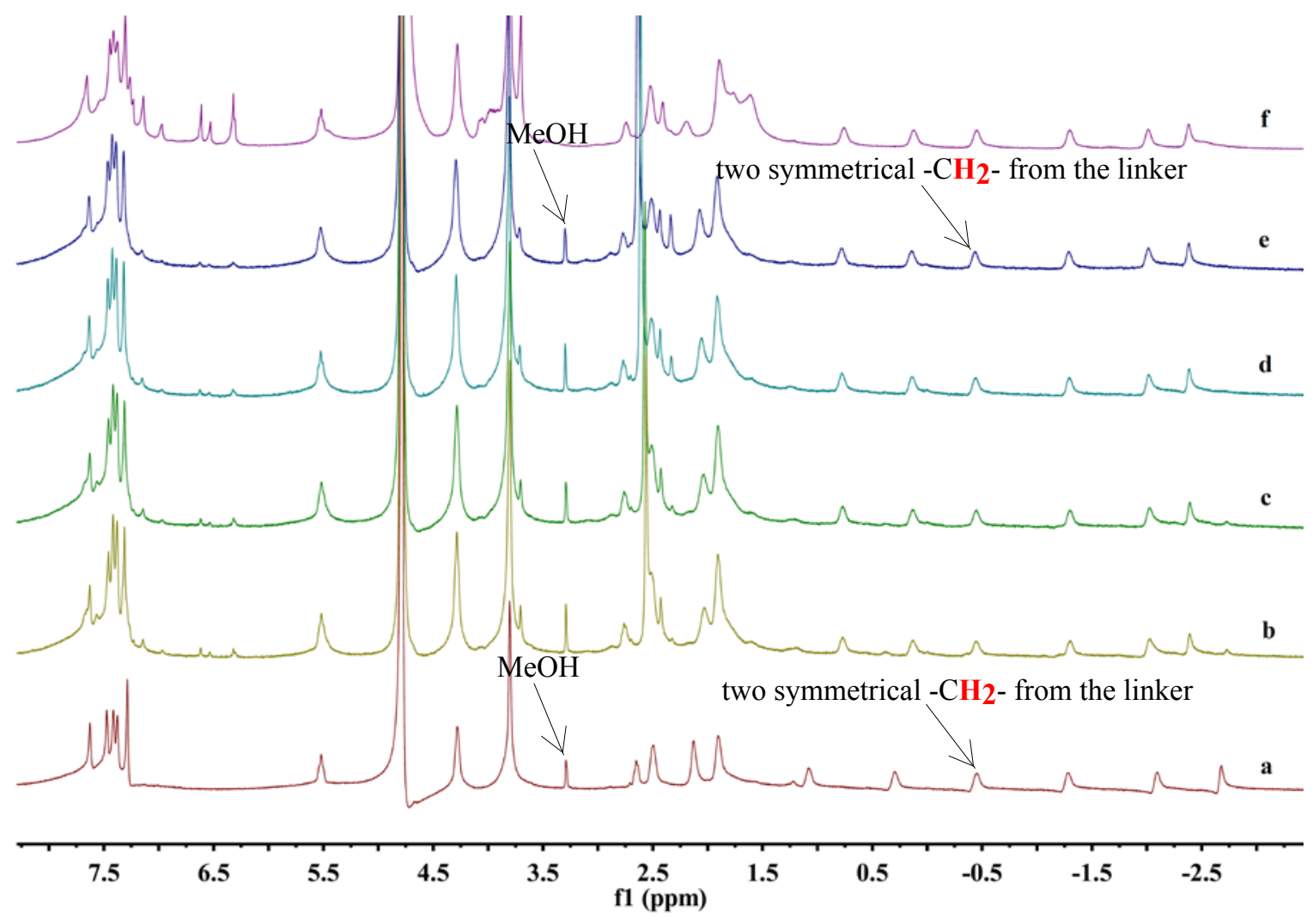

Figure S18. ${ }^{1} \mathrm{H}$ NMR spectra of cavitand 2 complexes (400 MHz, $299.5 \mathrm{~K}, \mathrm{D}_{2} \mathrm{O}$ ) (the peaks indicated with an arrow were used to determine yields): (a) $\mathrm{C}_{14}$ diamine $(1 \mathrm{mM}) /$ Cavitand 2 in $\mathrm{D}_{2} \mathrm{O}$, addition of 3 equiv. $\mathrm{NaOH}$ aqueous solution (70 $\mathrm{mM}$ in $\mathrm{D}_{2} \mathrm{O}$ ); (b) Addition of excess of disuccinimidyl succinate and shaking for 2 min. by hand; (c) After $10 \mathrm{~min}$. for (b); (d) After $60 \mathrm{~min}$. for (b); (e) After $120 \mathrm{~min}$. for (b); (f) The authentic target product 3c/cavitand 2 in $\mathrm{D}_{2} \mathrm{O}$. 


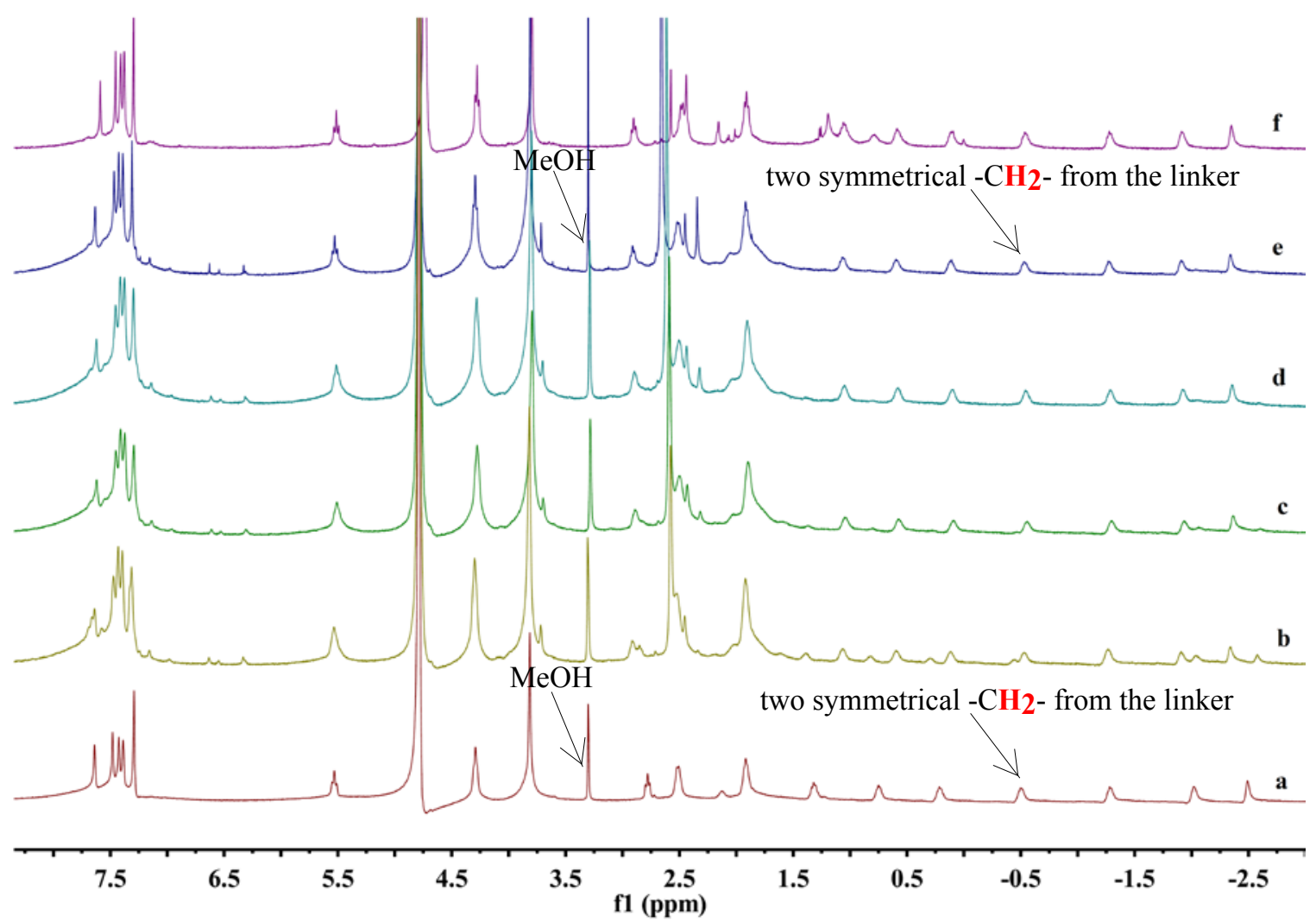

Figure S19. ${ }^{1} \mathrm{H}$ NMR spectra of cavitand 2 complexes (400 MHz, $299.5 \mathrm{~K}, \mathrm{D}_{2} \mathrm{O}$ ) (the peaks indicated with an arrow were used to determine yields): (a) $\mathrm{C}_{16}$ diamine $(1 \mathrm{mM}) /$ Cavitand 2 in $\mathrm{D}_{2} \mathrm{O}$, addition of 3 equiv. $\mathrm{NaOH}$ aqueous solution $\left(70 \mathrm{mM}\right.$ in $\mathrm{D}_{2} \mathrm{O}$ ); (b) Addition of excess of disuccinimidyl succinate and shaking for 2 min. by hand; (c) After 50 min. for (b); (d) After 100 min. for (b); (e) After 165 min. for (b); (f) The authentic target product $\mathbf{3 d}$ /cavitand $\mathbf{2}$ in $\mathrm{D}_{2} \mathrm{O}$. 


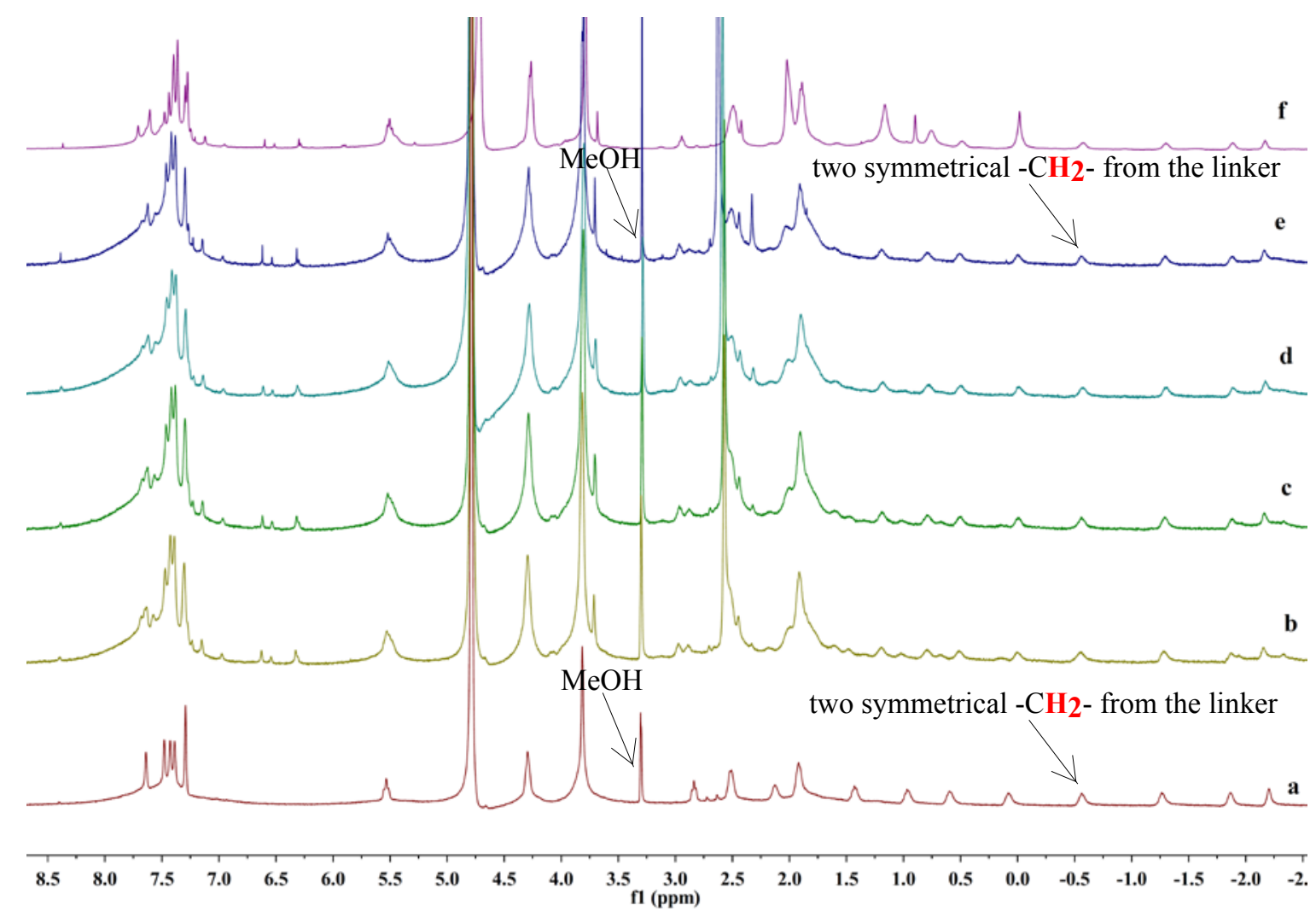

Figure S20. ${ }^{1} \mathrm{H}$ NMR spectra of cavitand 2 complexes (400 MHz, $299.5 \mathrm{~K}, \mathrm{D}_{2} \mathrm{O}$ ) (the peaks indicated with an arrow were used to determine yields): (a) $\mathrm{C}_{18}$ diamine (1 mM)/ Cavitand 2 in $\mathrm{D}_{2} \mathrm{O}$, addition of 3 equiv. $\mathrm{NaOH}$ aqueous solution $\left(70 \mathrm{mM}\right.$ in $\left.\mathrm{D}_{2} \mathrm{O}\right)$; (b) Addition of excess of disuccinimidyl succinate and shaking for 2 min. by hand; (c) After $10 \mathrm{~min}$. for (b); (d) After $40 \mathrm{~min}$. for (b); (e) After $120 \mathrm{~min}$. for (b); (f) The authentic target product 3e/cavitand 2 in $\mathrm{D}_{2} \mathrm{O}$. 


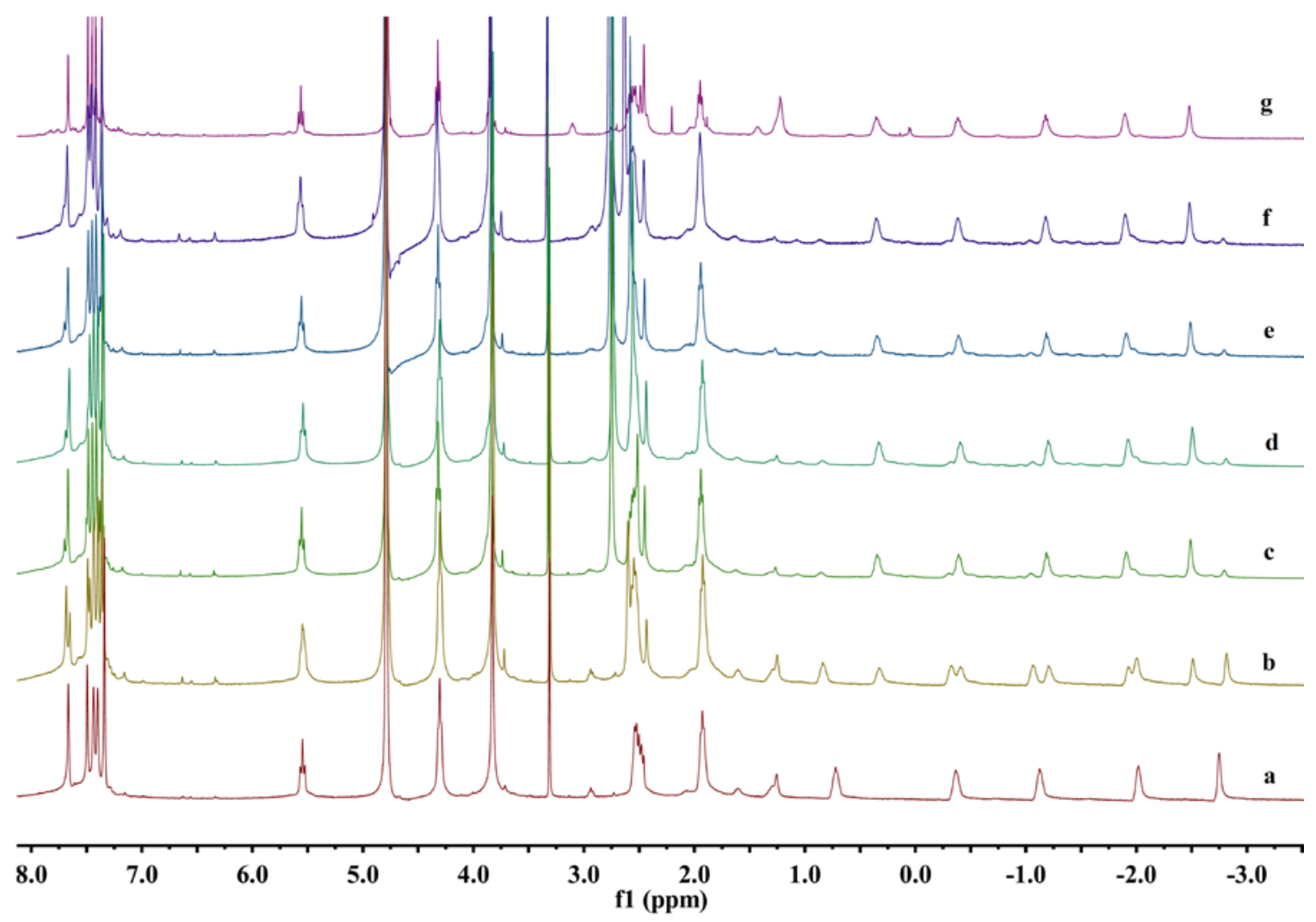

Figure S21. ${ }^{1} \mathrm{H}$ NMR spectra of cavitand 2 complexes (400 MHz, $299.5 \mathrm{~K}, \mathrm{D}_{2} \mathrm{O}$ ): (a) $\mathrm{C}_{12}$ diamine $(1 \mathrm{mM}) /$ Cavitand 2 in $\mathrm{D}_{2} \mathrm{O}$; (b) Addition of excess of disuccinimidyl succinate and shaking for 2 min. by hand; (c) After $24 \mathrm{hr}$ stirring inside the NMR tube at rt for (b); (d) After $36 \mathrm{hr}$ stirring inside the NMR tube at rt for (b); (e) Addition of more disuccinimidyl succinate and sonication at rt for $4 \mathrm{hr}$ for (d); (f) Sonication at $45{ }^{\circ} \mathrm{C}$ for $12 \mathrm{hr}$ for (e); (g) The authentic target product $3 \mathbf{b} /$ cavitand 2 in $\mathrm{D}_{2} \mathrm{O}$. 


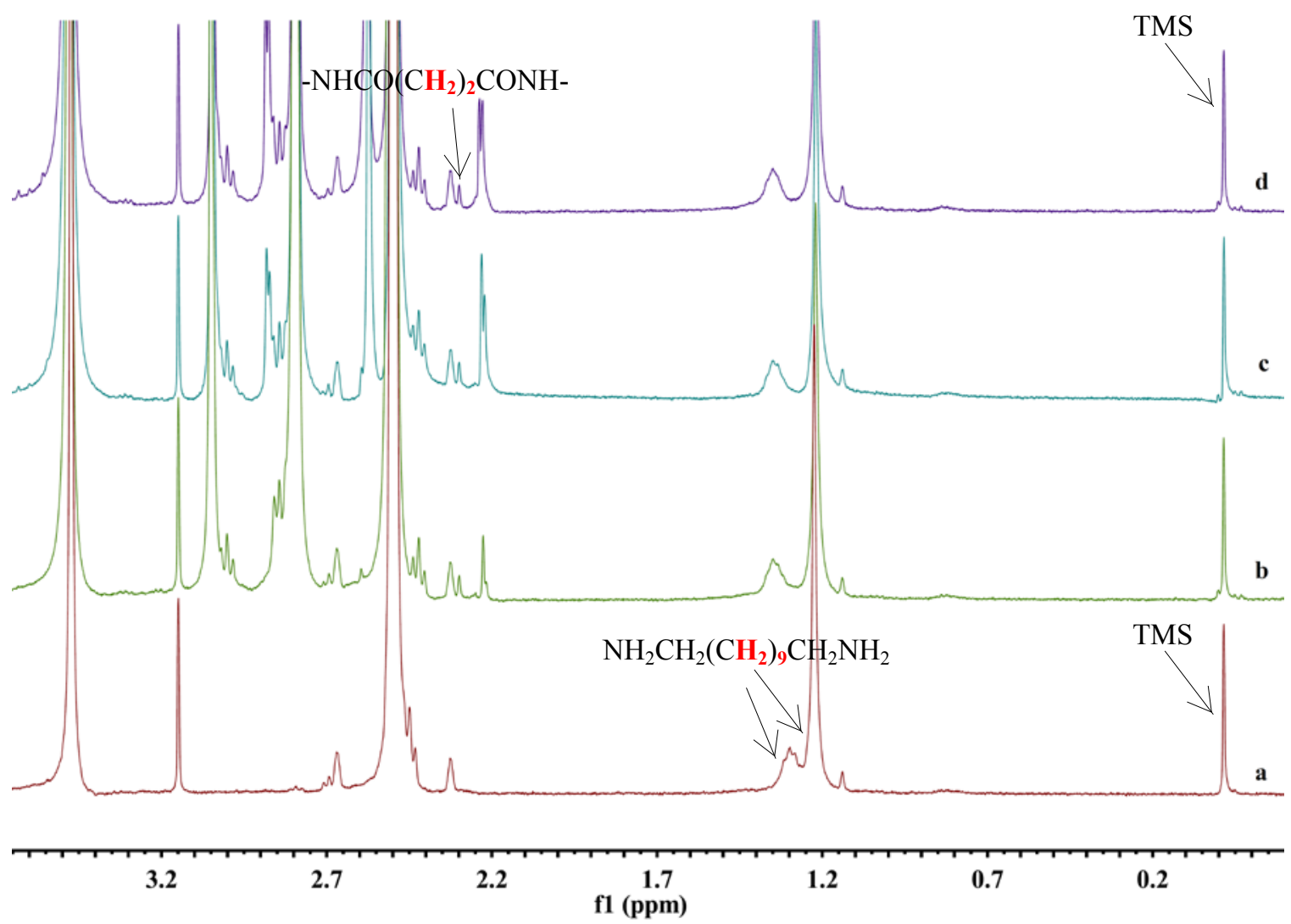

Figure S22. Partial ${ }^{1} \mathrm{H}$ NMR spectra (400 MHz, $299.5 \mathrm{~K}$, DMSO-d ${ }_{6}$ ) (the peaks indicated with an arrow were used to determine yields): (a) $\mathrm{C}_{11}$ diamine solution (1 mM) in DMSO- $_{6}$ (TMS as the internal standard). Addition of 3 equiv. $\mathrm{NaOH}$ aqueous solution (70 mM in $\mathrm{D}_{2} \mathrm{O}$ ); (b) Addition of excess of disuccinimidyl succinate to (a); (c) After 44 min. for (b); (d) After 130 min. for (b). 


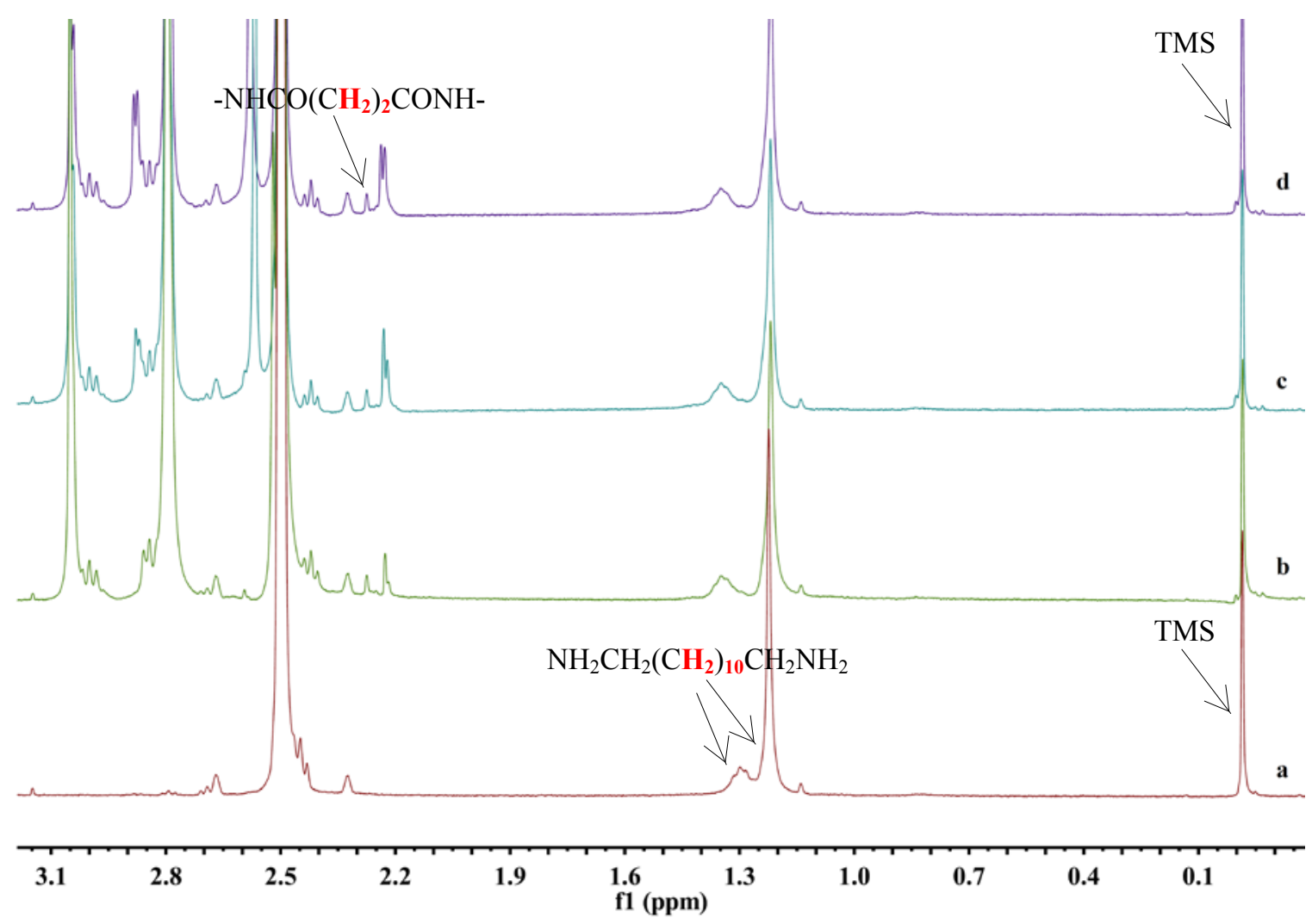

Figure S23. Partial ${ }^{1} \mathrm{H}$ NMR spectra (400 MHz, $299.5 \mathrm{~K}$, DMSO-d $\mathrm{d}_{6}$ ) (the peaks indicated with an arrow were used to determine yields): (a) $\mathrm{C}_{12}$ diamine solution (1 $\left.\mathrm{mM}\right)$ in DMSO-d $_{6}$ (TMS as the internal standard). Addition of 3 equiv. $\mathrm{NaOH}$ aqueous solution (70 mM in $\mathrm{D}_{2} \mathrm{O}$ ); (b) Addition of excess of disuccinimidyl succinate to (a); (c) After $32 \mathrm{~min}$. for (b); (d) After $115 \mathrm{~min}$. for (b). 

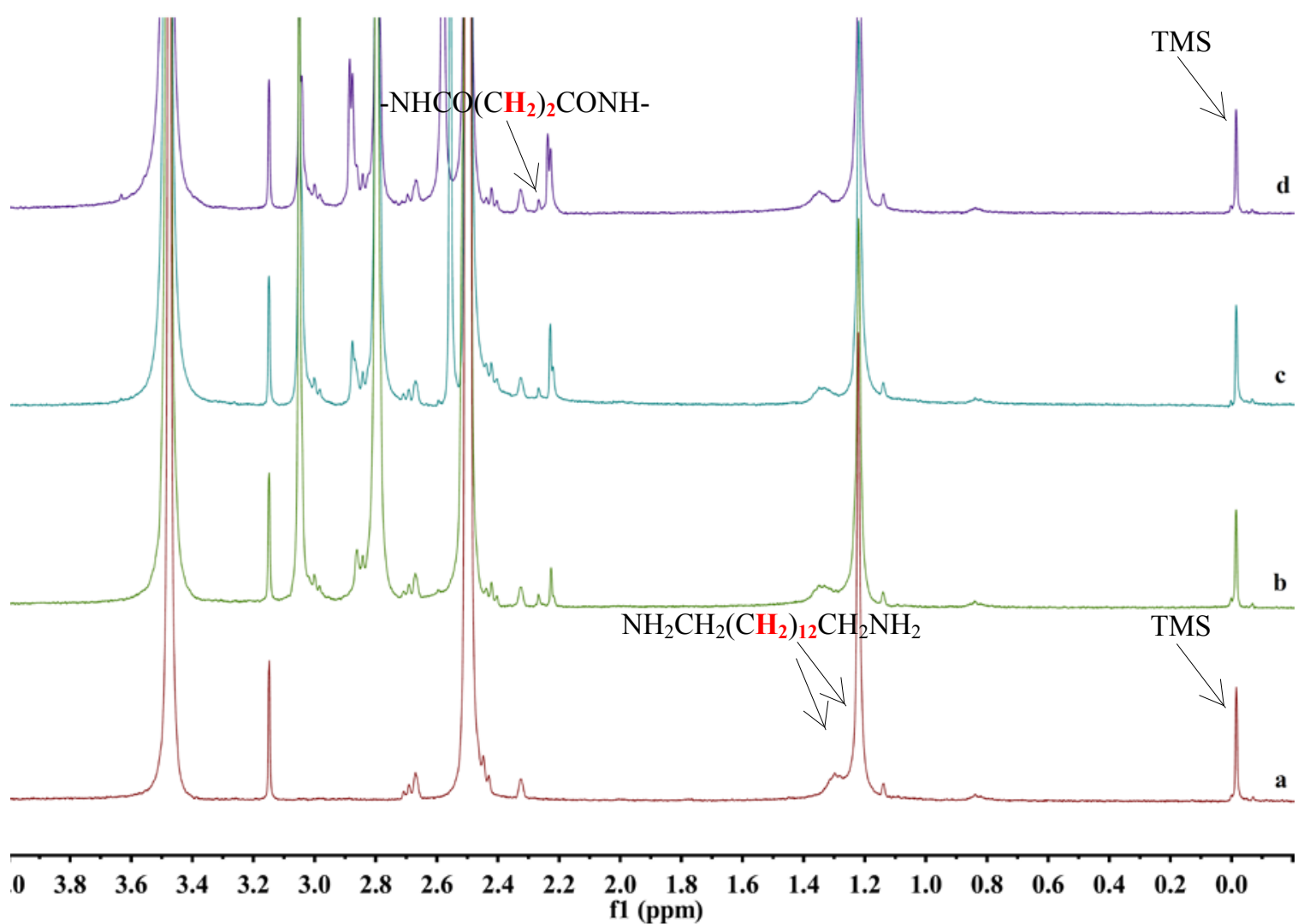

Figure S24. Partial ${ }^{1} \mathrm{H}$ NMR spectra (400 MHz, $299.5 \mathrm{~K}$, DMSO-d $\mathrm{d}_{6}$ ) (the peaks indicated with an arrow were used to determine yields): (a) $\mathrm{C}_{14}$ diamine solution (1 $\left.\mathrm{mM}\right)$ in $\mathrm{DMSO}_{6}$ (TMS as the internal standard). Addition of 3 equiv. $\mathrm{NaOH}$ aqueous solution (70 mM in $\mathrm{D}_{2} \mathrm{O}$ ); (b) Addition of excess of disuccinimidyl succinate to (a); (c) After 15 min. for (b); (d) After 130 min. for (b). 


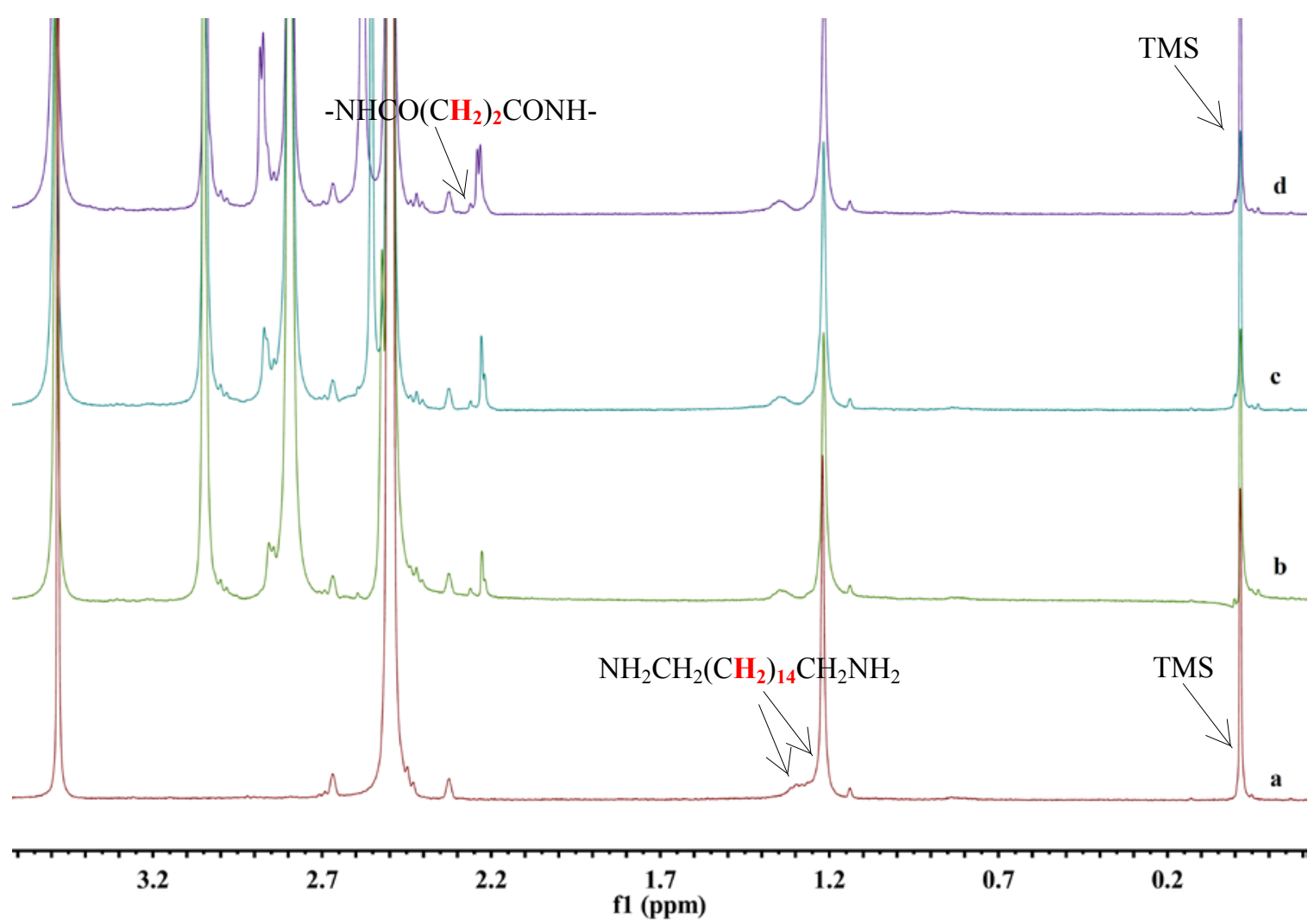

Figure S25. Partial ${ }^{1} \mathrm{H}$ NMR spectra (400 MHz, $299.5 \mathrm{~K}$, DMSO-d $\mathrm{d}_{6}$ ) (the peaks indicated with an arrow were used to determine yields): (a) $\mathrm{C}_{16}$ diamine solution (1 mM) in DMSO- $_{6}$ (TMS as the internal standard). Addition of 3 equiv. $\mathrm{NaOH}$ aqueous solution (70 mM in $\mathrm{D}_{2} \mathrm{O}$ ); (b) Addition of excess of disuccinimidyl succinate to (a); (c) After 10 min. for (b); (d) After 135 min. for (b). 

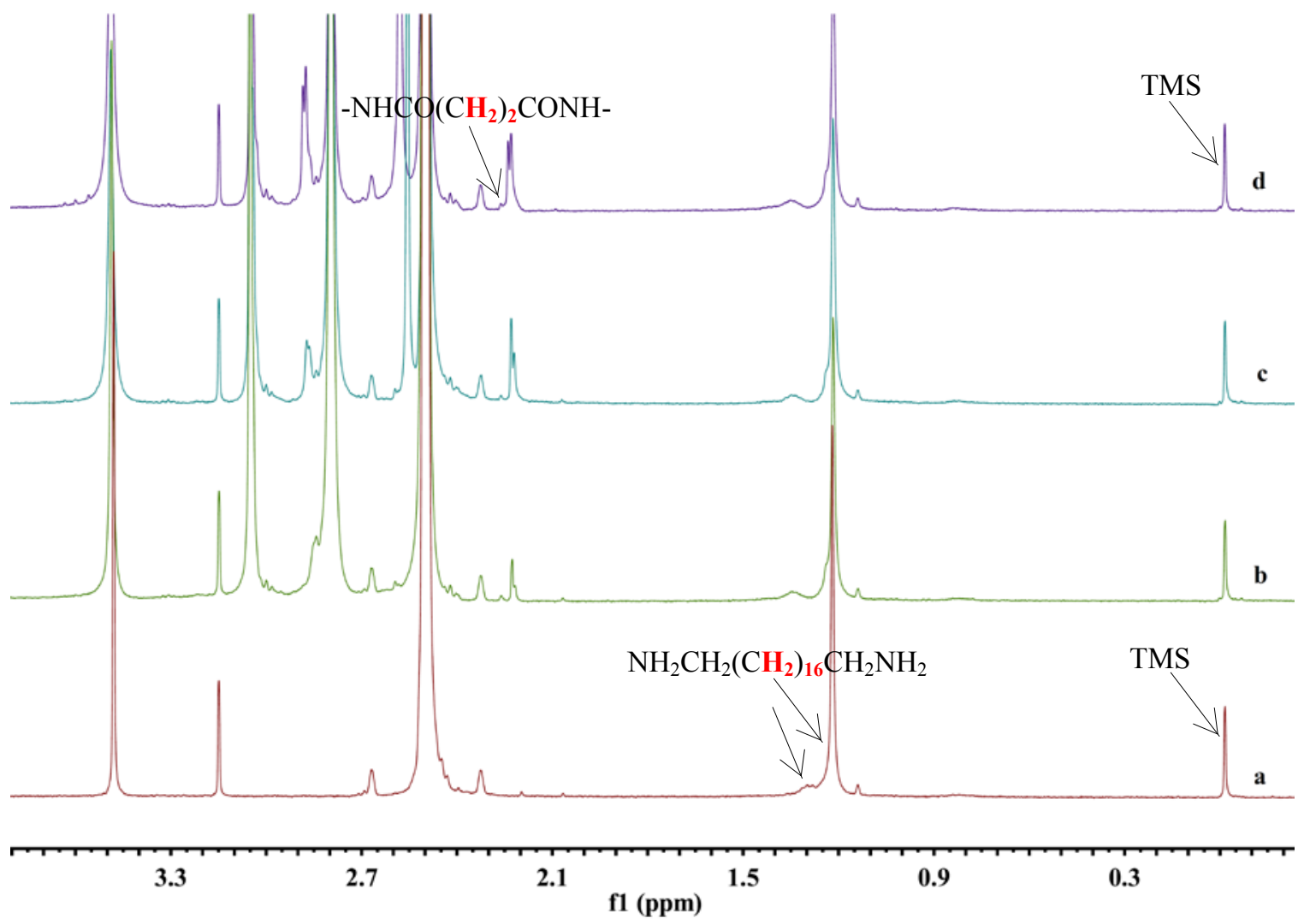

Figure S26. Partial ${ }^{1} \mathrm{H}$ NMR spectra (400 MHz, $299.5 \mathrm{~K}$, DMSO-d $\mathrm{d}_{6}$ ) (the peaks indicated with an arrow were used to determine yields): (a) $\mathrm{C}_{18}$ diamine solution (0.75 $\mathrm{mM}$ ) in $\mathrm{DMSO}_{6}$ (TMS as the internal standard). Addition of 3 equiv. $\mathrm{NaOH}$ aqueous solution (70 $\mathrm{mM}$ in $\mathrm{D}_{2} \mathrm{O}$ ); (b) Addition of excess of disuccinimidyl succinate to (a); (c) After $17 \mathrm{~min}$. for (b); (d) After $130 \mathrm{~min}$. for (b). 


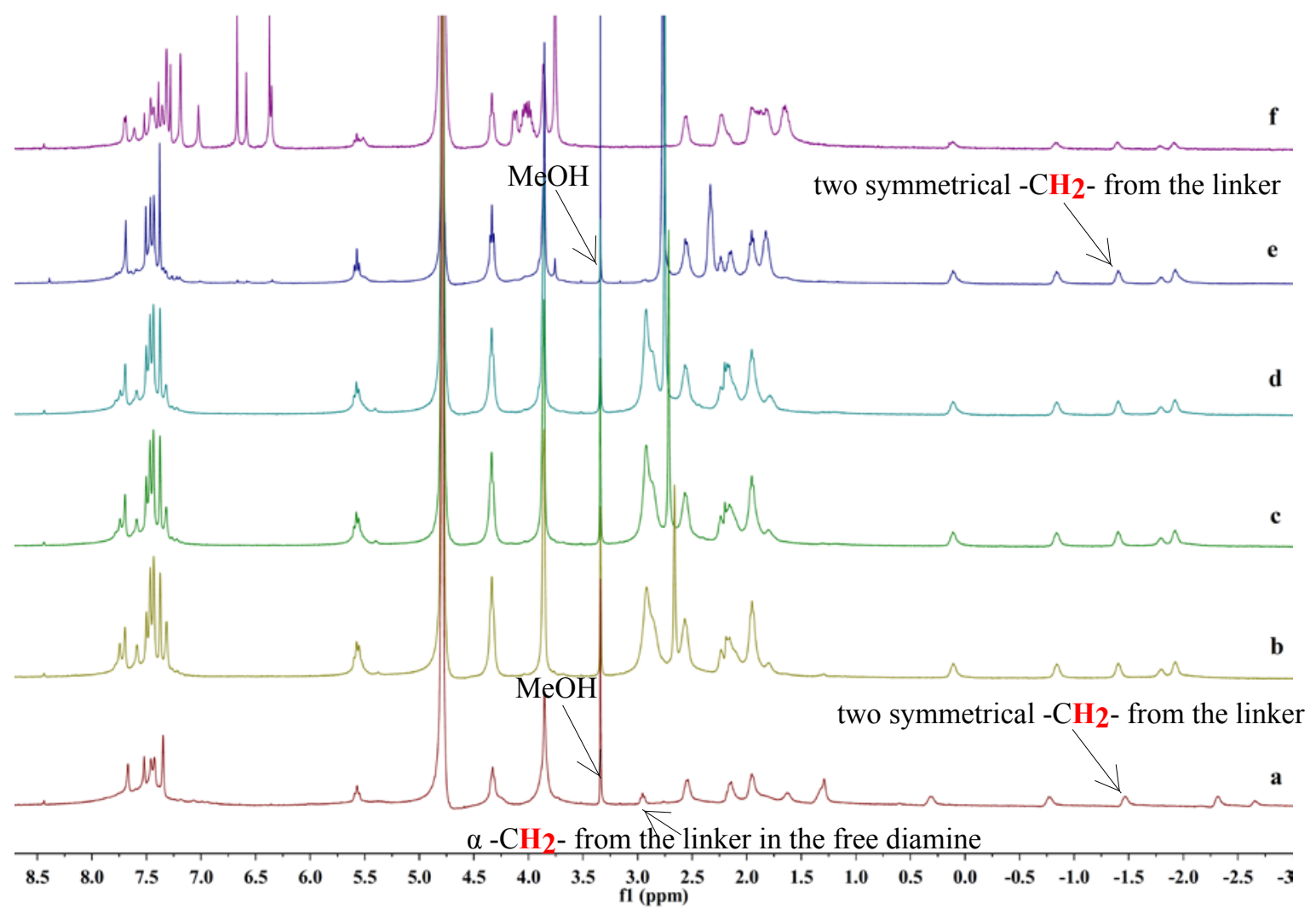

Figure S27. ${ }^{1} \mathrm{H}$ NMR spectra of cavitand 2 complexes (400 MHz, $299.5 \mathrm{~K}, \mathrm{D}_{2} \mathrm{O}$ ) (the peaks indicated with an arrow were used to determine yields): (a) $\mathrm{C}_{11}$ diamine $(1 \mathrm{mM}) /$ Cavitand 2 in $\mathrm{D}_{2} \mathrm{O}$, addition of 3 equiv. $\mathrm{NaOH}$ aqueous solution $\left(70 \mathrm{mM}\right.$ in $\left.\mathrm{D}_{2} \mathrm{O}\right)$; (b) Addition of excess of disuccinimidyl glutarate and shaking for 2 min. by hand; (c) After 40 min. for (b); (d) After 110 min. for (b); (e) After 35h for (b); (f) The authentic target product $\mathbf{4 a}$ /cavitand $\mathbf{2}$ in $\mathrm{D}_{2} \mathrm{O}$. 


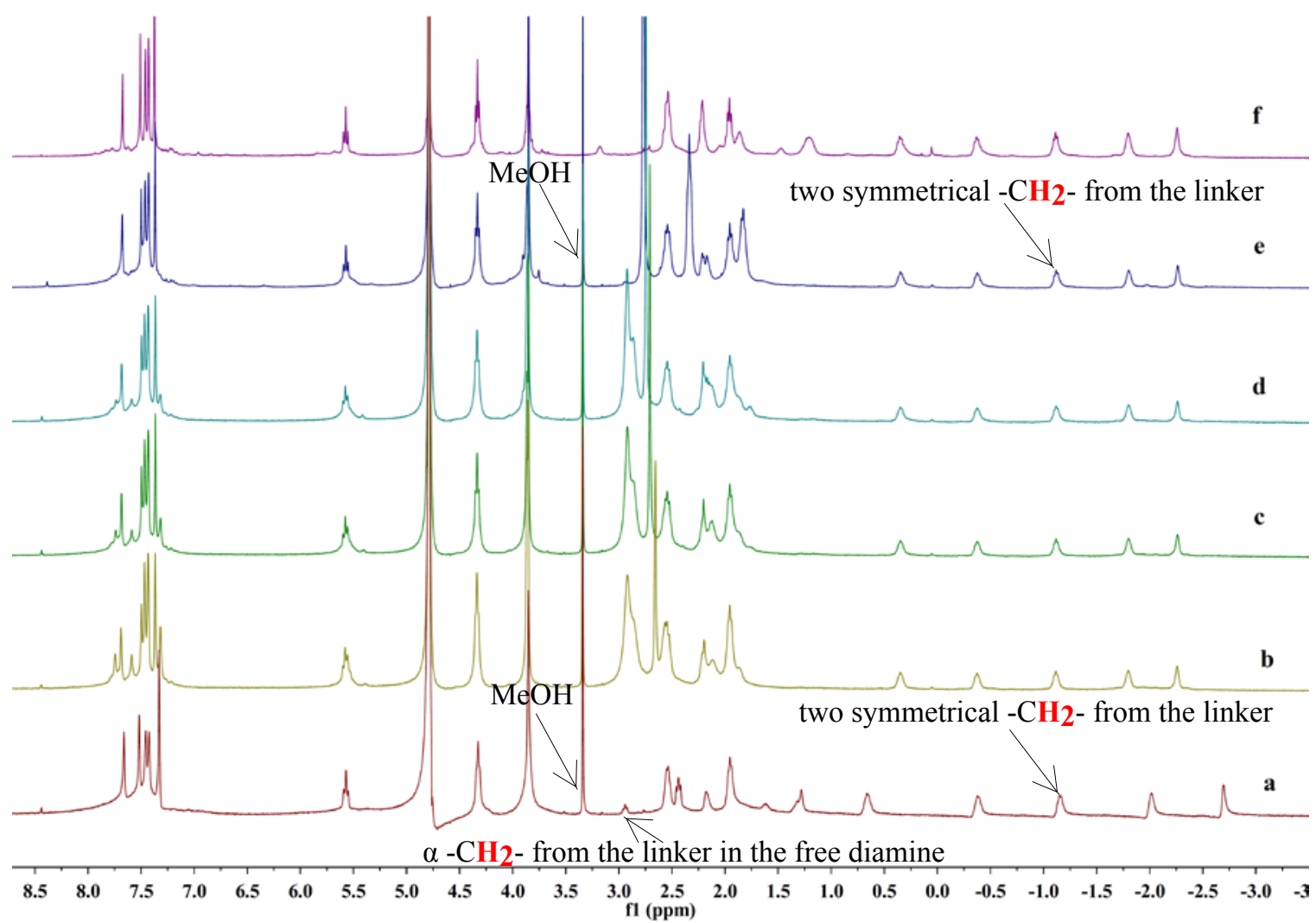

Figure S28. ${ }^{1} \mathrm{H}$ NMR spectra of cavitand 2 complexes (400 MHz, $299.5 \mathrm{~K}, \mathrm{D}_{2} \mathrm{O}$ ) (the peaks indicated with an arrow were used to determine yields): (a) $\mathrm{C}_{12}$ diamine (1 mM)/ Cavitand 2 in $\mathrm{D}_{2} \mathrm{O}$, addition of 3 equiv. $\mathrm{NaOH}$ aqueous solution (70 mM in $\mathrm{D}_{2} \mathrm{O}$ ); (b) Addition of excess of disuccinimidyl glutarate and shaking for 2 min. by hand; (c) After 45 min. for (b); (d) After 110 min. for (b); (e) After 35h for (b); (f) The authentic target product $\mathbf{4 b}$ /cavitand $\mathbf{2}$ in $\mathrm{D}_{2} \mathrm{O}$. 

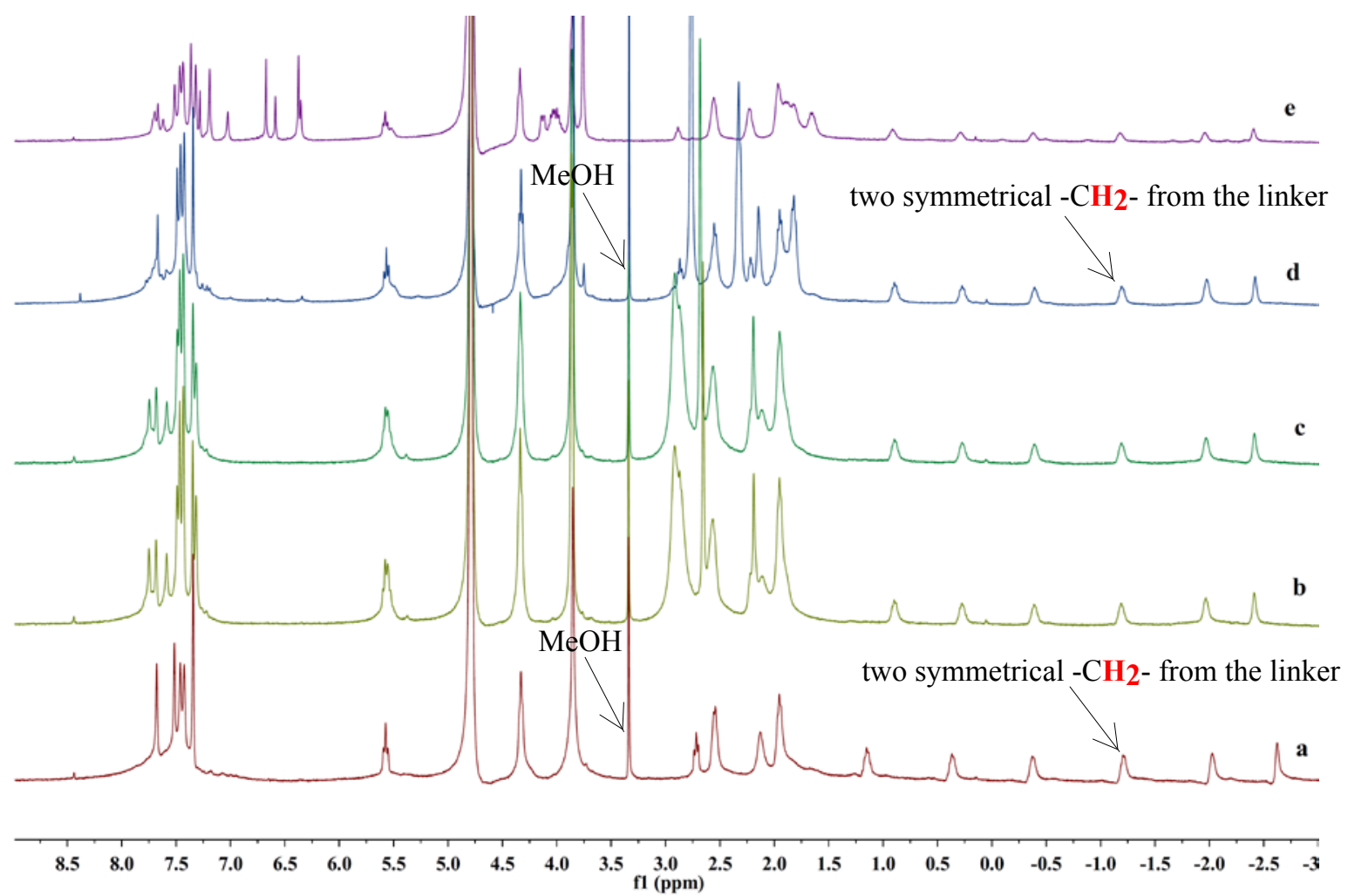

Figure S29. ${ }^{1} \mathrm{H}$ NMR spectra of cavitand 2 complexes $\left(400 \mathrm{MHz}, 299.5 \mathrm{~K}, \mathrm{D}_{2} \mathrm{O}\right.$ ) (the peaks indicated with an arrow were used to determine yields): (a) $\mathrm{C}_{14}$ diamine $(1 \mathrm{mM}) /$ Cavitand 2 in $\mathrm{D}_{2} \mathrm{O}$, addition of 3 equiv. $\mathrm{NaOH}$ aqueous solution (70 $\mathrm{mM}$ in $\mathrm{D}_{2} \mathrm{O}$ ); (b) Addition of excess of disuccinimidyl glutarate and shaking for $2 \mathrm{~min}$. by hand; (c) After 20 min. for (b); (d) After 25h for (b); (e) The authentic target product 4c/cavitand 2 in $\mathrm{D}_{2} \mathrm{O}$. 

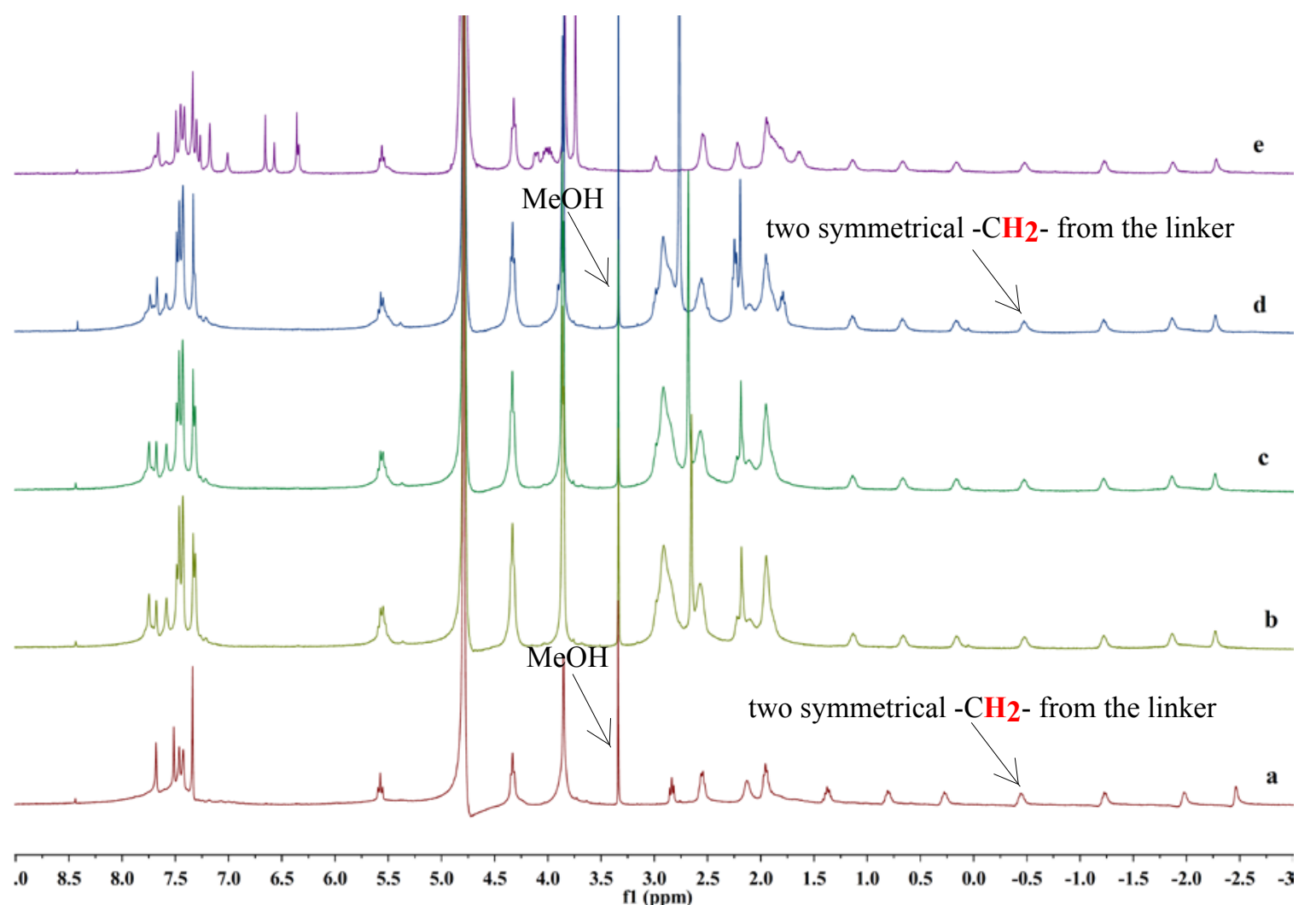

Figure S30. ${ }^{1} \mathrm{H}$ NMR spectra of cavitand 2 complexes (400 MHz, $299.5 \mathrm{~K}, \mathrm{D}_{2} \mathrm{O}$ ) (the peaks indicated with an arrow were used to determine yields): (a) $\mathrm{C}_{16}$ diamine $(1 \mathrm{mM}) /$ Cavitand 2 in $\mathrm{D}_{2} \mathrm{O}$, addition of 3 equiv. $\mathrm{NaOH}$ aqueous solution (70 mM in $\mathrm{D}_{2} \mathrm{O}$ ); (b) Addition of excess of disuccinimidyl glutarate and shaking for 2 min. by hand; (c) After 20 min. for (b); (d) After 235 min. for (b); (e) The authentic target product 4d/ cavitand 2 in $\mathrm{D}_{2} \mathrm{O}$. 


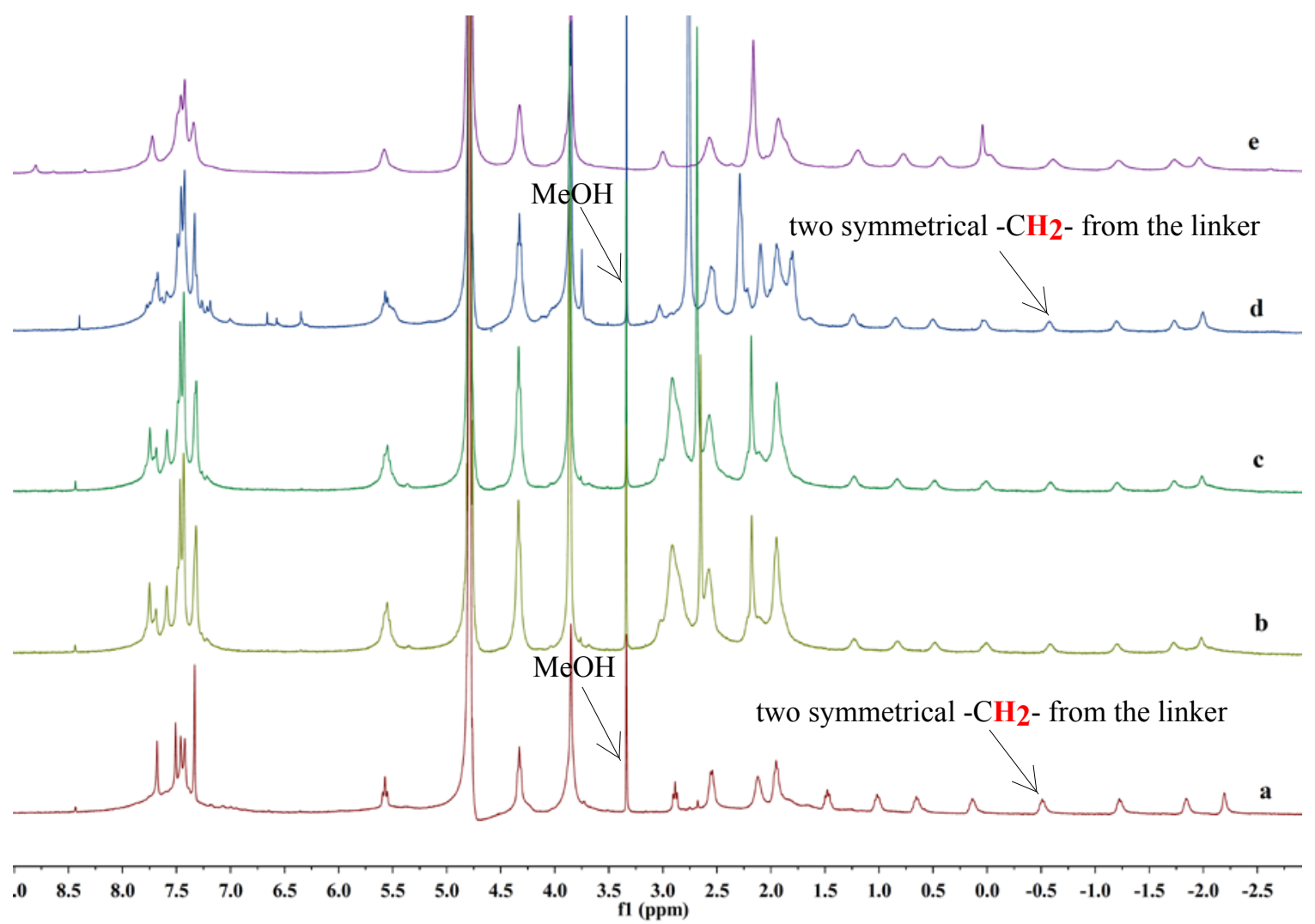

Figure S31. ${ }^{1} \mathrm{H}$ NMR spectra of cavitand 2 complexes (400 MHz, $299.5 \mathrm{~K}, \mathrm{D}_{2} \mathrm{O}$ ) (the peaks indicated with an arrow were used to determine yields): (a) $\mathrm{C}_{18}$ diamine $(1 \mathrm{mM}) /$ Cavitand 2 in $\mathrm{D}_{2} \mathrm{O}$, addition of 3 equiv. $\mathrm{NaOH}$ aqueous solution $\left(70 \mathrm{mM}\right.$ in $\left.\mathrm{D}_{2} \mathrm{O}\right)$; (b) Addition of excess of disuccinimidyl glutarate and shaking for 2 min. by hand; (c) After 25 min. for (b); (d) After 25h for (b); (e) The authentic target product 4e/cavitand 2 in $\mathrm{D}_{2} \mathrm{O}$. 


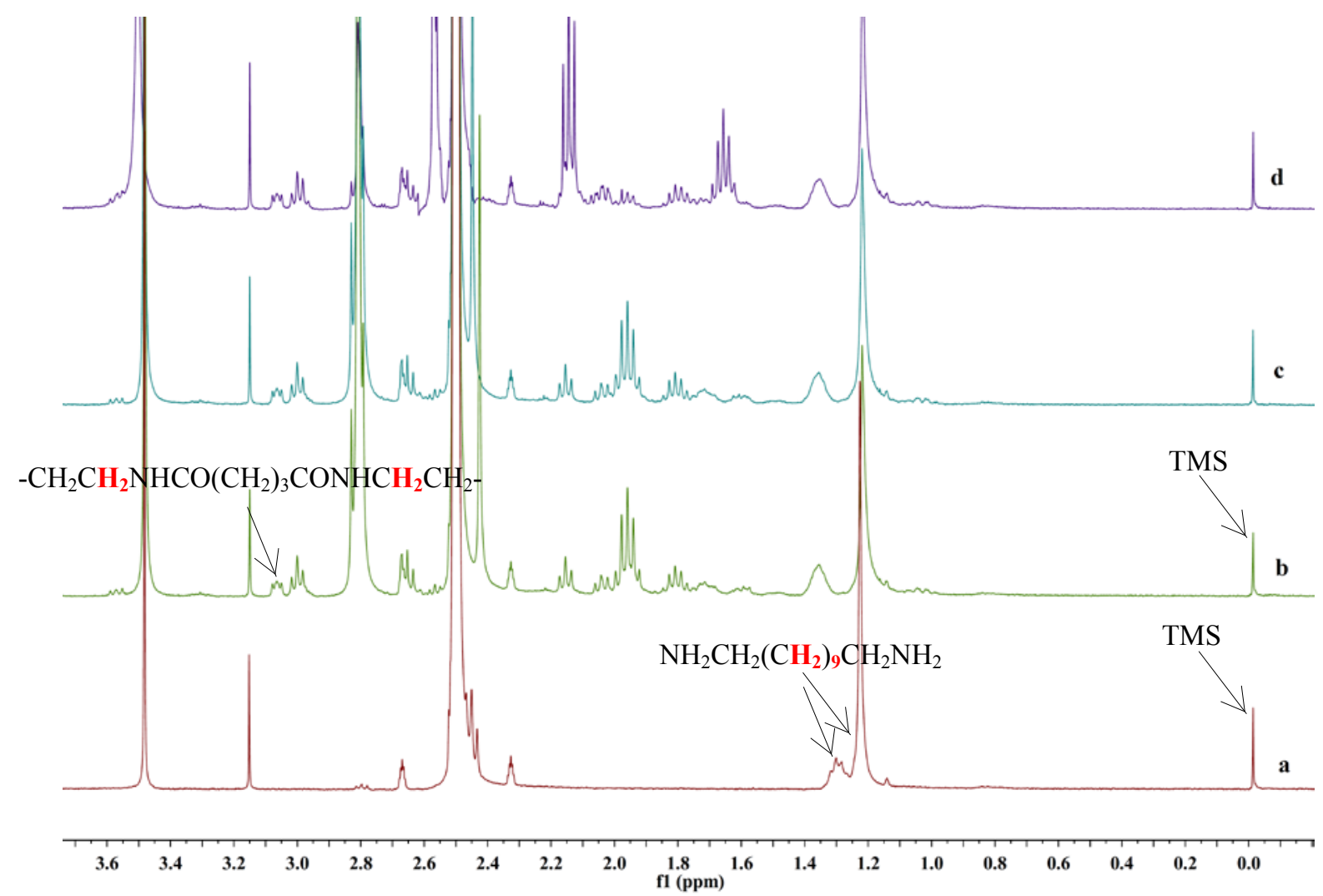

Figure S32. Partial ${ }^{1} \mathrm{H}$ NMR spectra (400 MHz, $299.5 \mathrm{~K}$, DMSO-d $\mathrm{d}_{6}$ ) (the peaks indicated with an arrow were used to determine yields): (a) $\mathrm{C}_{11}$ diamine solution (1 $\left.\mathrm{mM}\right)$ in $\mathrm{DMSO}_{6}$ (TMS as the internal standard). Addition of 3 equiv. $\mathrm{NaOH}$ aqueous solution (70 mM in $\mathrm{D}_{2} \mathrm{O}$ ); (b) Addition of excess of disuccinimidyl glutarate to (a); (c) After 15 min. for (b); (d) After 25h for (b). 

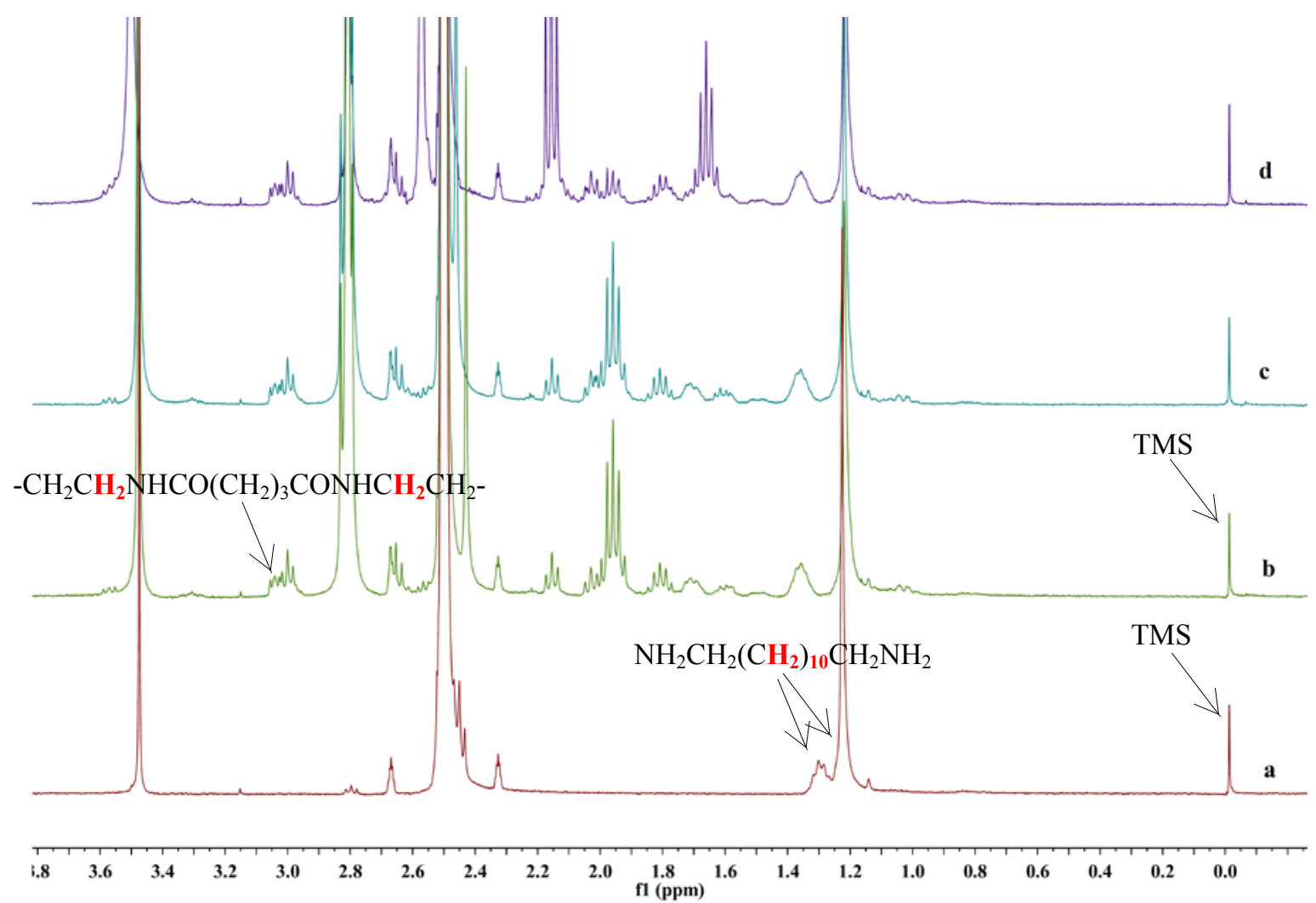

Figure S33. Partial ${ }^{1} \mathrm{H}$ NMR spectra (400 MHz, $299.5 \mathrm{~K}, \mathrm{DMSO}-\mathrm{d}_{6}$ ) (the peaks indicated with an arrow were used to determine yields): (a) $\mathrm{C}_{12}$ diamine solution (1 mM) in DMSO-d $_{6}$ (TMS as the internal standard). Addition of 3 equiv. $\mathrm{NaOH}$ aqueous solution (70 mM in $\mathrm{D}_{2} \mathrm{O}$ ); (b) Addition of excess of disuccinimidyl glutarate to (a); (c) After 19 min. for (b); (d) After 25h for (b). 


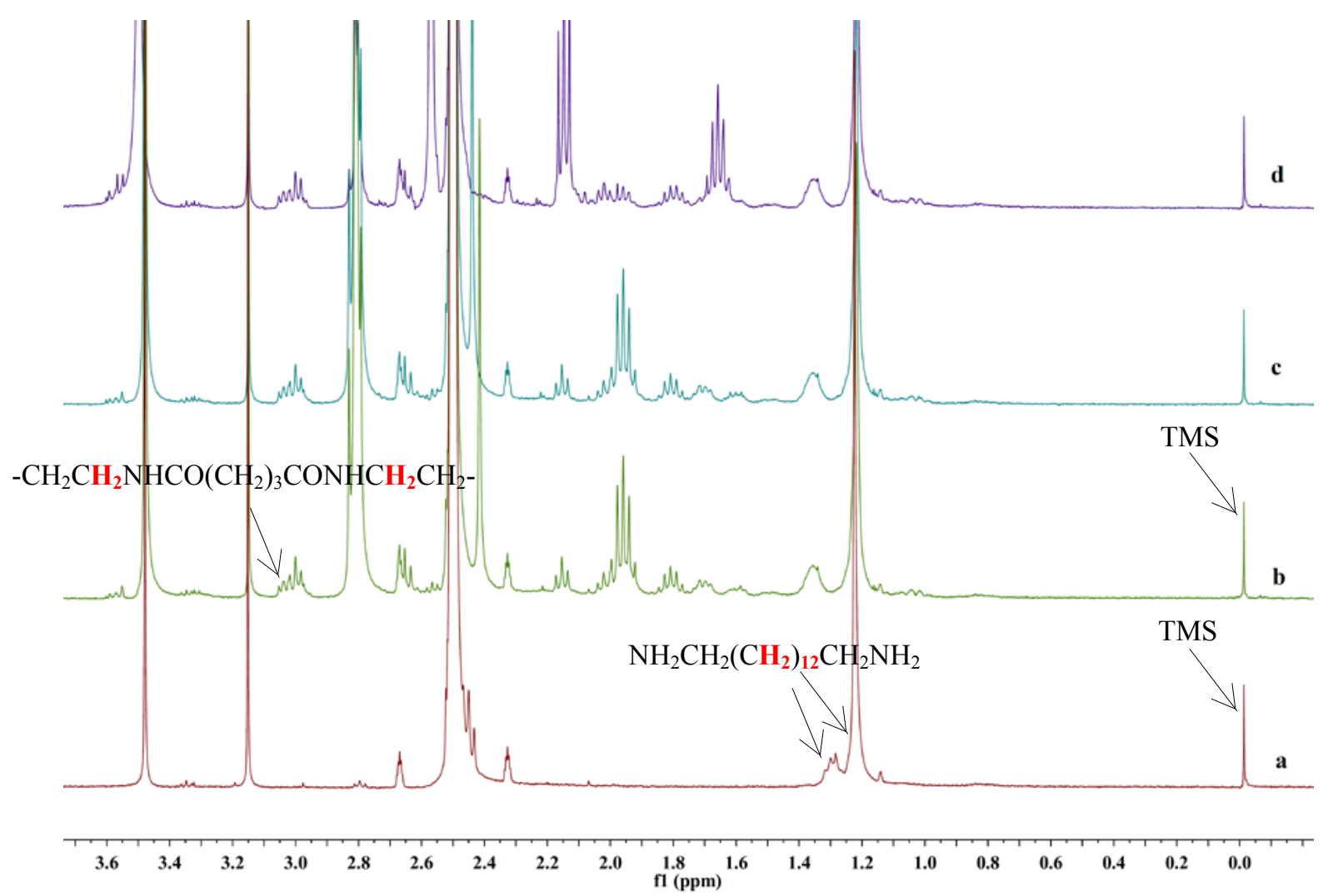

Figure S34. Parts of the ${ }^{1} \mathrm{H}$ NMR spectra $\left(400 \mathrm{MHz}, 299.5 \mathrm{~K}\right.$, DMSO- $\mathrm{d}_{6}$ ) (the peaks indicated with an arrow were used to determine yields): (a) $\mathrm{C}_{14}$ diamine solution (1 mM) in DMSO-d $_{6}$ (TMS as the internal standard). Addition of 3 equiv. $\mathrm{NaOH}$ aqueous solution (70 mM in $\mathrm{D}_{2} \mathrm{O}$ ); (b) Addition of excess of disuccinimidyl glutarate to (a); (c) After 12 min. for (b); (d) After 25h for (b). 

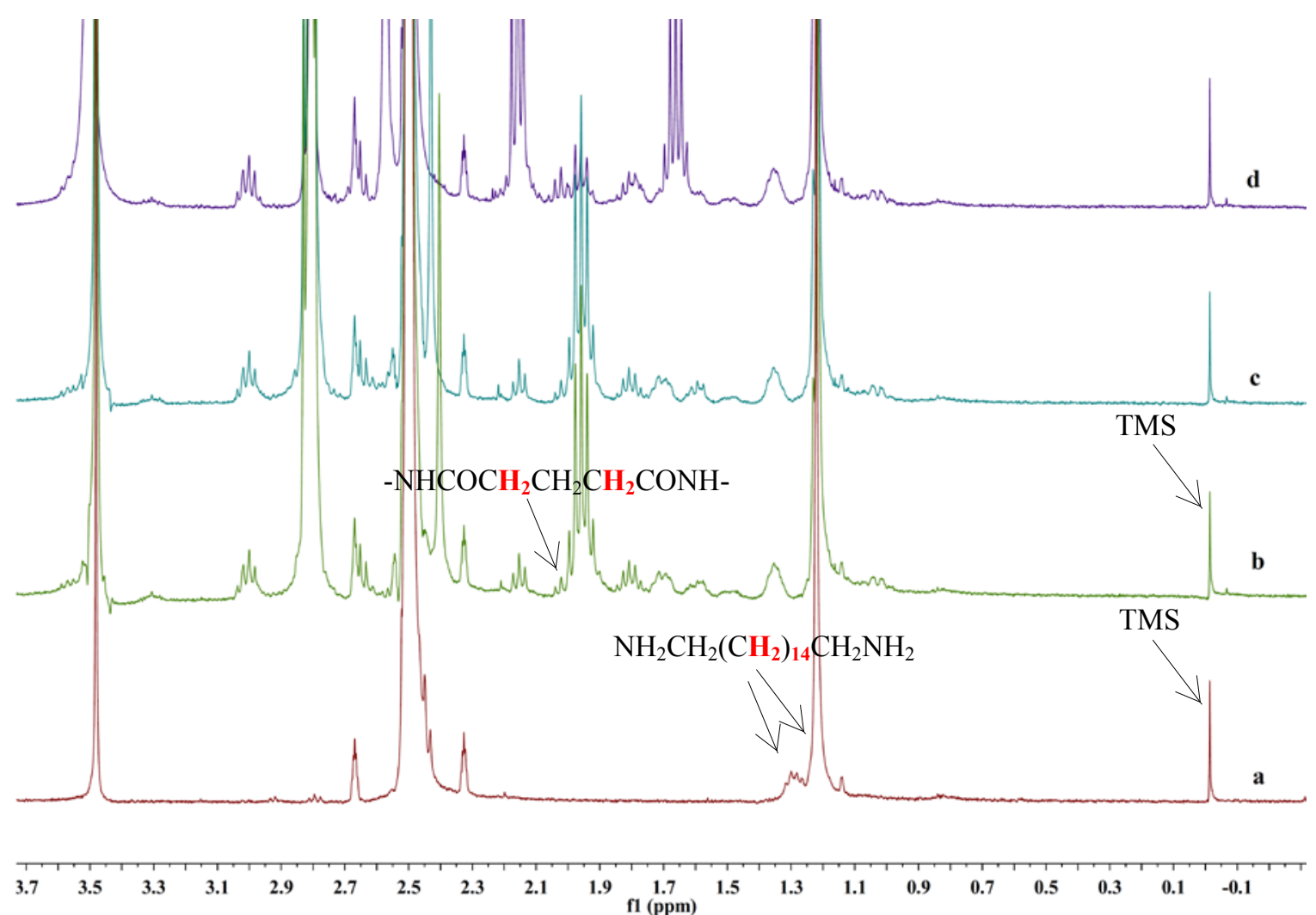

Figure S35. Partial ${ }^{1} \mathrm{H}$ NMR spectra $\left(400 \mathrm{MHz}, 299.5 \mathrm{~K}\right.$, DMSO- $\mathrm{d}_{6}$ ) (the peaks indicated with an arrow were used to determine yields): (a) $\mathrm{C}_{16}$ diamine solution (1 mM) in DMSO- $_{6}$ (TMS as the internal standard). Addition of 3 equiv. $\mathrm{NaOH}$ aqueous solution (70 mM in $\mathrm{D}_{2} \mathrm{O}$ ); (b) Addition of excess of disuccinimidyl glutarate to (a); (c) After 9 min. for (b); (d) After 24h for (b). 

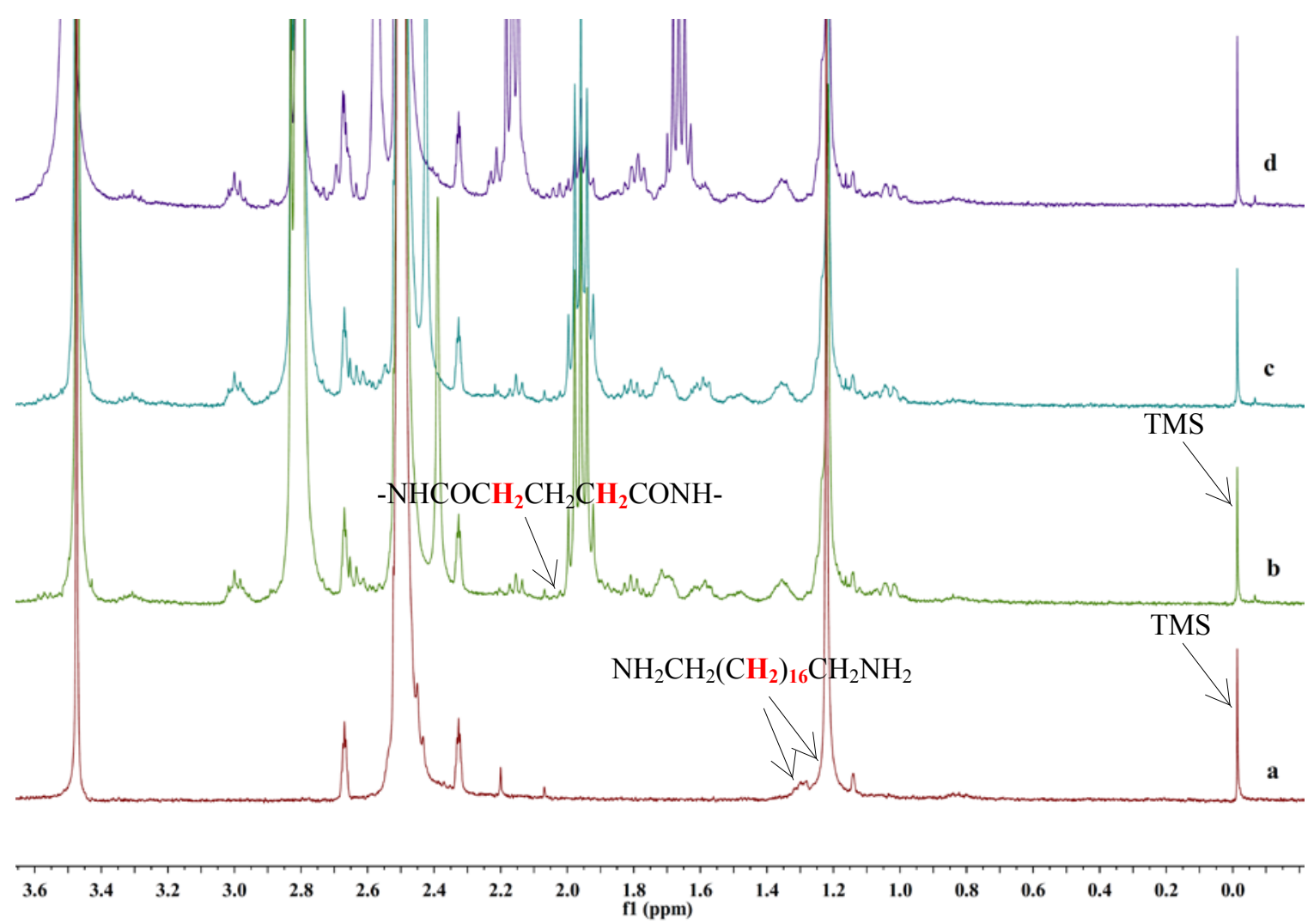

Figure S36. Partial ${ }^{1} \mathrm{H}$ NMR spectra $\left(400 \mathrm{MHz}, 299.5 \mathrm{~K}\right.$, DMSO- $\mathrm{d}_{6}$ ) (the peaks indicated with an arrow were used to determine yields): (a) $\mathrm{C}_{18}$ diamine solution (0.75 $\mathrm{mM}$ ) in DMSO-d $_{6}$ (TMS as the internal standard). Addition of 3 equiv. $\mathrm{NaOH}$ aqueous solution (70 $\mathrm{mM}$ in $\mathrm{D}_{2} \mathrm{O}$ ); (b) Addition of excess of disuccinimidyl glutarate to (a); (c) After 11 min. for (b); (d) After 24h for (b). 


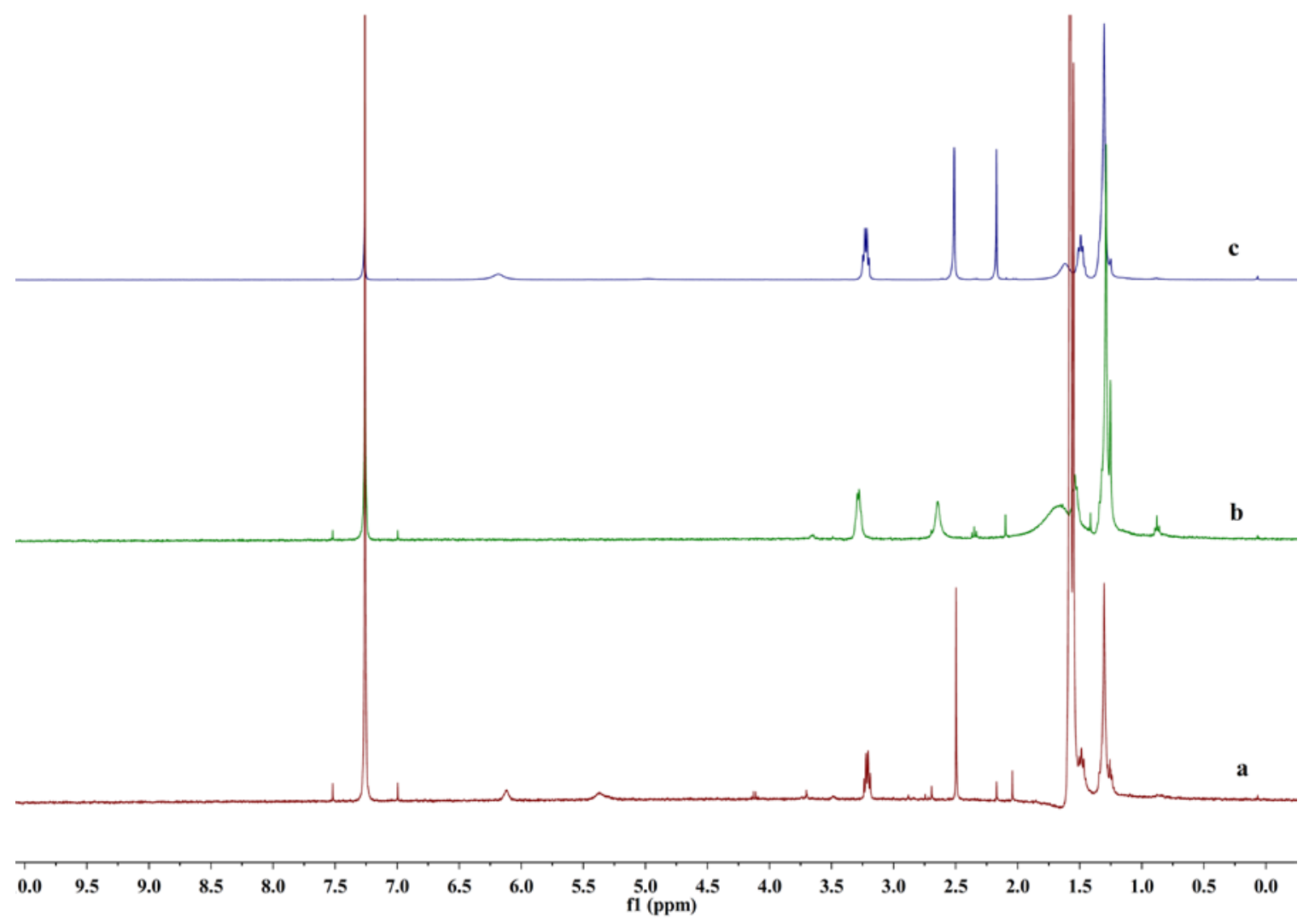

Figure S37. ${ }^{1} \mathrm{H}$ NMR spectra ( $400 \mathrm{MHz}, 299.5 \mathrm{~K}, \mathrm{CDCl}_{3}$ ): (a) $\mathrm{CDCl}_{3}$ extraction solution for the reaction mixture between $\mathrm{C}_{12}$ diamine and disuccinimidyl succinate (excess) in the presence of cavitand 2. (b) After purification for (a) by silica gel column and confirmed by HRMS (see Fig. S38); (c) Authentic product $\mathbf{3 b}$. 

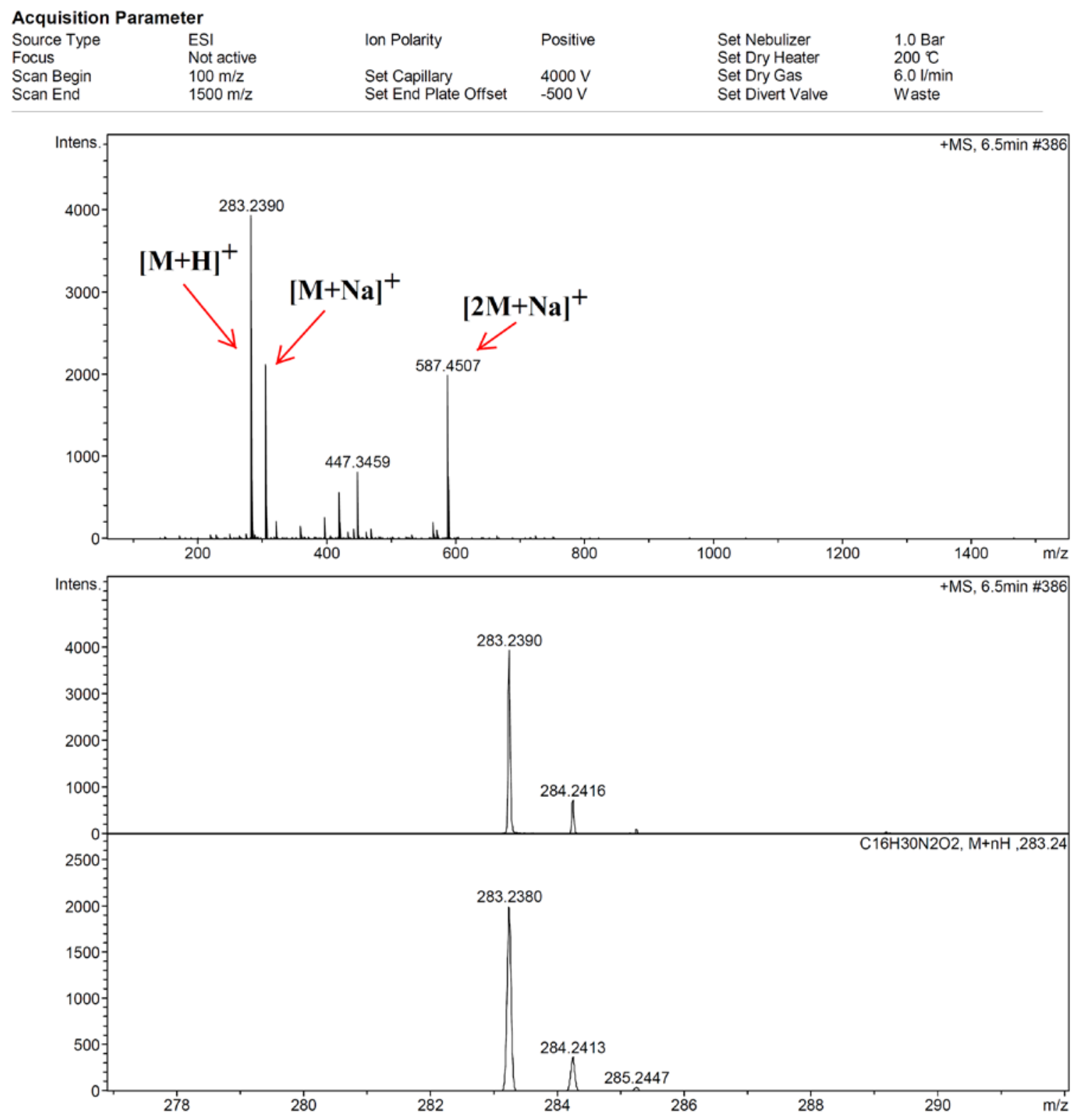

Figure S38. HRMS for Fig. S37 (b) 

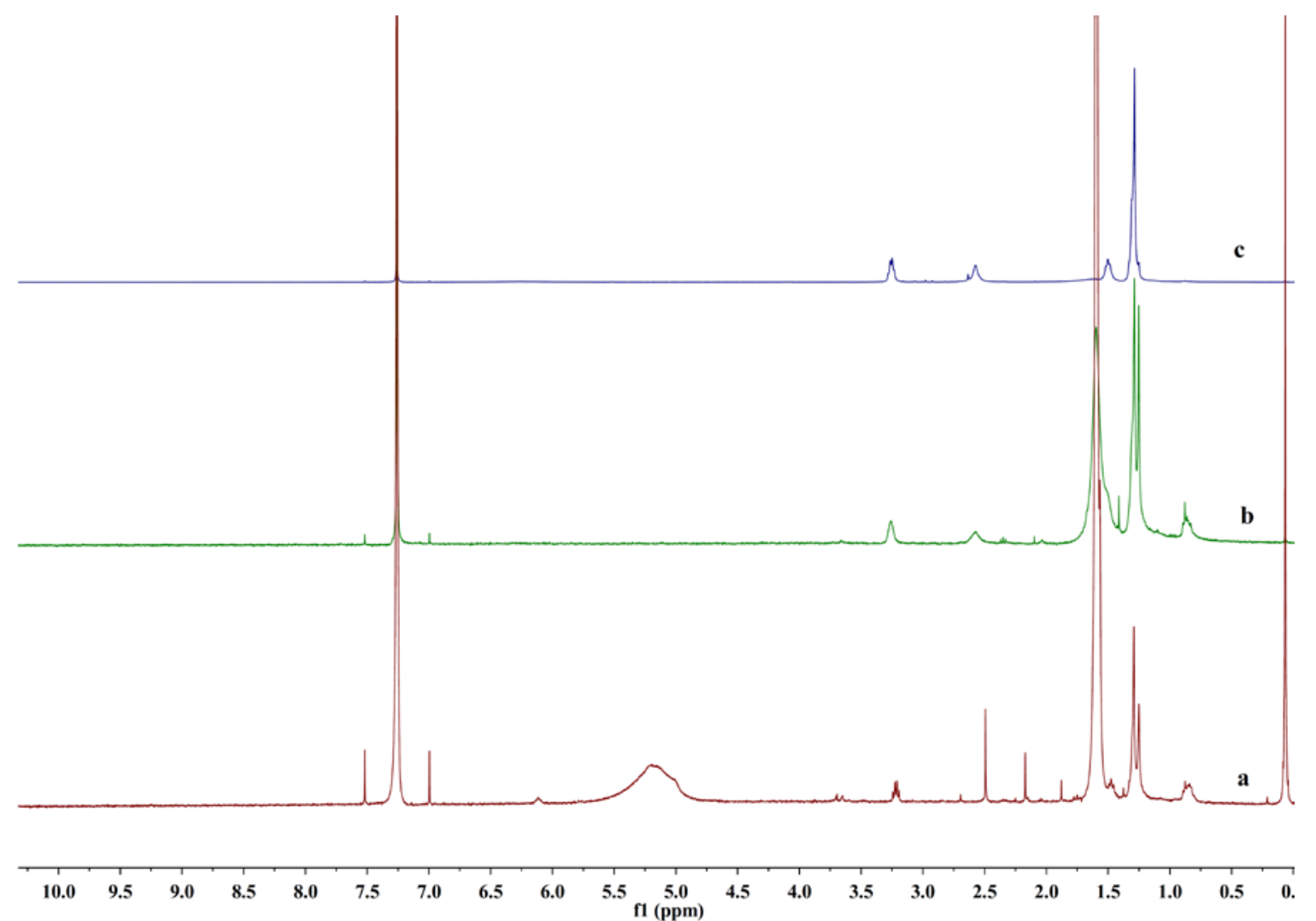

Figure S39. ${ }^{1} \mathrm{H}$ NMR spectra (400 MHz, $299.5 \mathrm{~K}, \mathrm{CDCl}_{3}$ ): (a) $\mathrm{CDCl}_{3}$ extraction solution for the reaction mixture between $\mathrm{C}_{14}$ diamine and disuccinimidyl succinate (excess) in the presence of cavitand 2. (b) After purification for (a) by silica gel column and confirmed by HRMS (see Fig. S40); (c) Authentic product 3c. 

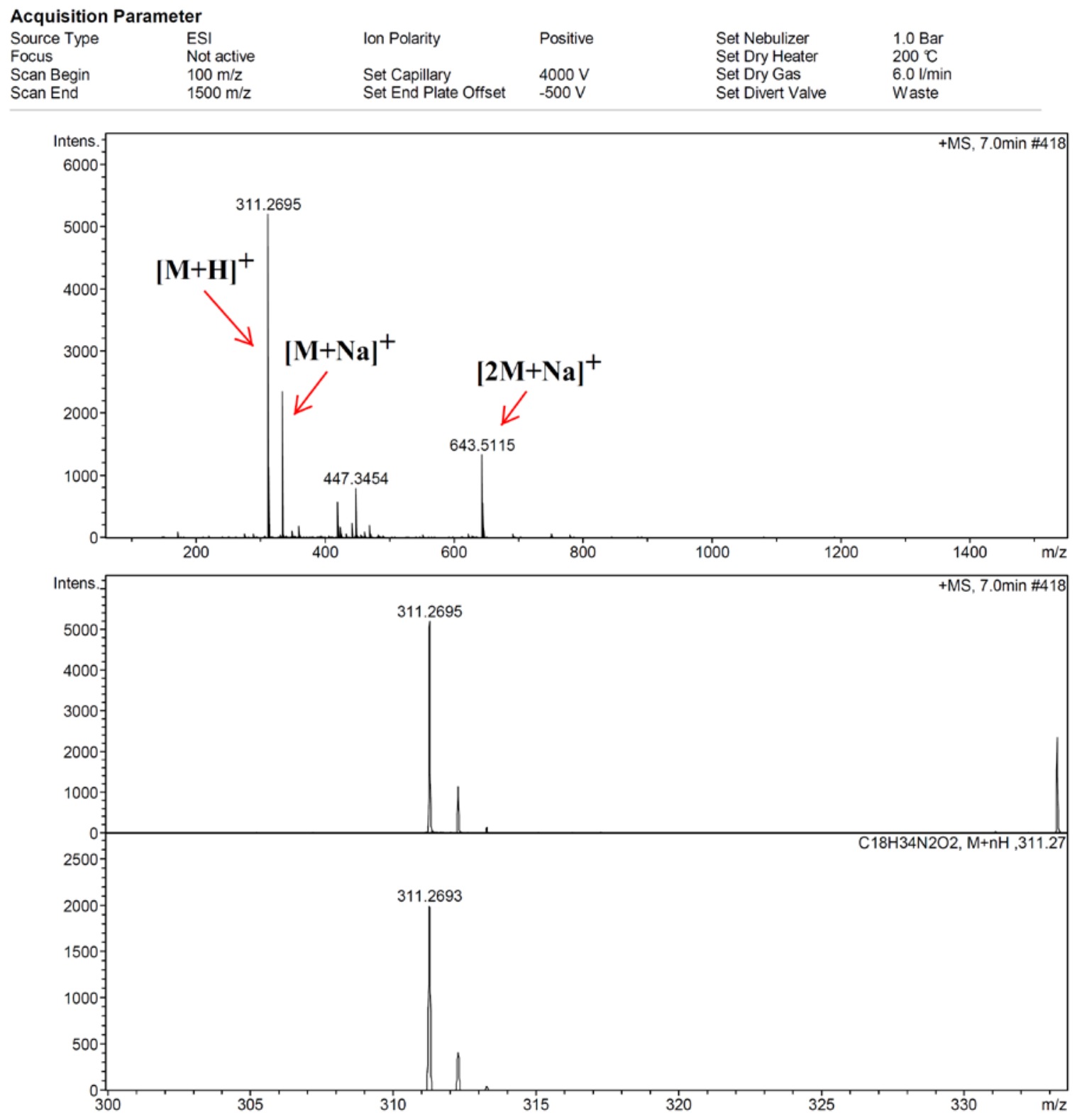

Figure S40. HRMS for Fig. S39 (b) 

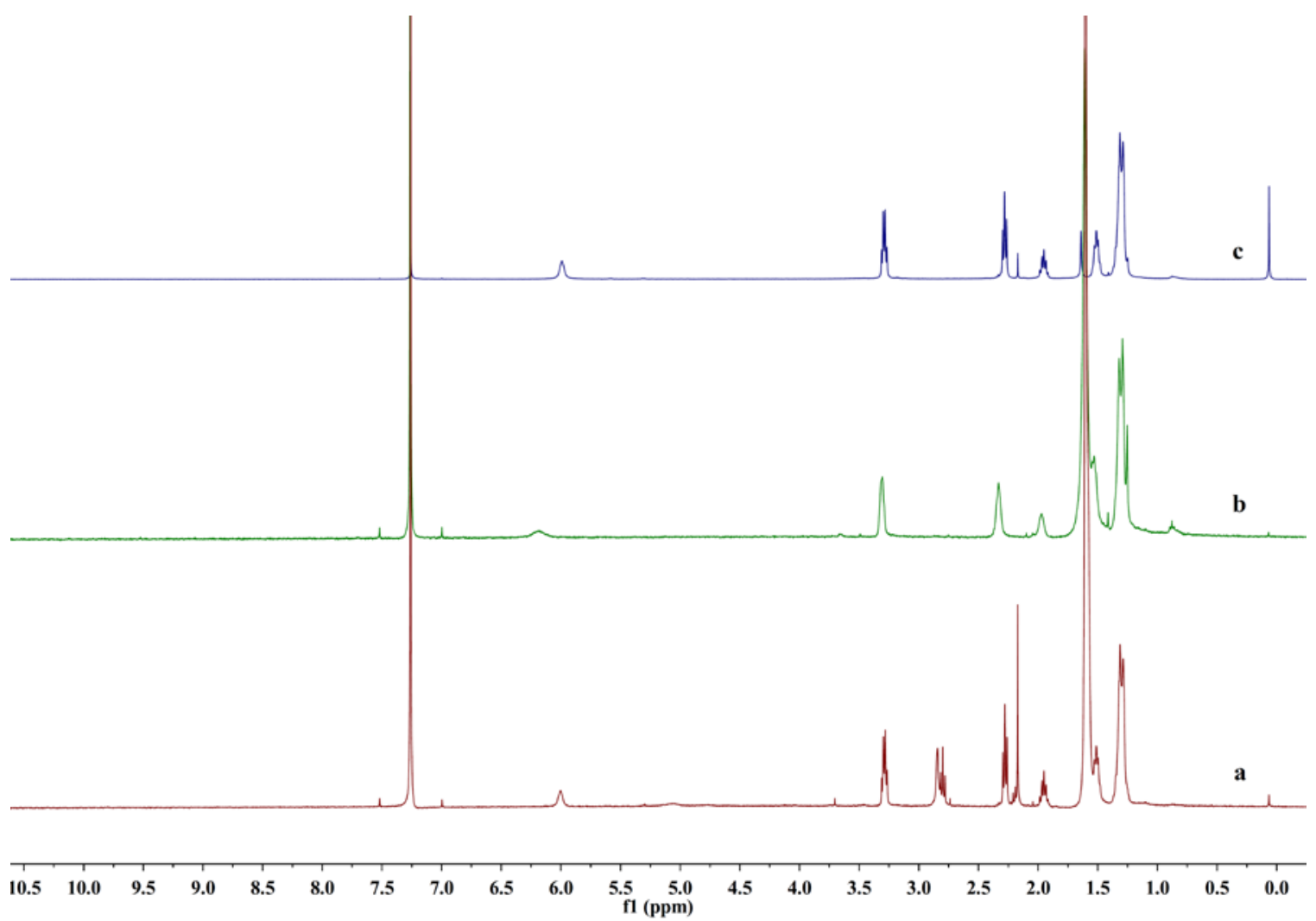

Figure S41. ${ }^{1} \mathrm{H}$ NMR spectra (400 MHz, $\left.299.5 \mathrm{~K}, \mathrm{CDCl}_{3}\right)$ : (a) $\mathrm{CDCl}_{3}$ extraction solution for the reaction mixture between $\mathrm{C}_{12}$ diamine and disuccinimidyl glutarate (excess) in the presence of cavitand 2. (b) After purification for (a) by silica gel column and confirmed by HRMS (see Fig. S42); (c) Authentic product $\mathbf{4 b .}$ 


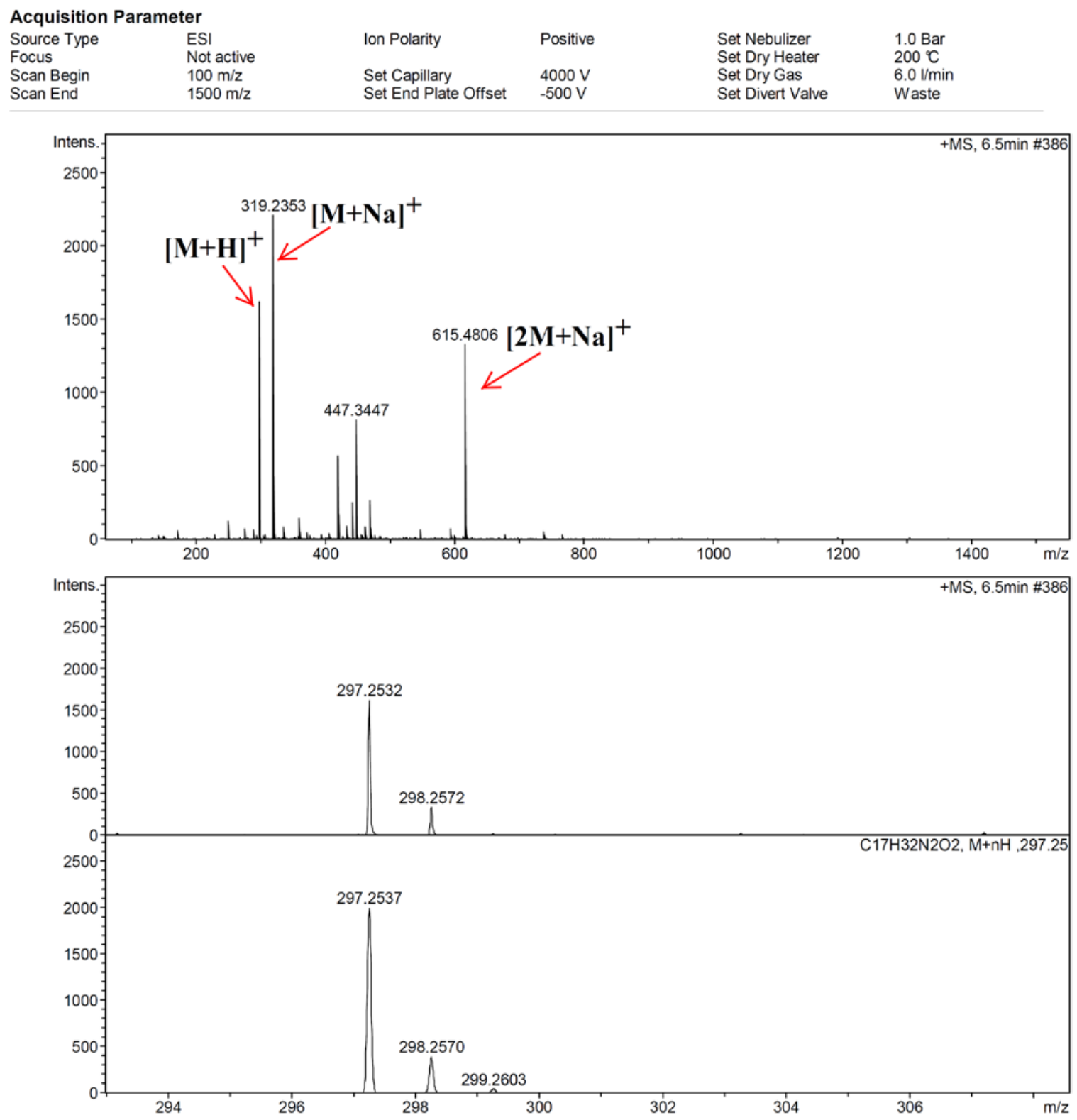

Figure S42. HRMS for Fig. S41 (b) 


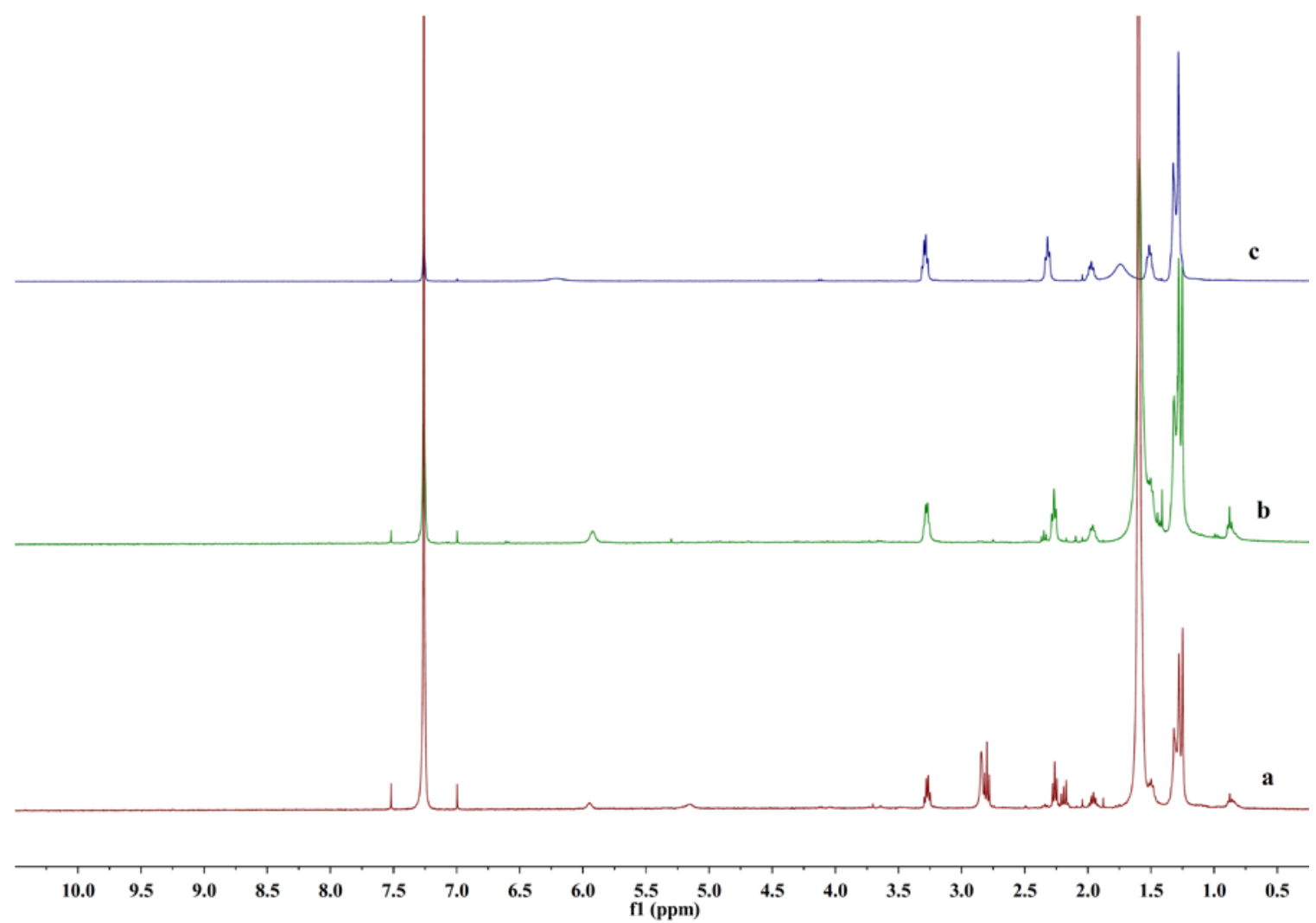

Figure S43. ${ }^{1} \mathrm{H}$ NMR spectra (400 MHz, $299.5 \mathrm{~K}, \mathrm{CDCl}_{3}$ ): (a) $\mathrm{CDCl}_{3}$ extraction solution for the reaction mixture between $\mathrm{C}_{14}$ diamine and disuccinimidyl glutarate (excess) in the presence of cavitand 2. (b) After purification for (a) by silica gel column and confirmed by HRMS (see Fig. S44); (c) Authentic product 4c. 


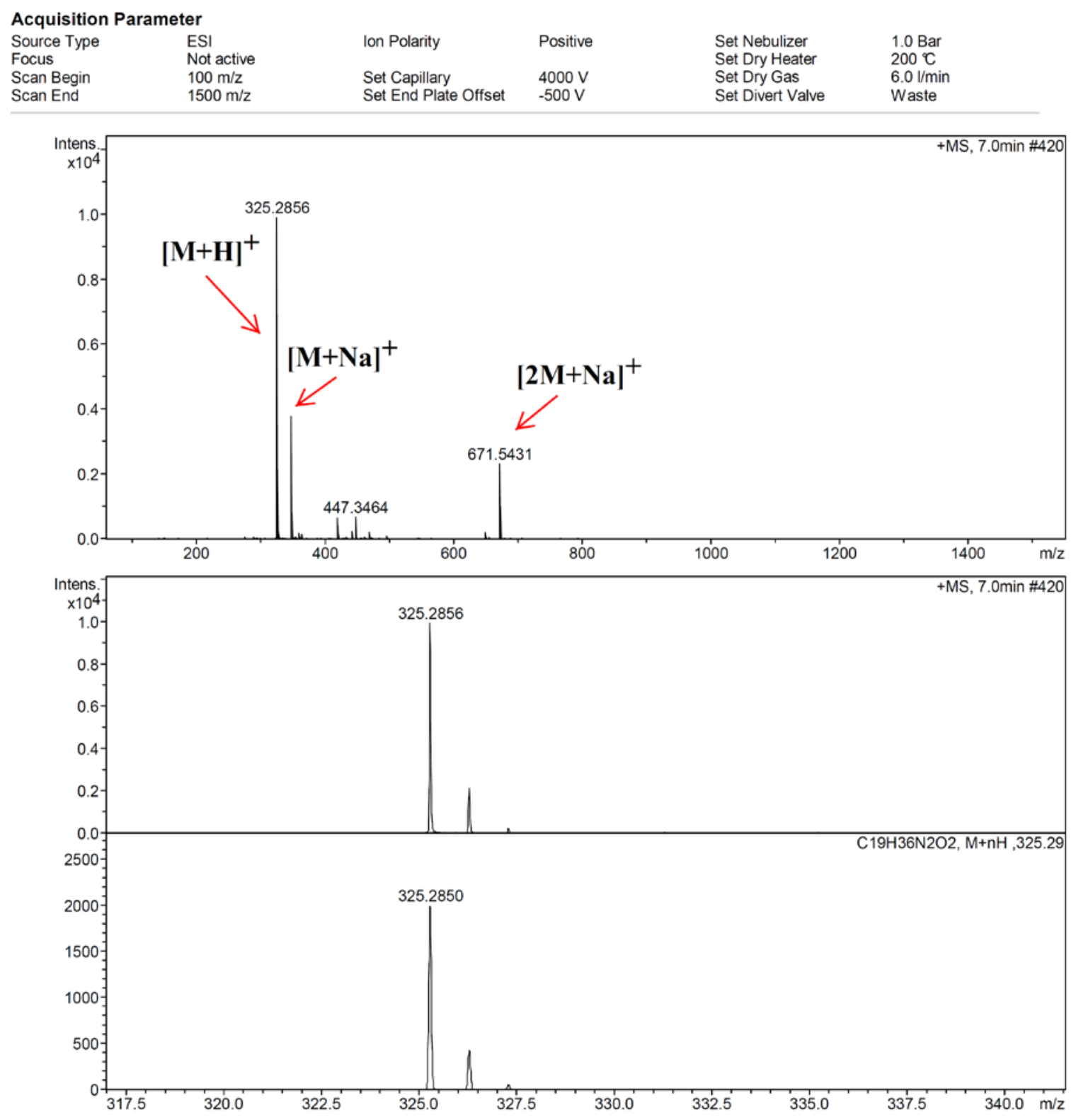

Figure S44. HRMS for Fig. S43 (b) 


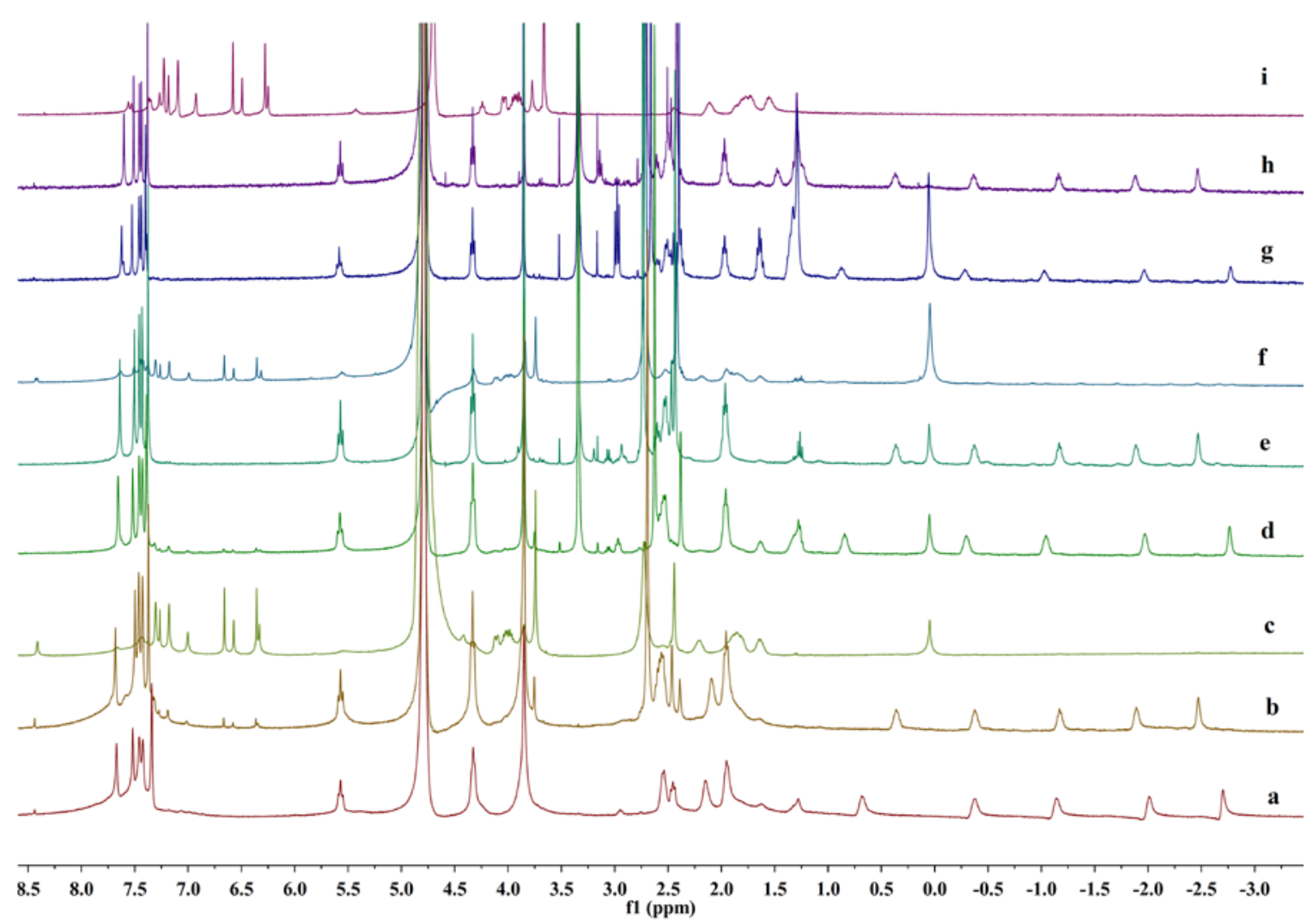

Figure S45. ${ }^{1} \mathrm{H}$ NMR spectra of cavitand 2 complexes (400 MHz, $299.5 \mathrm{~K}, \mathrm{D}_{2} \mathrm{O}$ ): First run: (a) $\mathrm{C}_{12}$ diamine/Cavitand 2 in $\mathrm{D}_{2} \mathrm{O}$, addition of $\mathrm{NaOH}$ aqueous solution; (b) Addition of excess of disuccinimidyl succinate, after $180 \mathrm{~min}$; (c) For (b), removing the product by extraction with $\mathrm{CDCl}_{3}$ and recycling the cavitand; Second run: (d) $\mathrm{C}_{12}$ diamine/cavitand 2 recycled from (c) in $\mathrm{D}_{2} \mathrm{O}$, addition of $\mathrm{NaOH}$ aqueous solution; (e) Addition of excess of disuccinimidyl succinate, after 23h; (f) For (e), removing the product by extraction with $\mathrm{CDCl}_{3}$ and recycling the cavitand; Third run: (g) $\mathrm{C}_{12}$ diamine/cavitand 2 recycled from (f) in $\mathrm{D}_{2} \mathrm{O}$; (h) Addition of $\mathrm{NaOH}$ aqueous solution and then excess of disuccinimidyl succinate, after 24h; (i) Pristine cavitand 2 in $\mathrm{D}_{2} \mathrm{O}$ for comparison; 


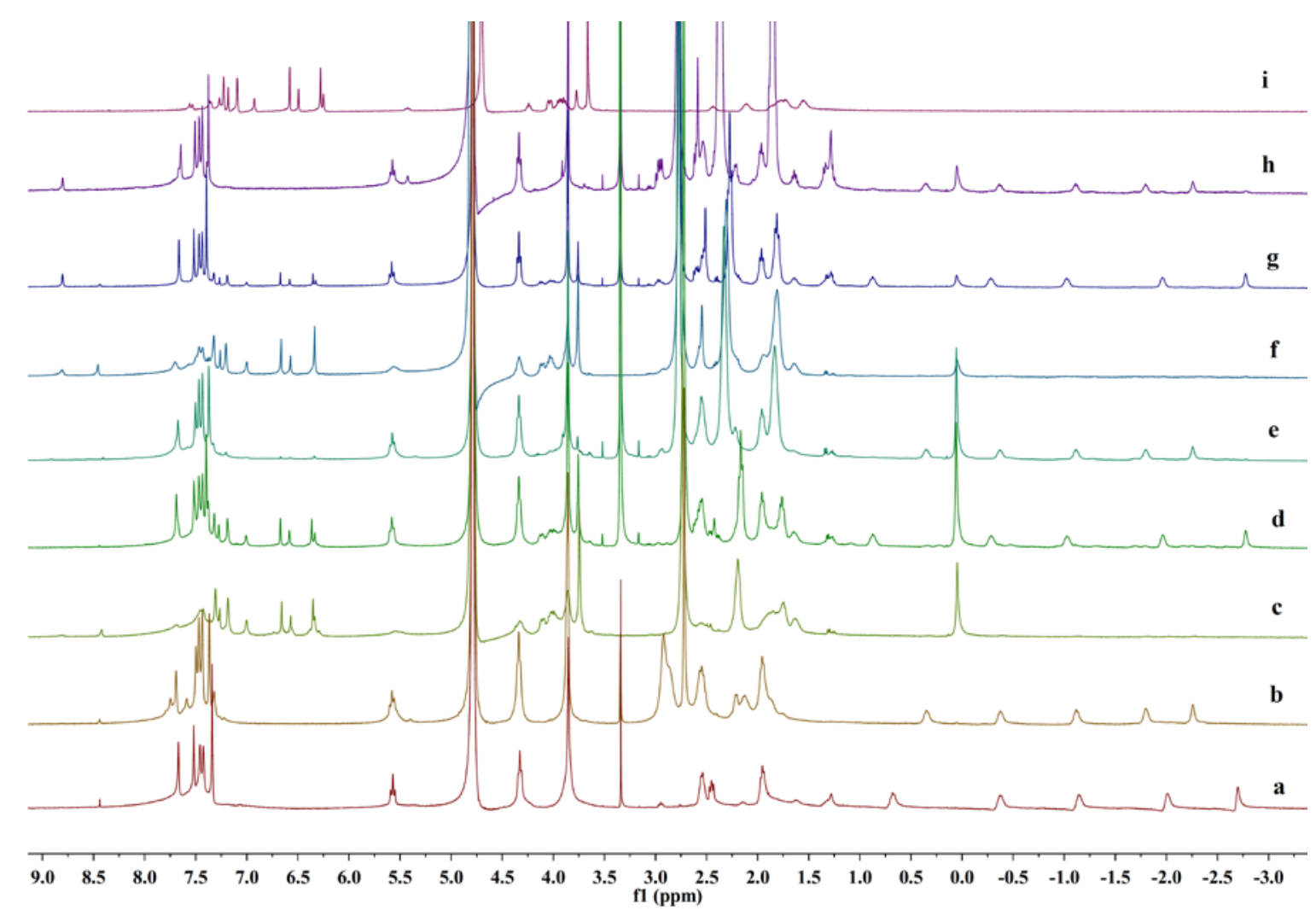

Figure S46. ${ }^{1} \mathrm{H}$ NMR spectra of cavitand 2 complexes (400 MHz, $299.5 \mathrm{~K}, \mathrm{D}_{2} \mathrm{O}$ ): First run: (a) $\mathrm{C}_{12}$ diamine/Cavitand 2 in $\mathrm{D}_{2} \mathrm{O}$, addition of $\mathrm{NaOH}$ aqueous solution; (b) Addition of excess of disuccinimidyl glutarate, after $60 \mathrm{~min}$; (c) For (b), removing the product by extraction with $\mathrm{CDCl}_{3}$ and recycling the cavitand; Second run: (d) $\mathrm{C}_{12}$ diamine/cavitand 2 recycled from (c) in $\mathrm{D}_{2} \mathrm{O}$, addition of $\mathrm{NaOH}$ aqueous solution; (e) Addition of excess of disuccinimidyl glutarate, after 24h; (f) For (e), removing the product by extraction with $\mathrm{CDCl}_{3}$ and recycling the cavitand; Third run: (g) $\mathrm{C}_{12}$ diamine/cavitand 2 recycled from (f) in $\mathrm{D}_{2} \mathrm{O}$, addition of $\mathrm{NaOH}$ aqueous solution; (h) Addition of excess of disuccinimidyl glutarate, after 26h; (i) Pristine cavitand 2 in $\mathrm{D}_{2} \mathrm{O}$ for comparison; 


\section{References}

1 Mosca, S.; Yu, Y.; Gavette, J. V.; Zhang, K.-D.; Rebek, J., Jr. J. Am. Chem. Soc. 2015, 137, 1458214585.

2 Zou, L.; Pang, H.-L.; Chan, P.-H.; Huang, Z.-S.; Gu, L.-Q.; Wong, K.-Y. Analyst 2008, 133, 11951200.

3 Castillo, J. A.; Infante, M. R.; Manresa, A.; Vinardell, M. P.; Mitjans, M.; Clap, P. ChemMedChem 2006, 1, 1091-1098.

4 Tanev, P. T.; Liang, Y.; Pinnavaia, T. J. J. Am. Chem. Soc. 1997, 119, 8616-8624.

5 Akae, Y.; Koyama, Y.; Sogawa, H.; Hayashi, Y.; Kawauchi, S.; Kuwata, S.; Takata, T.; Chem. Eur. J. 2016, 22, 5335-5341.

6 Panova, A.; Dicosimo, R.; Brugel, E.; Wilson, T. PCT Int. Appl. (2006), WO 2006053296 A1 20060518. 